\title{
Aggressive behavior of psychiatric inpatients : measurement, prevalence, and determinants
}

Citation for published version (APA):

Nijman, H. (1999). Aggressive behavior of psychiatric inpatients : measurement, prevalence, and determinants. [Doctoral Thesis, Maastricht University]. Datawyse / Universitaire Pers Maastricht. https://doi.org/10.26481/dis.19991216hn

Document status and date:

Published: 01/01/1999

DOI:

10.26481/dis.19991216hn

Document Version:

Publisher's PDF, also known as Version of record

\section{Please check the document version of this publication:}

- A submitted manuscript is the version of the article upon submission and before peer-review. There can be important differences between the submitted version and the official published version of record.

People interested in the research are advised to contact the author for the final version of the publication, or visit the DOI to the publisher's website.

- The final author version and the galley proof are versions of the publication after peer review.

- The final published version features the final layout of the paper including the volume, issue and page numbers.

Link to publication

\footnotetext{
General rights rights.

- You may freely distribute the URL identifying the publication in the public portal. please follow below link for the End User Agreement:

www.umlib.nl/taverne-license

Take down policy

If you believe that this document breaches copyright please contact us at:

repository@maastrichtuniversity.nl

providing details and we will investigate your claim.
}

Copyright and moral rights for the publications made accessible in the public portal are retained by the authors and/or other copyright owners and it is a condition of accessing publications that users recognise and abide by the legal requirements associated with these

- Users may download and print one copy of any publication from the public portal for the purpose of private study or research.

- You may not further distribute the material or use it for any profit-making activity or commercial gain

If the publication is distributed under the terms of Article $25 \mathrm{fa}$ of the Dutch Copyright Act, indicated by the "Taverne" license above, 
AGGRESSIVE BEHAVIOR OF PSYCHIATRIC INPATIENTS 
(1) H. Nijman, Maastricht 1999

ISBN: 9052782628

Vommeving en druk:

Datawyse | Universitaire Pers Maastricht 


\title{
AGGRESSIVE BEHAVIOR OF PSYCHIATRIC INPATIENTS
}

Measurement, prevalence, and determinants

\author{
Proefschrift \\ ter verkrijging van de graad van doctor \\ aan de Universiteit Maastricht, \\ op gezag van de Rector Magnificus, \\ Prof. dr. A.C. Nieuwenhuijzen Kruseman \\ volgens het besluit van het College van Decanen, \\ in het openbaar te verdedigen op \\ donderdag 16 december 1999 om 12.00 uur \\ door
}

Henk Nijman 
PROMOTOR

Prof. dr. H.L.G.J. Merckelbach

BEOORDELINGSCOMMISSIE

Prof. dr. H. Crombag (voorzitter)

Prof. dr. M. Hengeveld, Academisch Ziekenhuis Leiden

Dr. L. Henkelman, ZorgOnderzoek Nederland

Prof. dr. G. Kok

Dr. J. van Os 
VOOR JUDY 



\section{CONTENTS}

INTRODUCTION

1 INPATIENT AGGRESSION:

PREVALENCE, MEASUREMENT, DETERMINANTS, AND PREDICTION

$\begin{array}{ll}\text { Introduction } & 14\end{array}$

$\begin{array}{ll}\text { Background } & 14\end{array}$

$\begin{array}{ll}\text { Prevalence of aggression } & 16\end{array}$

$\begin{array}{ll}\text { Measurement of aggression } & 18\end{array}$

Determinants of aggression 20

$\begin{array}{ll}\text { Auto-aggression } & 22\end{array}$

$\begin{array}{ll}\text { Prediction of aggression } & 24\end{array}$

$\begin{array}{ll}\text { Research questions } & 25\end{array}$

2 AGGRESSIVE BEHAVIOR ON AN ACUTE PSYCHIATRIC ADMISSIONS WARD 33

Summary $\quad 34$

Introduction $\quad 34$

$\begin{array}{ll}\text { Methods } & 35\end{array}$

Results $\quad 37$

Discussion $\quad 41$

3 PREVENTION OF AGGRESSIVE INCIDENTS ON A CLOSED PSYCHIATRLC WARD 45

Summary $\quad 46$

Introduction $\quad 46$

Methods $\quad 49$

Results

Discussion $\quad 54$

$4 \quad$ CROWDING AND AGGRESSION

Summary $\quad 58$

Introduction $\quad 58$

Methods $\quad 59$

Results $\quad 60$ 
5 THE STAFF OBSERVATION AGGRESSION SCALE - REVISED (SOAS.R)

Summary

Introduction

Methods

Results

Discussion

6 SELF-MUTILATING BEHAVIOR OF PSYCHIATRIC INPATIENTS

Summary

Introduction

Methods

Results

Discussion

AN EXPLANATORY MODEL OF AGGRESSION IN PSYCHIATRIC HOSPITALS

Summary

Introduction

Interventions

Discussion

Limitations of staff observations

Prevalence of aggression

Determinants of aggression

Prevention of aggression

Directions for future research

SAMENVATTING

SUMMARY

APPENDIX 1 : SOAS-R

REFERENCES

LIST OF PUBULICATIONS

DANKWOORD 


\section{INTRODUCTION}

Throughout the ages, society has reacted to aggressive behavior of psychiatric patients by incarcerating, secluding, and restraining them (e.g., see Foucault, 1975; Fisher, 1994; Shorter, 1997). In spite of the great progress that has been made in treating psychiatric disorders since the discovery of effective psychotropic agents in the 1930s (Shorter, 1997), impatient violence is still a prevalent phenomenon (e.g., Nijman, Allertz, à Campo, Merckelbach et al., 1997; Drinkwater \& Gudjonsson, 1989). Especially during the first week(s) of admission, when medication has not yet had time to become effective, rates of aggression are high (e.g., Nijman, Allertz $\&$ à Campo, 1995). In order to protect the violent individual from harming himself or other people, seclusion and restraint are still commonly used in Dutch psychiatry (Nijman et al., 1995; Nijman, Duangto, Ravelli, Merckelbach et al., 1994; Nijman, Ravelli \& Merckelbach, 1992) and in other western countries (Fisher, 1994).

Apart from the physical and psychological consequences for both patients and staff, patient violence also has considerable financial implications (Hyde \& Harrower-Wilson, 1995; Hunter \& Carmel, 1992). For these reasons, prevention of aggression should have a high priority in psychiatric hospitals. However, effective prevention requires that the determinants of aggressive behavior in psychiatric hospitals are well-understood.

Ever since Freud (1923) attributed destructive behavior to an id-drive he called the death instinct, psychiatric researchers have attempted to explain violence in terms of the background and characteristics of violent individuals. Less emphasis has been put on the role played by the situation or the context in whicly patients becomes violent (see Krawkowski \& Czobor, 1997; Friis \& Helldin, 1994).

However, within psychiatric hospitals, a number specific cues can be found which may elicit aggression. For instance, a substantial number of patients reside in psychiatric hospitals against their will. In the Netherlands, the number of involuntary admissions has increased markedly over the past few years (e.g., Nijman, à Campo \& Ravelli, 1999). Under the Dutch civil law, more specifically the Bijzondere Opnemingen in Psychiatrische Ziekenhuizen 
rule (the law BOPZ in short), psychiatric patients can be admitted against their will if their behavior endangers their own safety or the safety of others (Dekker, 1997). In many cases, however, involuntarily admitted patients are hospitalized without they understanding or agreeing with the treatment rationals. During their stay in hospital, patients may also be confronted with other forms of coercion such as seclusion and the use of mechanical restraints. Although measures are taken in order to safeguard the patient and the environment, these measures in themselves may elicit anger, frustration. and aggression in the patient.

In the present dissertation, aggressive behavior of psychiatric inpatients is studied from the perspective of the context in which it occurs. That is to say, attention is focused not only on patient variables that are relevant in explaining violence, but also on staff and ward variables that may play a role in eliciting a patient's aggression against others, against property, or against himself / herself.

The first chapter gives an outline of what is known about the prevalence, measurement, and determinants of aggressive incidents in psychiatric hospitals. From this review, the main research questions are derived.

In chapters 2 to 6 empirical findings are presented. Chapter 2 presents the results of a descriptive study on the prevalence and potential antecedents of aggressive behavior on an acute psychiatric admissions ward. The demographics of patients involved in violence are also explored in this first study. On the basis of this descriptive material, an intervention study was designed. The intervention study was conducted on three locked wards of psychiatric hospital Welterhof. The effects of five preventive strategies on the overall frequency and severity of aggressive incidents were evaluated against control conditions. The preventive measures aimed at improving staff-patient interaction and communication. The results of this study are reported in chapter 3.

In chapter 4 , the connection between certain ward variables and violent behavior are examined in more detail. Specifically, the relationship between ward crowding and ward space, on the one hand, and aggression, on the other hand, was investigated. This study was conducted on two closed admissions wards of the psychiatric hospital Broeders Alexianen in Tienen, Belgium. 
$\left.11\right|^{I n t r o d u c t i o n}$

Chapter 5 evaluates the psychometric properties of the aggression scale used in the above-mentioned studies. This scale is termed the Stafl Observation Aggression Scale (SOAS) and was introduced by Palmstiema and Wistedt in 1987. The study described in chapter 5 sought to validate the severity scores of this instrument, based on the data of 556 aggressive incidents registered on six closed wards of the psychiatric hospitals Welterhof, Broeders Alexianen, and Vallerius. On the basis of the findings of this study, a Revised version of the aggression scale, termed SOAS-R was developed.

The potential antecedents of a specific form of aggression, namely selfmutilating behavior, are exploned in chapter 6 . Self-mutilating behavior was studied separately, since the circumstances under which this behavior occurred were found to be quite different from those of interpersonal violence. Finally, in chapters 7 and 8, the empirical and literature findings of the present dissertation are discussed. The findings are integrated into an explanatory model of inpatient aggression. This model is briefly outlined in chapter 7 . Chapter 8 describes valuable research avenues for future studies. 

CHAPTER 1

Inpatient aggression: prevalence, measurement, determinants, and prediction 


\section{INTRODUCTION}

In this chapter, the theoretical backgrounds of the current dissertation are described. More specifically, the problem that aggressive behavior of patients poses to society and the way in which it is dealt with are discussed. A review of what is already known about the prevalence, measurement, determinants, and prediction of aggressive behavior is also provided. On the basis of this background information, the research questions that are addressed in the following chapters are formulated.

\section{BACKGROUND}

Although empirical research (Shah, Fineberg \& James, 1991; Tardiff, 1992) indicates that the majority of patients with psychiatric disorders do not engage in violent behavior, their potential aggressiveness is perceived as a threat by the public. Reports in the media of severe offenses of (former) psychiatric patients provoke fear in the community (see Taylor, Leese, Williams, Butwell et al., 1998). A sad example of this is the case of a schizophrenic patient in Amsterdam who murdered a girl with a baseball-bat. As a result of this tragedy, psychiatric patients were threatened and harassed by their neighbors (see Janssen \& Steketee, 1996). Understandably, the community reacts to such incidents with proposals to make the criteria for involuntary admission and compulsory treatment more liberal. To a certain extent, empirical studies conrobonte the public belief that psychatric problems are linked to a raised risk of violence. Bjorkly (1995), for example, summarizes the literature by saying that "evidence now indicates that mental disorder may be a consistent, but modest, risk factor for the occurrence of aggtession" (p. 492).

However, a number of (ethical) questions need to be addressed before involuntary hospitalization of psychiatric patients can be justified. For example, can an individual be forced to undergo treatment or should every person have the right to refuse it? And is it possible to predict dangerous behavion of psychiatric patients? Also; is it possible to quantify the severity of aggressive behavior in a meaningful way? 
Monahan and Shah (1989) provide two rationales for coercive treatment of which "the first and most obvious one is the police power rationale" and "(.) the second is the State's patemalistic or parens patriae power" (p. 541). In the first rationale, the emplasis is placed on protecting society from harm. The second rationale stresses society's duty to care for people who are unable to do so for themselves. In the Netherlands, a shift from the parens parriate rationale to the police potuer rationale has occurred with the introduction of the new legislation in 1994 (a set of law rules referred to as BOPZ; see Dekker, 1997). This shift can be characterized as a change from what is best for the patient, (i.e., 'bestwil criterium') to protecting persons and society from danger (i.e., 'gevaarscriterium'; e.g., Nijman, à Campo \& Ravelli, 1993; Nijman, et al., 1999; Ravelli, De Vooght, van Loo \& Nijman, 1996) Under the BOPZ, patient's right to self-determination is the central doctrine (see Ravelli et al., 1996). Exceptions to this doctrine may be made only if the patient's behavior constitutes a direct danger to the safety of persons or society at large. In these instances, the judge has to decide whether involuntary admission is required. Remarkably, since the introduction of the $\mathrm{BOPZ}$, the number of involuntarily admissions has increased, whereas a decline was anticipated (Poletiek, 1997; Nijman et al., 1999). This trend combined with large-scale attempts in the Netherlands to de-institutionalize (chronic) psychiatric patients promotes a situation in which Dutcli psyclaiatric hospitals will increasingly be populated with a selective and probably more aggressive patient group (Nijman et al., 1999). It should be noted that in the Netherlands, forced hospitalization does not mean that the patient has to comply with the proposed treatment (see Ravelli et al., 1996). Clearly, having a higher proportion of potentially dangerous and sometimes not effectively treatable patients in the psychiatric hospital may only transfer the problem of violence from society to hospitals. Due to these developments, the safety of care-givers and (fellow) patients will become an even more important issue in psychiatric hospitals in the future. Meanwhile, for an effective safety-policy, reliable methods of collecting data on the prevalence and determinants of aggressive behavior in psychiatric institutions are urgently needed. In the present dissertation, the prevalence, measurement, determinants, and prevention of aggression are approached from such a safety-policy perspective. 


\section{PREVALENCE OF AGGRESSION}

Reviews on the this topic reveal that about $10 \%$ of hospitalized psychiatric patients (Tardiff, 1992; Bjorkly, 1995) have engaged in violence prior to admission. Reliance on hospitalized samples may lead to an overestimation of the prevalence of aggressive behavior in the psychiatric population as a whole (Monahan \& Shah, 1989). Yer, for psychiatric outpatients also, the empirical data make "a convincing preliminary case for an association be tween mental illness and community violence" (Mulvey, 1994; p. 664).

As violence is a major selection criterium for psychiatric hospitalization (e.g. Fuller Torrey, 1994), the frequency of aggressive acts among psychiatric inpatients can be assumed to be higher than those found in community samples. On the basis of the literature, Bjorkly (1995) estimates that 15 to $30 \%$ of hospitalized psychatric patients have been involved in physical assaults. However, no reliable national databases are available from which rates of aggressive behavior in psychiatric hospitals can be easily determined (Drinkwater \& Gudjonsson, 1989). Thus, the prevalence of violent behavior in psychiatric facilities has to be estimated by comparing the results from several descriptive studies. Table 1 summarizes the findings of the main prevalence studies. As can be seen, frequencies of aggressive incidents range considerably from as low as 0.15 assault per bed per year (Fottrell, 1980) to as high as 88.8 incidents per bed per year (Brizer, Convit, Krakowski \& Volawka, 1987). These differences will be largely due to the selection of patients studied. The samples vary from general psychiatric hospital populations (e.g., Fottrell, 1980) to specialized high security wards (Brizer et al., 1987). Apart from that, criteria used to definc and measure aggressive behavior deviate considerably across the studies, thereby adding to the inconsistency of the results. Table 1 further demonstrates that older and, in general retrospectively conducted, studies yielded lower aggression prevalences than did the more recent prospective ones in which aggression was monitored with staff observation scales specifically designed for this purpose.

The absence of reliable statistics is also true for the Netherlands. This is illustrated by the results of a nation-wide survey conducted by the Dutch inspectorate for mental health on the prevalence of aggressive behavior in psychiatric hospitals. In the 39 general psychiatric hospitals that participated in this 
survey, the estimated 6-monthly rates of aggressive incidents varied from 1 to 1120 incidents. A more detailed and reliable study was conducted by Broers and de Lange in 1996. These researchers found prevalence rates rang ing from 1.2 to 5.1 per bed for eight Dutch closed psychiatric wards over a 8 weeks period. As can be seen in table 1 , the derived yearly frequencies were 22.8 incidents per bed on the locked admissions wards and 1.7 .6 incidents per bed on the long stay wands. Note that both physical and verbal incidents were included in that study.

The various prevalence studies converge on the notion that the nursing staff form the most likely target of assaultive behavior (Drinkwater \& Gudjohnson, 1989; Shah et al, 1991; Tam, Engelsmann \& Fugere, 1996; Nijman et al., 1997a; Canmel \& Hunter, 1989; Chueng. Schweitzer, Tuckwell \& Crowley, 1996). Further, there is consensus that the vast major ity of assaults by psychiatric inpatients does not result in serious injury of staff members (Drinkwater \& Gudjonsson; Cooper \& Mendonca, 1991; Nijman et al., 1997; Chueng et al., 1996). However, the number of empirical studies that addressed the consequences of inpatient aggression in terms of injuries, sick leaves, and costs is limited. The North-American researchers Carmel and Hunter did study the physical and financial consequences of violence in a Californian forensic psychiatric hospital with 973 beds (Carmel \& Hunter, 1989; Hunter \& Carmel, 1992). In 1986, a total of 135 serious injuries were sustained by 121 different staft members. Of these 121 staff nembers, 107 were ward nurses (Camel \& Hunter, 1989). In 1988, the number of injuries was highly similar (i.e., 134 injuries were sustained; Hunter 8 Canmel, 1992). The average costs of the injuries were estimated to be 5,719 , making the total annual loss $\$ 76,290$. Although these result cannot be easily extrapolated to Dutch psychiatric hospitals, they do suggest that, apart from the physical and psychological consequences for personel, inpatient aggression has considerable financial implications.

As mentioned above, comparisons between the cited prevalence studies are complicated by the use of different definitions of aggression. Drinkwater and Gudjonsson summarize these problems as follows: "A survey of the litarature reveals a wide range of different definitions, with very little consensus between them. This has resulted in inconsistent and unreliable categorization, which creates difficulties when comparing results from different studies" 
(1989; p. 289). Indeed, a close look at the most commonly used instruments for recording aggression of psychiatric patients yields different descriptions of the behavior. More information on the measuring potentials of the various aggression instruments is provided below.

\section{MEASUREMENT OF AGGRESSION}

Instruments for measuring aggressive behavior of psychiatric patients can be roughly divided into self-rating aggression scales and observer aggression scales (Bech, 1994). Most research on self-reported aggression measures has been done in non-violent normal subjects such as psychology students (Yudofsky, Silver, Jackson, Endicott et al., 1986). A well-known and widely used self-rating questionnaire for measuring hostility and anger is the Buss-Durkee Hostility Inventory (Buss-Durkee, 1957). On the basis of the literature, Bjørkly (1995) noted about this scale that "(..) its predictive value for adult psychiatric patients has not been convincing so far" (p. 493). Referring to self-rating scales of aggressive behavior, the same author, identifies a serious shortcoming of them, namely that: "(.) major problems in obtaining self-report measures from psychotic patients complicates this approach to prediction research" (Bjorkly, 1995, p. 493). In similar vein, Yudofsky et al. (1986) point out that "many patients are not angry between aggressive episodes, and do not reliably recall or admit to past violent events" (p. 35). Since self-reports of aggressive behavior provided by acutely disturbed patients may lack reliability (see also Bech, 1994), it is not surprising that most prewalence and intervention studies rely on scales in which aggressive acts are recorded by others. Such aggression observer scales are usually completed by the nursing staff. Well-known examples of staff observation aggression scales are:

- the Overt Aggression Scale (OAS; Yudofsky et al., 1986);

- the Staff Observation Aggression Scale (SOAS; Palmstierna \& Wistedt, 1987);

- the Scale for the assessment of Agitated and Aggressive Behavior (SAAB; Brizer et al., 1987). 
- the Modified version of the Overt Aggression Scale (MOAS; Kay, Wolkenfield \& Murril, 1988);

- the Social Dysfunction and Aggression Scale (SDAS-9; Wistedt, Rasmussen, Pedersen, Malm et al., 1990);

- the Violence Scale (VS; Morrison, 1994);

The review by Bech (1994) provides a clear overview of the differences in scope and psychometric properties of these scales. According to Bech (1994), a general limitation of the various observer aggression scales is that their inter-reporter reliability has not been established. However, for most of the scales mentioned above, reliability research has been conducted. For example, the intraclass correlation coefficients of the OAS indicate good reliability (Yudofsky et al., 1986). Furthermore, the average correlation between OAS total severity scores given by independent raters was 0.87 . For the Modified version of this instrument, the MOAS, the intemal, inter-reporter, and re-test reliability were found to be high (Kay et al., 1988). Initial psychometric testing of the SOAS did also suggest high reliability. For example, Palmstiema and Wistedt (1987) reported an intraclass correlation of the total SOAS score between independent observers of 0.96 . On the basis of this and other SOAS findings, Shah et al. (1991) evaluated the SOAS as an instrument "of particular interest (..) with evidence of good reliability and validity" (p. 307). Importantly, the SOAS is the only scale that collects information about the circumstances that triggered the aggression (see Bech, 1994). Since the SOAS takes into account why the patient becomes aggressive, it seems to acknowledge the fact that situational variables may contribute to aggression. However, unlike the OAS, the MOAS, the SAAB, the SDAS-9, and the VS, the SOAS was not designed to record auto-aggressive behavior. The studies described in the present dissertation recorded aggressive behavior, using a Revised Version of the SOAS, termed SOAS-R. In this Revised Version, an option was added for monitoring auto-aggressive acts (i.e. self-mutilating and suicidal behavior). In the literature, a number of " (.) urgent calls for the study of the coexistence of disordered behaviors (.)" are found (Hillbrand, 1995; p. 668). However, "(..) the relationship between self-destructiveness and interpersonal violence has received little scientific scrutiny" (Hillbrand, 1995, p. 668). Obviously, theri, inclusion of auto-aggression in the SOAS-R will facilitate research on the 
origins of different types of aggression. Further evaluation of the psychometric properties of the (revised) SOAS is one of the research goals of the current dissertation. Thus, chapter 2 addresses the inter-reporter reliability of the SOAS in more detail while the validity of the severity scores of the SOAS are an important topic in chapter 5.

\section{DETERMINANTS OF AGGRESSION}

Apart from discussions about the psychometric qualities of instruments for measuring aggression in psychiatric institutions, there has been some debate as to the demographic and psychopathological profiles that characterize violent patients. In general, aggressive inpatients are thought to be younger, to be more often admitted involuntarily, and to be more often diagnosed as schizophrenic than non-aggressive patients (see reviews of Davis, 1991; Shah et al., 1991; Tardiff, 1992; Bjørkly, 1995). Paranoid schizophrenia and schizo-affective disorder (Grossman, Haywood, Cavanangh, Davis et al., 1995) are particularly thought to be associated with violence. However, as can been seen in table 2 , the association between violence and schizophrenia is far from clear. Mulvey (1994; p.665) attributes these inconsistent findings to the fact that "the relationship of mental illness and violence has been examined using very broadly defined measures of these two constructs". He goes on to argue that "active symptoms are probably more important as a risk factor than is simply the presence of an identifiable disorder" (p. 665). In line with this, recent studies stress that the contents of active delusions and hallucinations may elucidate the connection between psychosis and violence (Tardift, 1992; Junginger, 1996; Taylor et al., 1998).

Mania, personality disorders, substance abuse, and organic brain disease are also thought to be associated with a heightened level of aggressive behavior (Tardiff, 1992). However, table 2 reveals that several studies have failed to find a robust relationship between diagnostic category and aggression (e.g., Kay et al., 1988; Palmstierna, Lassenius \& Wistedt, 1989; Nijman et al., 1997a). In contrast to popular belief, a body of evidence demonstrates that male patients are no more likely to become aggressive than female patients (see Davis, 1991; Shah et al., 1991; Tardiff, 1992; Nijman et al., 1997a; Palmstiema 
8. Wistedt, 1989). Some studies, though, indicate that men and women may differ in the type of aggressive behavior they display. For example, Lee, Villar, Juthani, and Bluestone (1989) found males to be more assaultive while femalles more otten engaged in suicidal behavior.

Compared to the relatively large number of studies on the characteristics of violent patients, little work has been done on the contribution of situational variables (e.g., staff and ward variables) to aggressive behavior (see Friis $\&$ Helldin, 1994). The effects of staff education and training on the frequency of violent incidents have attracted some scientific interest (e.g., Infantino \& Musingo, 1985; Phillips \& Rudestam, 1995; Carmel \& Hunter, 1990; Rixtel, Nijman \& Jansen, 1997). Most of these studies (but not all, see Rixtel et al., 1997) found that training staff how to react to threatening situations can lead to a decline in the frequency or severity of aggressive incidents. There is a pacity of empirical research on the effects that ward environment (e.g., ward space, architecture, crowding, and ward atmosphere) may have on aggression. The few studies that have been done in this area have come up with mixed results (see Friis \& Helldin, 1994). In particular, the causal link between overpopulation and the frequency of violent behavior" "(.) has been controversial in research on both humans and other species" (Drinkwater \& Gudjonsson, 1989; p. 292). For instance, Palmstiema, Huitfeldt and Wistedt. (1991) found on a 19 bed acute admissions ward that the frequency of aggressive incidents per patient was rased during crowded periods. This was particularly true for patients suffering from schizophrenia or schizophreniform disorder. On the basis of these findings, these Swedish researchers decided to test the effects of a reduction of the number of beds from 19 to 10 . The anticipated decline in incidents was not found (Pallnstiema \& Wistedt, 1995). It should be noted, though, that the second part of the study which involved the bed reduction, took place allmost 3 years after the completion of the first registration period. The background characteristics of the patient group needing acute psychatric care may have altered durng this period under influence of changes in the organization of other (outpatient) facilities (see Palmstierna $\&$ Wistedt, 1995). Unfortunately, no control ward was included in this quasi-experimental study. In chapter 4 of the present dissertation, the association between ward crowding and aggression will be studied in further detail. 


\section{AUTO-AGGRESSION}

Earlier studies indicate that automaggressive acts and outwardly directed aggression are associated with each other (see Brown, Botsis \& van Praag, 1994; Hillbrand, 1995). That is to say, outwardly violent individuals appear to have a higher likelihood of engaging in auto-aggressive acts as well (and vice versa). However, remarkably little effort has been made to determine whether the two types of aggressive behavior share the same etiological and situational determinants (see Hillbrand, 1995).

Auto-aggression can be divided in self-mutilating and suicidal behavior. Generally, self-mutilation is distinguished from suicidal behavior by defining the former as inflicting direct and deliberate harm to one"s body without having the conscious intent to die (see Winchel \& Stanley, 1991; Simeon, Stanley, Francis, Mann et al., 1992; Suyemoto, 1998). In practice, however, this distinction is not easily made. In cases of severe self-natilation, it may be hard to identify afterwards whether the patient aimed at dying from the self-inflicted injuries. The opposite may also be true. That is to say, a substantial proportion of suicide attempts do not appear to be motivated by a conscious desire to die. The number of suicide attempts, committed in Dutch psychiatric inpatient facilities far exceeds the number of completed suicides (i.e., 2700 attempts and 240 completed suicides; Brunnenberg \& Bijl, 1998). Indeed, on the average, every completed suicide is preceded by abour 10 suicide attempts. It is plasible, therefore, that a number of attempts serve other purposes than solely to end life (e.g, a cry for help).

Whether auto-aggressive behavior is motivated by an urge to die may only be leamed by asking the patient about the act (see Suyemoto, 1998). In the current dissertation, all staff observations of inwardly directed aggression are referred to as auto-aggression (see chapter 5). Staff members observing auto-aggressive behavior were not asked to assess the suicidal intent of auto-aggressive acts. In chapter 6 , an attempt is made to study self-mutilation separately from suicidal behavior. This was done by asking auto-aggressive patients whether their behavior was motivated by an intent to die, or should rather be regarded as self-mutiating.

The reported prevalence rates of self-mutiation in psychiatric populations vary from 5.8\% (Langbehn \& Phohl, 1993) to 77\% (Zlotnick, Shea, 
Perlstein, Simpson et al., 1996), while in the general population, the life-time prevalence has been estimated at $0.75 \%$ (Favazza \& Conterio, 1988). Reports of extreme self-mutilating behavior include eye enucleation, facial skinning, and amputation (Favazza, 1989).

Why some psychiatric patients inflict pain on thernselves is ill understood. Exploration of self-reported motives for self-mutilation yields a broad spectrum of different reasons. Favazza (1989) identified the following themes; religious themes (e.g., identification with Christ, sinfulness, heavenly commands, influence of demons), sexual themes (e.g., desire to be a female, fear of homosexuality, control of hypersexuality, obsession with amputation), tension release, return to reality, establishing control, feeling secure and unique, influencing others, negative perceptions, pressure from alter personalities, venting anger, relief from alienation, and irresistible urges. Following an empirical approach, Shearer (1994) reached a highly similar conclusion. Of the 62 female bordeline patients in that study, $41(66 \%)$ reported to have inflicted harm on themselves repeatedly. Out of a list of 17 possible functions of self-mutilation, these 41 patients had to indicate the 3 items that applied best to them. Interestingly, all 17 reasons were chosen. The function of self-mutilation was most often portrayed as "to feel concrete pain when the other pain I am feeling is so overwhelming and confusing that I can't grasp it" (Shearer, 1994, p. 525). More than half of the self-mutilating patients (59\%) endorsed this specific item. Self-mutilation as self-punishment was chosen by $49 \%$ of the patients and $39 \%$ viewed the behavior as a strategy to reduce anxiety and despair. On the basis of patients responses, Shearer (1994) reached the conclusion that "there was considerable diversity in the practice of self-injury on dimensions such as impulsivity versus premeditation, privacy versus exhibitionism, and experience of pain and relief" (p. 524).

The motives reported by patients for their self-mutilation clearly appear to be diverse. This also seems to be the case for the (bio)psychological mechanisms underlying self-mutilation. To account for self-mutilating behavior, a multitude of hypotheses have been postulated (see Suyemoto, 1998; Zlotnick et al., 1996). In the current dissertation, an attempt was made to evaluate two specific hypotheses. The first hypothesis views self-mutilation as originating from (past) physical and sexual abuse experiences (e.g., Darche, 1990; Lester, 1991; Langbehn \& Pfohl, 1993; Zlotnick et al., 1996) 
and being connected to dissociation in later life (e.g., Zlomick et al, 1996). The second hypothesis regards self-injurious behavior as being part of a more general impulse control disorder, pointing to an underlying serotonergic dysfunction (e.g., Simeon et al., 1992; van Praag, Plutchik \& Conte, 1986).

\section{PREDICTION OF AGGRESION}

For effective prevention, it is important that clinicians, at least to some extent, are able to predict aggression (Harris \& Rice, 1997). There has been some debate about whether clinical judgment about the risk of aggression is superior to actuarial prediction methods. In clinical judgment, information about the probability and risk of violence is processed inside the head of the decision-maker (i.e., the clinician), whereas conclusions based on actuarial (or statistical) methods are drawn on the basis of established empirical knowledge (Dawes, Faust \& Meehl, 1989). In a recent review about risk appraisal of violent behavior, Harris and Rice (1997) concluded that "actuarial methods are more accurate in predicting risk than unaided clinical judgement" (p. 1168; see, for a similar conclusion, Dawes et al., 1989). In contrast, Bjorkly (1995) claims that "recent research on clinical and actuarial prediction of aggression has not been succesffud in finding a single factor, instrunent or method of high predicrive validity" (p. 490)

Meanwhile, a history of violent behavior is consistently reported as being one of the best predictors of aggression (i.e., Palmstierna \& Wistedt, 1990; Shah et al., 1991; Tardiff, 1992; Harris \& Rice, 1997). Harris and Rice (1997) note that not only a track record of violence, but also poor social adjustment, substance abuse, anti-social personality disorder, and psychopathy are closely linked to a heightened risk of violence.

It should be stressed that research in this field has traditionally been conducted in forensic or criminal samples (see Harris \& Rice, 1997). The number of studies focusing on the prediction of aggression in acutely admitted psychiatric populations is limited (e.g., Palmstiema \& Wistedt, 1989; McNiel \& Binder, 1991; McNiel \& Binder, 1995). Palnstierna and Wistedt (1989) found that the prediction of aggressive behavior in acutely involuntarily admitted patients by means of statistical predictors was of limited value. 
In that study, only violent behavior prior to hopitalization and drug use, other than alcohol, were found to be weakly correlated with subsequent aggression. The other risk factors (e.g., unemployment, homelessnes, poor compliance, alcohol abuse, organic brain disorder, low intelligence, and recent ideas of persecution) did not contribute significantly to the prediction of aggression. Palmstiema and Wistedt (1989) argue that "one explanation could be that risk factors valid in predicting violence among outpatients are not valid in an acute inpatient setting" (p. 154).

Recent results of $\mathrm{McNiel}$ and Binder $(1991,1995)$ are also difficult to reconcile with the alleged superiority of actuarial prediction. These authors demonstrated that estimates of the risk of violence provided by staff members working on acute psychiatric admissions wards possess high predictive value. Clearly, further research on how violence of acutely admitted inpatients can best be predicted is needed. Furthermore, it is obvious that in the various predictive nodels of inpatient aggression, no proper attention has been given to the potential role of situational variables in promoting violence. Meanwhile, several studies indicate that " (..) a broad range of situational variables (overcrowding, lack of privacy, inactivity, staff characteristics, limit setting, etc.) may provoke aggression in the inpatient setting" (Bjorkly, 1995, p. 494).

\section{RESEARCH QUESTIONS}

From the literature findings reviewed above, the main research issues of the present dissertation were derived. More specifically, the following questions will be addressed in the next chapters:

- How prevalent is aggression on locked psychiatric wards of Dutch and Belgian hospitals? (chapters 2 and 5 )

- Are there certain temporo-spatial patterns in the prevalence of aggressive incidents on a closed psychiatric ward? (chapter 2)

- For what reasons do psychiatric patients become aggressive? (chapters 2 and 4)

- Which patient variables are associated with (auto-)aggressive behavior? (chapters 2 and 6) 
CHAPTER I | Inpatient aggression: prevalence, measurement, determinants, and prediction 26

- Can the number and severity of aggressive incidents on a closed psychiatric admissions ward be reduced by improving staff-patient communication? (chapter 3)

- Is ward crowding associated with inpatient violence? (chapter 4)

- Is the SOAS a practical and reliable instrument to record aggressive incidents? (chapters 2 and 5)

- Can the validity of the SOAS severity scoring system be improved? (chapter 5)

- Is self-mutilation associated with traumatic experiences in childhood and dissociative symptoms? (chapter 6)

- Is self-mutilation associated with other impulse control problems like anger, irritability, and hostility, obsessive-compulsiveness, and sensation seeking? (chapter 6) 

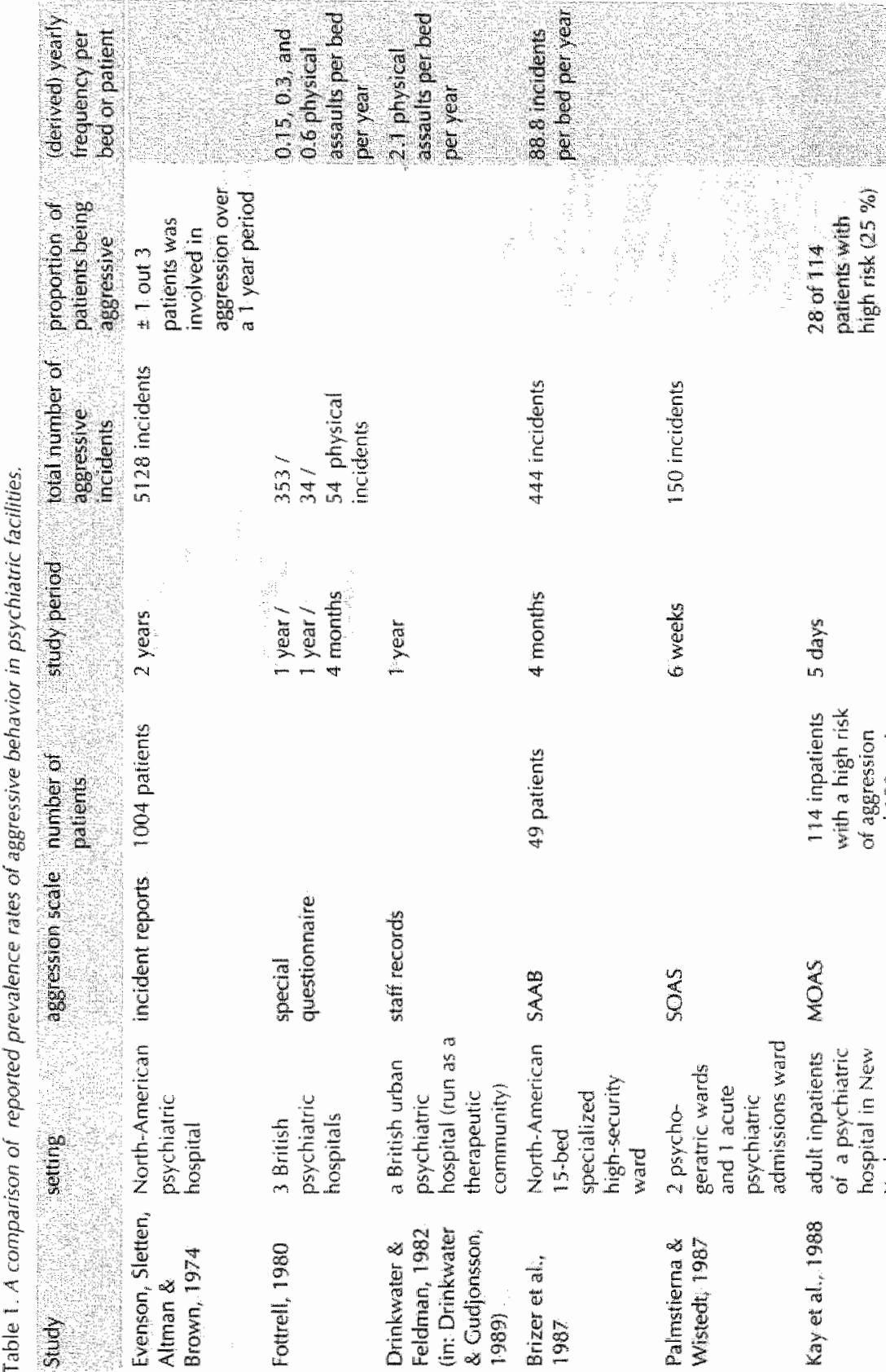

证

票

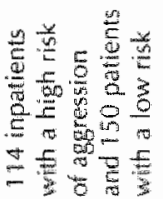

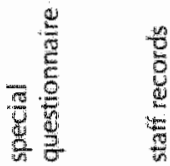

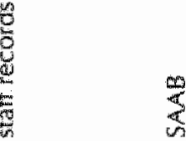

8

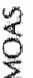

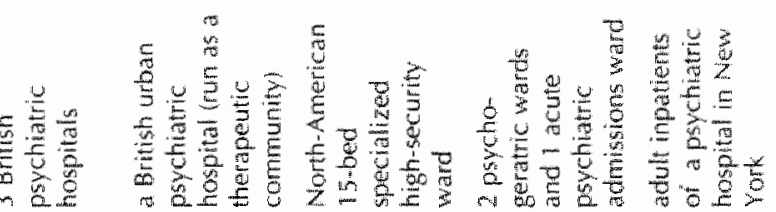

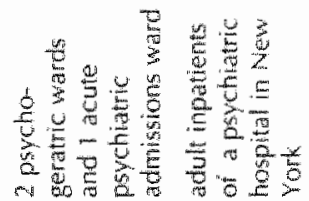

\begin{tabular}{|c|c|c|c|c|}
\hline 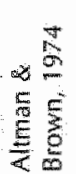 & $\begin{array}{l}0 \\
\frac{8}{2} \\
= \\
\overline{2} \\
\frac{5}{5}\end{array}$ & 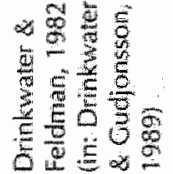 & 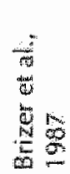 & 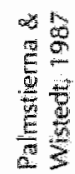 \\
\hline
\end{tabular}



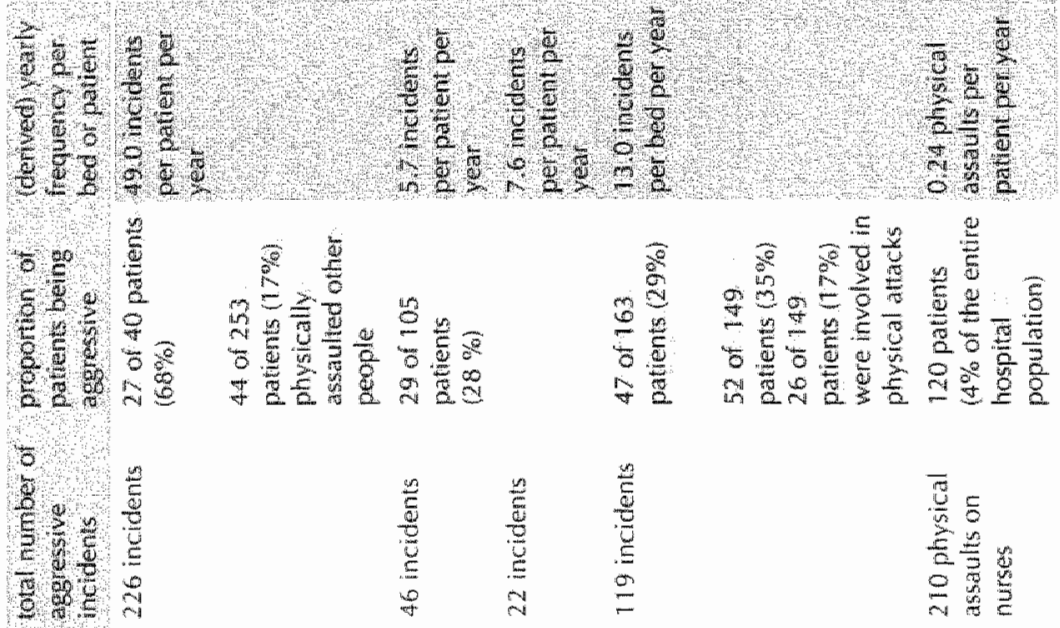

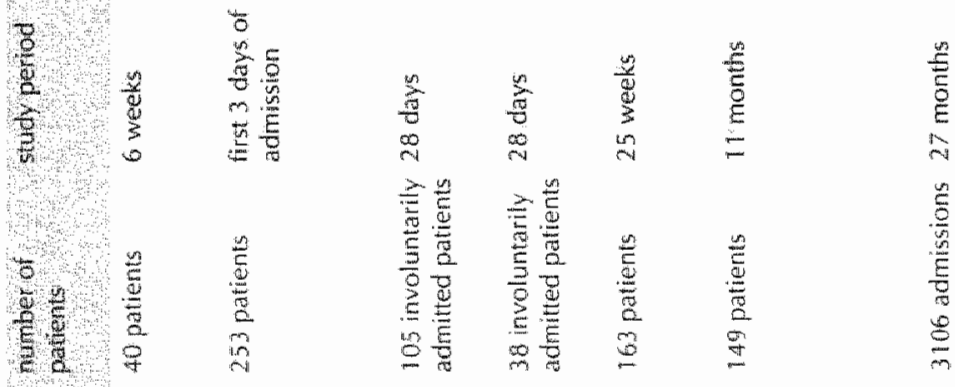

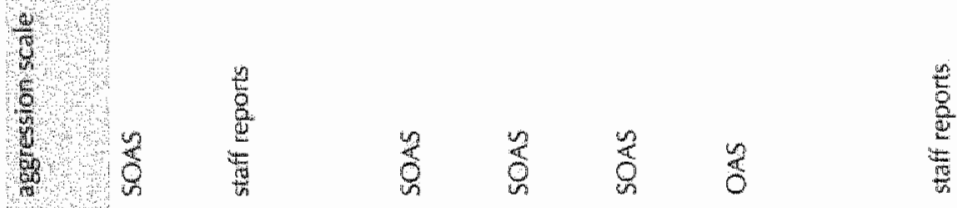

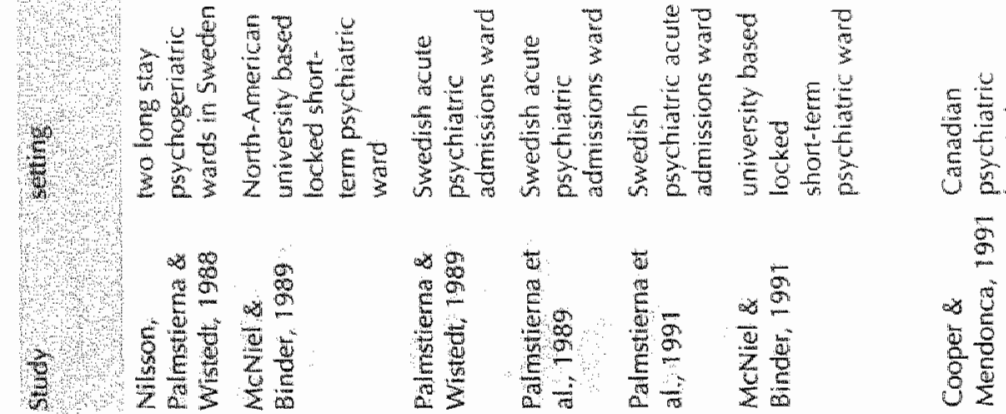



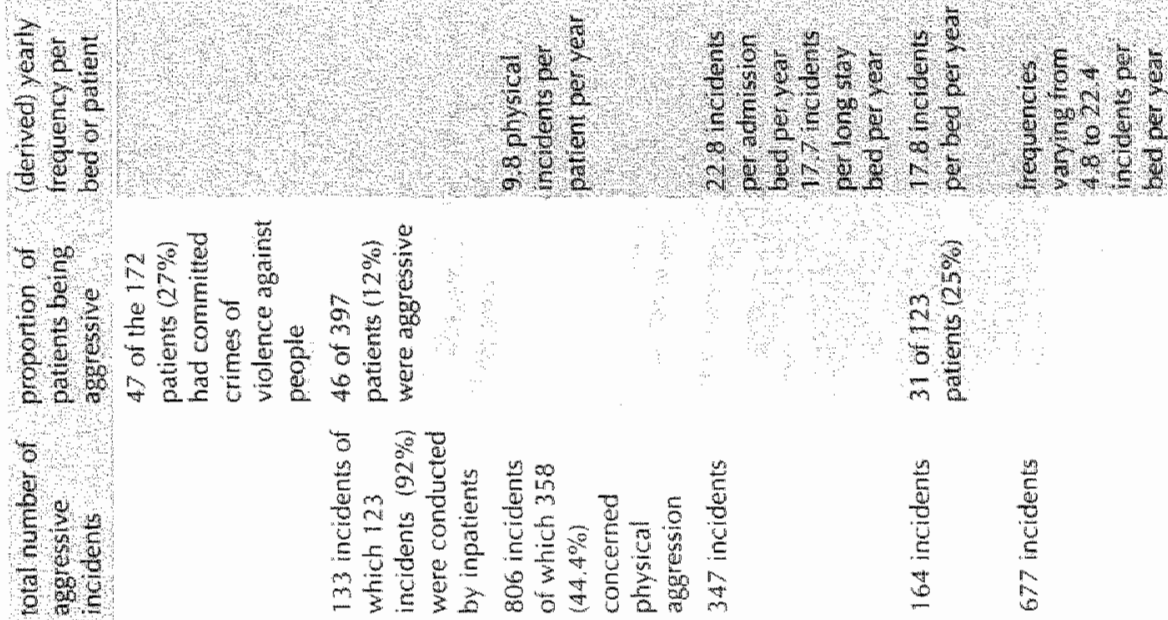

$\frac{9}{8}$
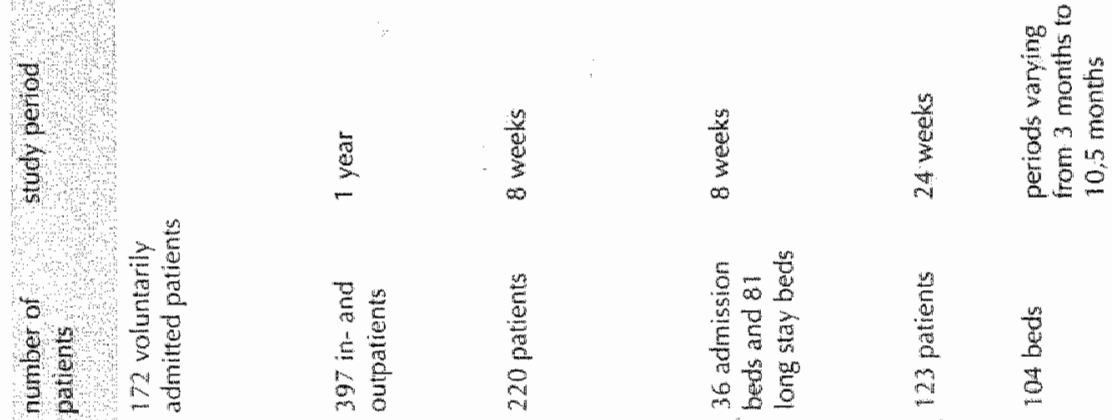

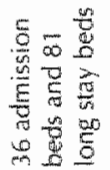

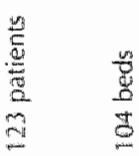

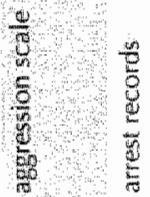

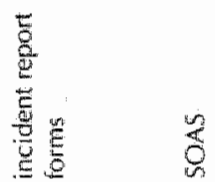

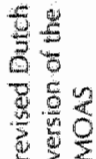

$\frac{x}{4}$

$2+$ कै

$\frac{3}{4}$

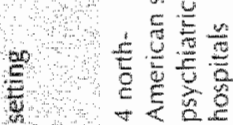

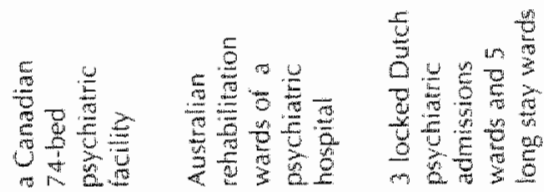

要要

这 E

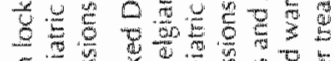
Eบ

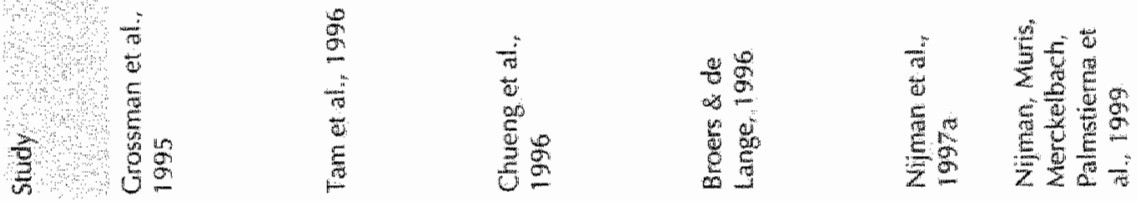



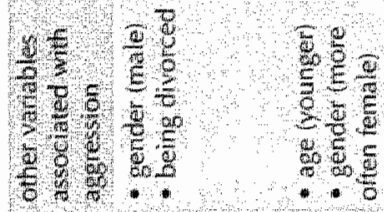

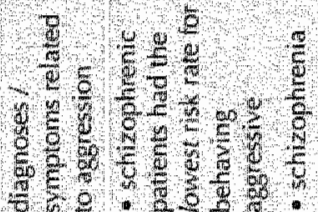
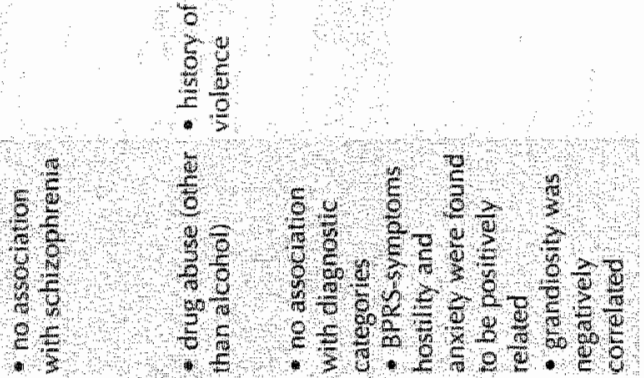

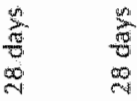

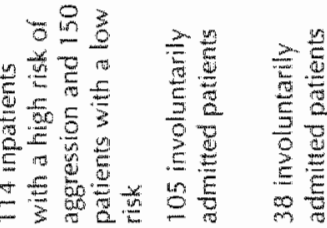

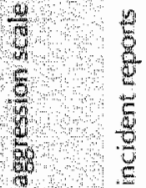

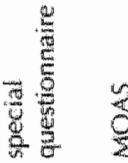
8

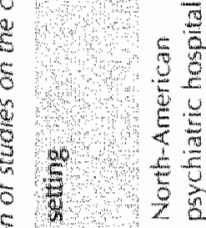

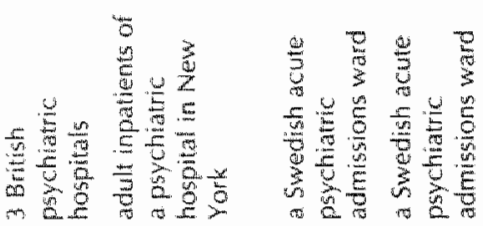

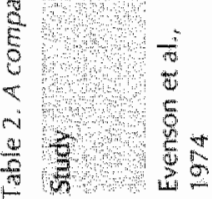

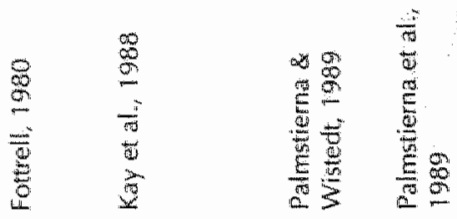



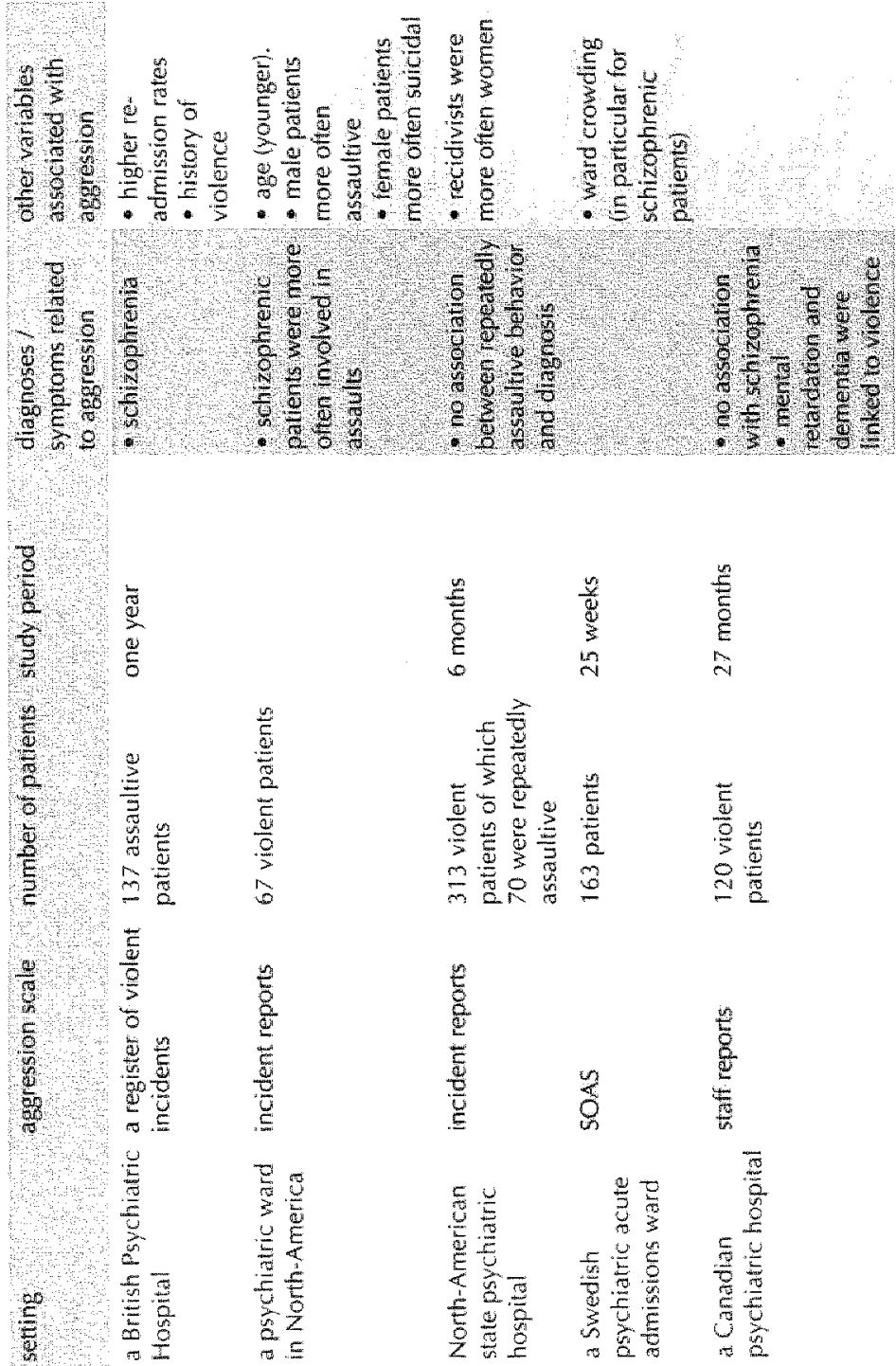

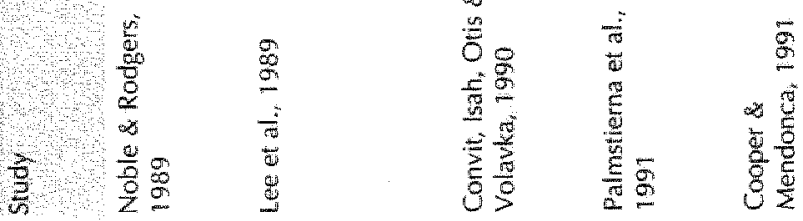




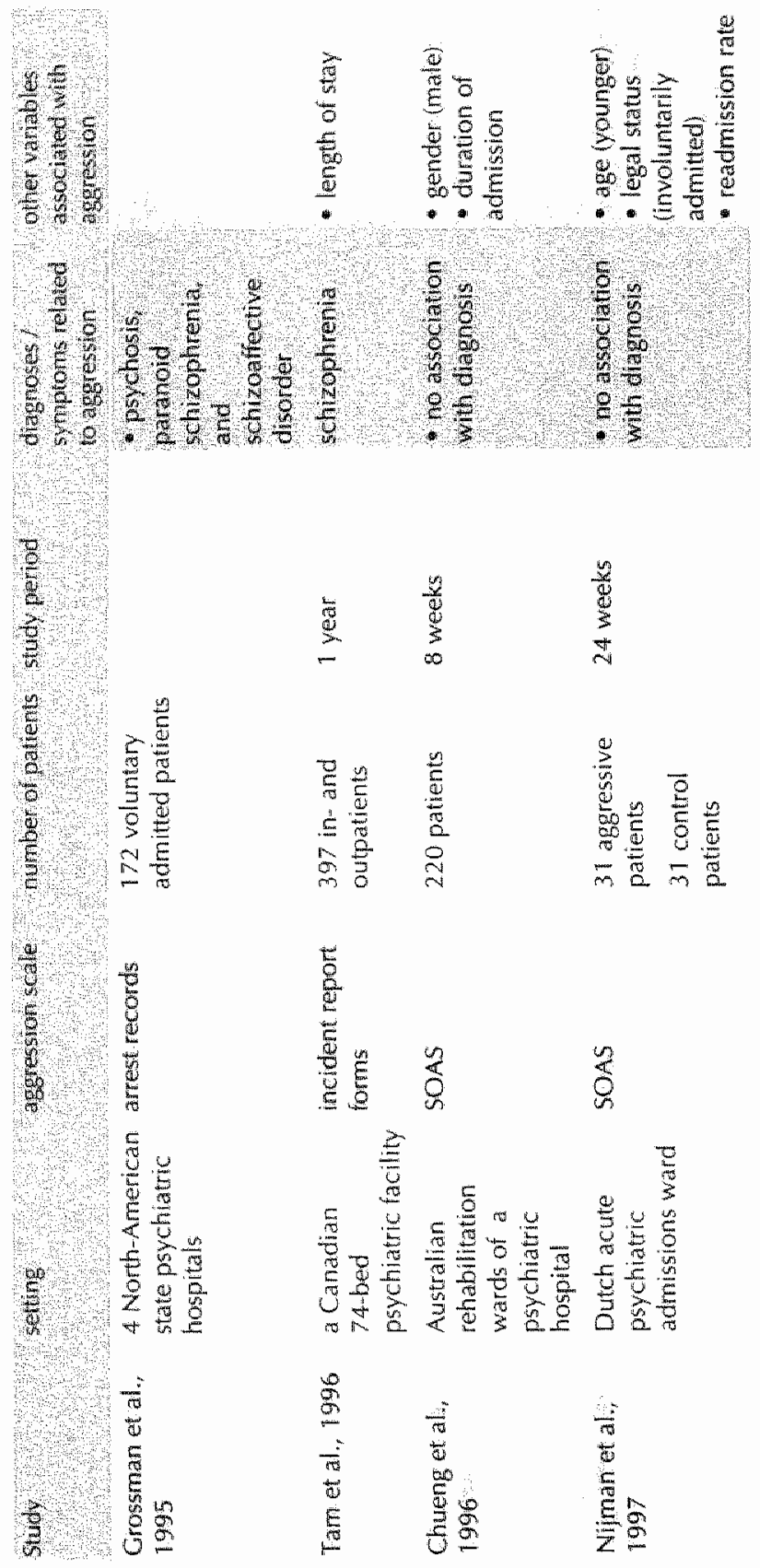


CHAPTER 2

\section{Aggressive behavior on an acute psychiatric admissions ward'}

1 This chapter appeared as Nijman, H.L.L., Allettz, W.F.F., Merckelbach, H.L.G.J., à Campo, J.M.L.G. \& Ravelli. D.P. (1997). Aggressive Behavior on an acute psychiatric admissions ward. Europeatu Jostmal of Pychiatry, 11, 106-114. 


\section{SUMMARY}

The purpose of this study was twofold. Firstly, to evaluate the reliability and usefulness of the Staff Observation Aggression Scale (SOAS), an instrument for measuring aggressive behavior in the clinical situation. Secondly, to examine the prevalence of aggressive incidents and the circumstances under which they occur on an acute psychiatric admissions ward. During a period of 24 weeks, 164 aggressive incidents were recorded. The SOAS proved to be a suitable instrument for measuring aggressive behavior with fair-to-good inter-reporter reliability. Aggressive behavior was especially likely to occur in the afternoon from noon to 3.00 p.m. It frequently took place in the day rooms of the ward, in or near the staff office, and in front of the locked exit door of the ward. Patients involved in the incidents were younger and more often involuntarily admitted than non-aggressive control patients. Gender and diagnosis were not found to be related to aggressive behavior.

\section{INTRODUCTION}

Aggressive behavior in psychiatric patients, both verbal and physical, is a widespread phenomenon in psychiatric hospitals. Psychiatric nurses, in particular, are at risk of being confronted with aggressive behavior by patients (Shah et al,, 1991; Tam et al., 1996). Shah et al. (1991) noted that the frequency of violence among psychiatric patients seems to be increasing. In spite of the seriousness of this problem, only crude statistics on aggressive incidents are available for Dutch psychiatric wards. This is demonstrated by a study of the Dutch Inspectorate for Mental Health (1992). That study reported estimated six-month rates of aggressive incidents in 39 general psychiatric hospitals ranging from 1 to 1120 .

In other countries, there have been a number of studies concerning the prevalence of aggression in psychiatric hospitals. In their review, Shah et al. (1991) conclude that comparisons between these studies are complicated by a number of problems such as differences in definitions of aggressive behavior, differences in populations, and differences in reporting methods. These studies do show, however, that aggressive patients are younger, are 
more often admitted involuntarily, and are more often diagnosed as schizophrenic than non-aggressive patients. It should nevertheless be noted that several studies have failed to find a relationship between diagnosis and aggression (e.g., Kay et al., 1988; Palmstierna et al., 1989). For example, Palmstierna et al. (1989) found no relationship between aggressive behavior and diagnostic category in a sample of acute involuntarily admitted patients (see also Palmstierna \& Wistedt 1989). The stage of the illness may be a more important predictor of violence than diagnosis per se. The acute phase seems to be the most likely period for aggression (Davis, 1991).

Shah et al. (1991) also reviewed what is known about the temporo-spatial characteristics (i.e., location and time) of aggressive incidents. Aggression appeared to be common in the day rooms and dining rooms of the ward. In addition, aggressive incidents seemed to occur more often in the morning and on Mondays and less often during the night and at the weekend.

Little is known about the frequency and the temporo-spatial patterns of aggressive incidents on psychiatric wards in the Netherlands. Accordingly, the present study had two goals. Firstly, the study evaluated the reliability and usefulness of the Staff Observation Aggression Scale (SOAS) developed by Palmstierna and Wistedt as an instrument for measuring aggressive behavior in the clinical situation. For a detailed description of the SOAS, the reader is referred to Palmstiema and Wistedt (1987). These researchers have carried out various studies in which aggressive behavior was recorded using the SOAS (Palmstierna \& Wistedt 1987; Nillson et al., 1988; Palmstiema et al., 1989; Palmstierna \& Wistedt 1989; Palmstierna et al., 1991; Palmstierna \& Wistedt 1995). The second goal of the present study was to examine the frequency of aggressive incidents and the circumstances under which they occur.

\section{METHODS}

\section{PATIENTS}

The study was carried out on a closed acute admissions ward at psychiatric hospital Welterhof, the Netherlands. This ward contains 20 beds. A substantial number of patients are hospitalized involuntarily on this ward (about one 
third in 1993). Over the total period during which this study was conducted, 123 different patients had been on the ward.

\section{PROCEDURE}

During the period from 14-6-93 to 28-11-93 (24 weeks), the number and nature of aggressive incidents accurring on the ward were recorded using the SOAS. In order to study the full range of aggressive behavior, auto-aggressive acts were also recorded. The SOAS consists of 5 columns filled in by a staff member who wirnesses an aggressive incident. The 5 columns are: the provocation which led to the aggressive event, the means used by the patient during the aggressive event, the target of the aggression, the consequences for victims, and the measures taken to stop the aggression. Scores ranging from 0 to 4 can be allocated to the 3 central or "core" columns which are "the neans used" "the target of the aggression" and "the consequence(s) for the victim(s) of the aggression". The sum of the scores of these 3 core columns reflects the overall severity of the incident, with the maximum score being 12 (Palmstierna \& Wisted 1987). A plan of the ward was attached to each SOAS, enabling staff members to indicate the location of each aggressive incident. Each member of the team who witnessed an incident was asked to complete a SOAS. If more than one staff member saw an incident, members completed the SOAS independently. Multiple SOAS data of one incident were used to evaluate inter-reporter reliability of the SOAS. To this end, the (Pearson) correlation between the scores of these forms and the kappa were computed.

In addition, the following data were analyzed:

- number of aggressive incidents occurring on the ward and the circumstances surrounding them (e.g., place and time).

- measures taken to prevent further escalation.

- variables that distinguish aggressive patients from non-aggressive control patients. More specifically, age, gender, diagnosis, and legal status at the time of admission and the number of admissions were studied. 


\section{RESULTS}

\section{FREQUENCY AND SEVERITY OF AGGRESSIVE INCIDENTS}

Over the 24 weeks during which the study was conducted, 164 different aggressive incidents were reported. This is an average of 6.8 incidents per week, or approximately one incident per day. Following the scoring system of Palmstiema and Wistedt (1987), the grat majority of these incidents (122 or $74 \%$ ) met the criteria for "mild" aggression, 39 incidents (24\%) met the criteria for "moderate" aggressive incidents and only $3(2 \%)$ met the criteria for "severe" incidents. Four (2\%) of the 164 incidents pertained to auto-aggressive acts. The 164 incidents were initiated by 31 different patients out of a total of 123 patients $(25 \%)$ who had been on the ward during the period that the study was conducted.

\section{SOAS: INTER-REPORTER RELIABILITY}

There were 46 incidents for which at least two SOAS forms were completed by independent observers (i.e., staff members). Two forms were selected af randow for each of these 46 incidents. The (Pearson) product-moment correlation between the total SOAS severity scores of these 46 incidents was 0.87. The kappa of the total SOAS severity scores was 0.61 . A kappa between 0.40 and 0.75 indicates fair-to-good agreement (Lambert $\&$ Hill 1994).

\section{THE PROVOCATION OF THE AGGRESSION}

The likely cause or provocation of the aggression is reconded in the first columin of the SOAS. In 71 out of the 164 incidents (43\%), the provocation was not understood. In 54 cases ( $33 \%$ ), violence was provoked as a result of the patient being denied something (e.g., leaving the ward). In 22 cases $(13 \%)$, other patients provoked the patient. Fifteen incidents $(9 \%)$ were due to other factors (i.e., staff asking patient to take nedication and help with activities of daily living). For the remaining two incidents, antecedents were not specified. 


\section{MEANS USED BY THE PATIENT}

The means used by the patient during the aggressive incident are recorded in the second column of the SOAS. Of the 164 incidents, 43 (26\%) were exclusively verbal aggressive events. In more than half of the incidents, namely $57.9 \%$, the patient used hands or feet to hit or kick. In 26 cases (16\%), objects such as chairs or glassware were used.

\section{THE TARGET OF THE AGGRESSION}

In the majority of the cases (102 or 62\%), the aggression was directed at humans (i.e. staff members, patients or people from outside the ward). Staff members were involved in 63 out of these 102 cases $(62 \%)$. A minority of cases (35\%) involved violence directed exclusively against objects. In the remaining 4 cases $(2 \%)$, it was not clear what the target of the aggression was.

\section{CONSEQUENCE(S) FOR THE VICTIM(S)}

In the majority of the 164 incidents (70\%), there were no physical consequences for victims or objects. In 32 cases (20\%), objects were damaged or destroyed. In 18 cases ( $11 \%$ ), the violence had physical consequences for the victims. In one case, a staff member needed somatic treatment.

\section{MEASURES TO STOP AGGRESSION}

Staff members secluded the patient (with or without restraint) in about half of the incidents $(49 \%)$. This usually happened in the form of brief "time-outs". In 36 cases (22\%), the ward team was able to prevent further escalation by talking to the patient and in 25 aggressive incidents (15\%), no measures had to be taken. In 12 cases (7\%), the patient was calmly taken away from the place where the aggression had occurred. Finally, in 11 cases $(7 \%)$ other measures were taken.

\section{PL.ACE}

Figure 1 shows the locations of the aggressive incidents. About $21 \%$ of the aggressive incidents took place in the day rooms. Patients spend a great deal of their time in the day rooms and considerable interaction between the patients takes place here. Indeed, around half of the aggressive incidents occurring in these rooms ( $49 \%$ ) were directed against other patients. In or 
CHAPTER 2 Aggressive behavior on an acute psychiatric admissions ward

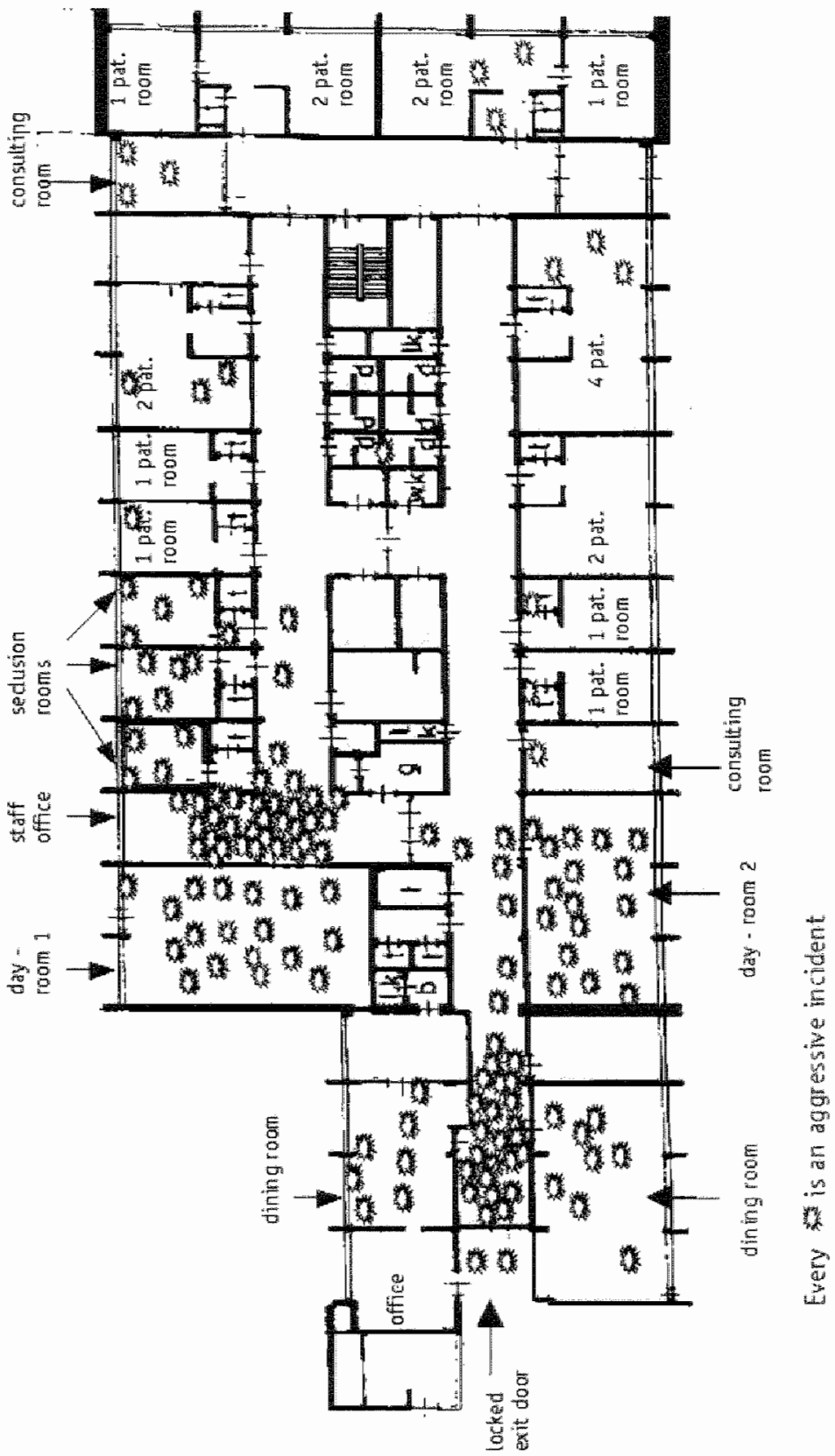


near the staff office, $20 \%$ of the incidents took place. Accordingly, aggression in this category was often directed against staff members (53\%). Twenty-four incidents $(15 \%)$ occurred near the locked outside door of the ward. Here, the aggression was usually directed against objects (75\%), commonly the locked door. These incidents are therefore less severe; the mean total SOAS score of these incidents was $3.83(s . d .=0.87)$, compared to $4.73(s . d=1.52)$ for the other incidents $[t(162)=4.09, p<0.01$, two-tailed]. In patients" bedrooms, $7 \%$ of the aggressive incidents took place. The mean total SOAS score for these incidents was higher than that for the other incidents [means being $5.42, s . d=2.43$ and $4.53, s . d .=1.37$ respectively; $t(162)=2.01, p<$ 0.05 , wo-tailed]. In 10 cases (6\%), the aggression took place outside the ward and in 7 cases the location was not specified.

\section{TEMPORAL DISTRIBUTION}

Figure 2 depicts the time distribution of the incidents. Forty-two out of the 164 incidents (26\%) took place between noon and 3.00 p.m. $\left[X^{2}(7)=76.4, p\right.$ $<0.01]$. The highest frequency of incidents $(10 \%)$ was found between 2.00 p.m. and 3.00 p.m. $\left[X^{2}(23)=101.5, p<0.01\right]$. There were also significant differences between the days of the week in terms of the frequency of aggressive incidents. Most incidents, namely 37 (23\%), took place on Mondays and the fewest incidents took place on Fridays, namely $13(8 \%)\left[X^{2}(6)=16.0, p<\right.$ $0.05]$.

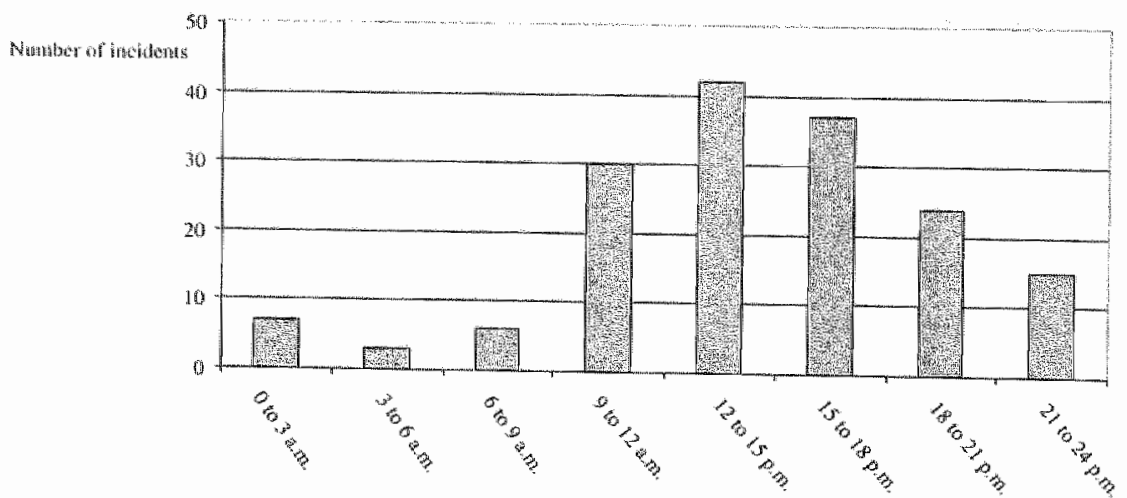




\section{CHARACTERISTICS OF AGGRESSIVE PATIENTS}

The subsample of 31 patients who were responsible for aggressive incidents was compared to a control sample of 31 patients selected at random. Control subjects had been on the ward for at least two weeks during the period under study and had not been involved in any aggressive incident. The aggressive subsample was significantly younger than the non-aggressive sample, mean ages being 31.6 years $\left(s . d_{.}=9.6\right)$ and 38.2 years $(s . d=10.2)$ respectively $[t(60)=2.65, p<0.05$, two-tailed]. In spite of the fact that aggressive patients were younger, they had a higher rate of re-admission $[t(60)=2.62, p<0.05$, two-tailed]. That is, aggressive patients were admitted on average 5.5 times, compared to 3.1 times for non-aggressive patients. In addition, aggressive patients were more often involuntarily admitted than non-aggressive control patients $\left[X^{2}(1)=4.17, p<0.05\right]$. The gender distribution of the two groups was identical; both groups contained 21 men and 10 women $\left[X^{2}(1)<1.0\right]$. For statistical analysis, the main discharge diagnoses of the patients were reduced to a limited number of categories. These categories were schizophrenia, other psychotic disorders (including psychosis NOS, brief reactive psychosis, delusional disorder ${ }^{*}$ and schizoaffective disorder), bipolar disorders, depressive disorders (including major depressions as well as depressions NOS and dysthymia), personality disorders, and other diagnoses. The aggressive group did not differ significantly from the non-aggressive group with regard to the frequency of the various diagnostic categories $\left[X^{2}(5)=\right.$ $5.75, p=0.33]$.

\section{DISCUSSION}

The main results of the present study can be summarized as follows.

1. The inter-reporter reliability (in terms of Pearson correlation and kappa) of the Dutch version of the SOAS appeared to be fair-to-good. Keeping in mind that the SOAS takes little time to complete, it thus seems to provide valuable information.

2. While the overall frequency of aggressive incidents was found to be relatively high, only a small number met the criteria for "severe" incidents. The distribution of incidents in terms of "mild", "moderate", and "severe" 
cases is, in fact, consistent with the initial findings of Palmstiema and Wistedt (1987). These authors reported frequencies of $83 \%$ (mild), $17 \%$ (moderate) and 0\% (severe). In a later study by Palmstiema et al. (1991) conducted at an acute psychiatric intensive care unit, 119 incidents were reported during a 25 -week period. Fiffy-four percent of these incidents were rated as moderate or severe. The 119 incidents in that study were initiated by 47 of 163 patients (29\%) who had been on the ward during the 25 weeks, compared to 31 out of 123 patients (25\%) during the 24 weeks of the present study. These results show that aggression on acute psychiatric wards is a prevalent problem, but is also limited to a minority of patients.

3. In accordance with the moderate severity of the incidents monitored in this study, most incidents, $146(89 \%)$, did not result in physical harm or injuries to other people. Eleven percent of the incidents did, however, have physical consequences for the victims. It is clear that aggression of psychiatric patients on a closed ward poses a serious threat to the safety of both staff members and patients. Moreover, verbal aggression and the constant threat of physical violence will also constitute a serious psychological strain for the staff. Serious verbal threats were made during the present study. For example, one patient threatened to kill a staff member on a number of occasions. Since these verbal threats can be recorded with the SOAS, the data gathered with this instrument also provide insight into the pressure under which the nursing team has to work.

4. As to the location of the incidents, aggression frequently took place in the day rooms, in or near the staff office and in front of the locked exit door of the ward. Patients spend a great deal of their time in the day rooms and considerable interaction between patients takes place here. Interaction between patients and staff members is common in or near the staff office. Probably, communication problems between patients or between patients and staff members are an important cause of agitation and aggression. Germane to this issue is a recent study of Whittington and Wykes (1996) that shows that $86 \%$ of aggressive incidents are preceded by interaction between staff members and patients. The concentration of aggressive incidents near the locked exit door raises the question of whether providing the patient with more information on the locked door and its function in treatment might result in a reduction of aggression. 
5. The time of the aggressive incidents was not evenly distributed over the hours of the day. There was an increased frequency between noon and 3.00 p.m., with a peak between 2.00 p.m. and 3.00 p.m. This pattern might be related to the working schedule: between $2.00 \mathrm{p}$.m. and 3.00 p.m., the staff is typically working in the staff office, making notes and completing patient files before a new shift starts at $3.00 \mathrm{pm}$. Supervision on the ward is minimal at this time. The staff members are visible to the patients through the staff-office window, but generally do not have time to speak to the patients. The collective withdrawal of the staff (accompanied by writing about and discussion of patients) may promote aggression by inducing suspicion or anxiety in the patients. For patients who are easily agitated, the relative inaccessibility of the nursing staff is perhaps an incentive to aggression. The question arises whether a different procedure of shift changes (e.g., where at least one member of the staff remains on the ward) might lead to a reduction in aggression.

In agreement with earlier studies (see Shah et al., 1991), aggressive incidents commonly took place on Mondays (23\%). It is possible that the start of demanding therapies after the weekend leads to aggressive behavior.

6. While aggressive patients were younger, were more often admitted involuntarily, and more often had a history of re-admissions than their nonaggressive counterparts, the aggressive patients in this study were not characterized by a certain psychopathological profile. That is to say, there were no significant differences between aggressive and non-aggressive subjects with regard to diagnosis. Becatse of the small sample size, a more fine-grained analysis of specific types of psychiatric disorders such as the paranoid type of schizophrenia, schizoaffective disorder (see Grossman et al., 1995), or borderline and antisocial personality disorder (see Tardiff, 1992) was not conducted in the present study. Clearly, the relationship between diagnosis and SOAS data warrants further study.

To summarize, the present study described the temporo-spatial patterns as well as the characteristics of aggressive incidents on a closed admissions ward. Statistics such as those presented in the present study are not only important in their own right, but also provide a background against which effects of interventions aimed at reducing aggressive behavior can be evaluated. 

CHAPTER 3

\section{Prevention of aggressive incidents on a closed psychiatric ward'}

1 This chapter appeared as: Nijman, H.L.I., Merckelbach, H.L.G.J., Allert, W.W.F. \& a Campo, J.M.L.G. (1997). Prevention of aggressive incidents on a closed psychiatric ward. Psyehiation Services, $48,694-698$. 


\section{SUMMARY}

Objective: This study examined whether interventions for preventing patients" aggression may reduce the number of aggressive incidents on a closed acute admissions ward of a psychiatric hospital in the Netherlands. Mertods: The number and severity of incidents of aggression on 3 closed wards were measured using the Dutch version of the Staff Observation Aggression Scalle (SOAS). Measurements were obtained for three-month periods before and after staff implemented interventions for preventing aggression on one of the wards. Interventions included a protocol for talking to patients. who exhibited aggressive behavior, discussing treatment goals with the patient shortly after admission, explaining why the ward's door was locked and the exit rules, providing a schedule of staff meetings to explain staff members' absence from the ward, and clarifying the procedure for making an appointment with the psychiatrists.

Results: The frequency of aggressive incidents declined on all three wards, with no significant diflerence between the ward where interventions were implemented and the two control wards. A marginally significant difference in severity of aggressive incidents was found between experimental and control wards after the introduction of the preventive measures, with incidents in the experimental ward tending to be less severe.

Conchsions. This study failed to find a robust effect of specific intervention measures on aggressive incidents. However, it did find evidence suggesting that standardized reporting by staff of aggressive incidents on closed psychiatric wards may in itself result in straightforward reduction of violent incidents.

\section{INTRODUCTION}

Aggression of psychiatric patients threatens the safety of both staff members and patients. As a result of violence of patients, staff members are sometimes forced to use seclusion or restraints in order to avert acute danger. While restraining a patient, staff members run the risk of getting injured (Camel, Hunter \& Staff, 1989; Rice, Harris, Varney \& Quinsey, 1989). Apart from 
this, the physical and psychological consequences of patient violence have considerable financial implications (Hunter \& Carmel, 1992). There are indications that the number of aggressive incidents in psychiatric hospitals is increasing (Shah et al., 1991). Especially for acute closed psychiatric wards, relatively high frequencies of aggressive incidents are reported (Nijman et al., 1997a; James, Fineberg, Shah \& Priest, 1990; Palmstierna et al., 1991). The psychiatric literature includes numerous suggestions for aggressionreducing interventions. However, relatively little is known about the effects of these interventions on the frequency of aggressive incidents. Palmstierna and Wistedt (1995) examined the effect of a reduction of the number of beds on the number of aggressive incidents per patient. These researchers found that this reduction did not affect the frequency of incidents per patient. However, the nature of the incidents did change. Violence between patients increased, whereas aggression towards staff members decreased. The aggressive incidents in that study were monitored by means of the Staff Observation Aggression Scale (SOAS; Palmstierna \& Wistedt, 1987). Interestingly, Nilsson et al. (1988) found that monitoring aggression with the SOAS in itself can lead to a reduction of incidents.

Using a therapeutic management protocol, Kalogjera, Bedi, Watson, and Meyer (1989) obtained a reduction of $64 \%$ of seclusions and restraints in three wards. Their protocol provides detailed suggestions as to how the staff should react to disruptive behavior of patients at an early stage. Physical assaults are, indeed, often preceded by prolonged periods of tension building. Rice et al. (1989, p. 95) state that "(..) violence rarely erupts without warning, but that patients usually first go from a calm state, through an anxious state, to a hostile state." In line with this, McNiel and Binder found that the staff of closed psychiatric wards is able to give a valid one week estimate of the risk of violence of patients (McNiel \& Binder, 1995; 1991). Also, threatening behavior prior to admission was found to be linked to subsequent episodes of seclusion and violence (McNiel \& Binder, 1989). Recently, Hunter and Carney Love (1996) reported a $40 \%$ reduction of incidents in dining rooms of a state forensic psychiatric hospital by using the principles of Total Quality Management (TQM). The reduction was obtained by the implementation of 5 interventions that were selected by a 10 
member multidisciplinary team using the TQM FADE (focus, analyze, develop, and execute) method.

One obvious limitation of the intervention studies described above (Palmstiema \& Wistedt, 1995; Kalogjera et al., 1989; Hunter \& Carney Love, 1996) is that they failed to include control conditions. Consequently, the possibility remains that in these studies, changes in aggressive incidents or in the number of seclusions and restraints were caused by factors not related to the interventions. Perhaps, staff members, knowing that a study is going on, become less likely to report violence.

A number of studies with a quasi-experimental design have been conducted to assess the effects of preventive measures on aggressive incidents. For example, effects of training staff members how to manage aggression have been studied in this way. Infantino and Musingo (1985) found that trained staff members were less often assaulted than untrained staff members. Phillips and Rudestam (1995) reported similar findings on the basis of a limited sample size. Carmel and Hunter (1990) did not find an association between staff training and the frequency of aggressive incidents. However, the severity of aggression (as measured by the number of staff injuries) was found to be less on wards where the staff had a strong commitment to aggression management training.

Based on a previous study concerned with the prevalence of inpatient aggression (Nijman et al., 1997a), the current study explored the effects of a number of interventions on the incidence of aggression in an acute psychiatric admissions ward. The interventions aimed at improving the communication between patients and staff members about treatment goals and strategies. A recent study of Whittington and Wykes (1996) clearly documented that communication problems between staff and patient can play an important role in initiating aggression. These researchers found that the large majority of aggressive incidents (i.e., 86\%) were preceded by interactions between staff members and patients. Simularly, Shah et al. (1991) argued that an authoritarian attitude of staff members, too little communication among staff members, insufficient competence of staff members, as well as limited working experience can contribute to aggression. Blair (1991) points out that a lack of consistency in limit setting and a denying, authoritarian, inflexible attitude may elicit aggression. In sum, then, there are good reasons to 
expect that training staff members how to cope with problematic behavior of patients and improving the way in which ward rules and treatment strategies are communicated to the patient might reduce aggressive behavior.

\section{METHODS}

\section{ASSESSMENT}

The study started on November 7, 1994. In 3 closed wards, each containing 20 beds, pre-intervention aggression scores were obtained for a period of 3 months (92 days). Aggressive behavior was recorded with the Dutch version of the SOAS. Auto-aggressive behavior was also monitored. The SOAS consists of 5 separate columns to code aggressive incidents: the provocation which led to the aggressive event, the means used by the patient during the aggressive event, the target of the aggression, the consequences for victims, and the measures taken to stop the aggression. Severity scores are given to the 3 central columns. The sum of these scores reflects the severity of an incident. The maximum score is 12 (Palmstierna \& Wistedt, 1987).

After the baseline period, a multidisciplinary team started to select and protocol interventions aimed at reducing aggressive behavior. This protocolling of interventions took place in 10 consensus meetings. The multidisciplinary team consisted of the psychiatrist and assistant psychiatrist of the experimental ward (see below), the head psychiatric nurse, 3 psychiatric nurses, the researcher, and the quality coordinator of the hospital. In two further sessions, the interventions were then introduced and explained to the entire staff of the experimental ward. The experimental ward was a closed psychiatric admissions ward. Two other wards (one closed admissions ward and one closed ward for further treatment) served as control conditions. After the implementation of the interventions on June 26, 1995, SOAS scores were obtained on all 3 wards for another period of 92 days. Below, this period will be referred to as the post-intervention period.

\section{INTERVENTIONS}

The following 5 interventions were used: 
1. Implementation of an aggression protocol based on the verbal interventions of the therapeutic managenent protocol of Kalogjera et al. (1989), This protocol consisted of a number of verbal steps taken by staff members in case of disruptive behavior of patients. The first step was to inform the patient about what exactly constituted the (threatening) aggressive behavior. Next, the consequences of this behavior were explained to the patient. Emotions caused by the disruptive behavior, such as fear, anxiety or worry on the part of staff members or fellow patients, were also communicated to the patient. The patient was then informed that he or she had to regain control and stop the (threatening) aggressive behavior. Finally, the measures that had to be taken if the patient did not regain control were announced. Each of these verbal interventions was directed at initiating communication with the patient about aggression at an early stage. Attempts of the patient to change the disruptive behavior were positively reinforced by staff members.

In cases where these verbal interventions had no effect, incidents were evaluated together with the patient after he or she had calmed down. This evaluation took place within 24 hours after the incident. The evaluation was carried out by using a standard evaluation form and consisted of three parts. To begin with, the patient was told what had occurred and what the results of the aggressive behavior were. The patient was also informed why certain (restricting) measures had been taken. Secondly, and in contrast to the protocol of Kalogjera et al. (1989), the patient was then asked to describe what had taken place, in his or her view. This was done because in a previous study on aggression ( $\mathrm{Nijman}$ et al., 1997a), it was found that in $43 \%$ of the incidents, the provocation of the aggression was not understood by staff members. In the third and last part of the evaluation, preventive strategies were discussed with the patient and written down on the evaluation form.

2. Discussing treatment goals and strategies with the patient within 24 hours after admission. During this session, ward rules were also explained to the patient by the (assistant) psychiatrist and written down on a treatment planning form. Both the (assistant) psychiatrist and the patient signed the form. Immediately after this, copies of this form were handed out to the patient and to the nursing staff and one copy was filed in the medical file. 
In this way, all parties were given consistent information about limit setting and treatment goals and strategies.

3. Providing detailed information about the locked exit door of the ward. In an earlier study, it was found that $15 \%$ of the aggressive incidents occurred near this door (Nijman et al., 1997a). It is plausible to assume that patients do not always understand why and when the ward door is locked. To provide clarity in this matter, printed cards were made with the ward exit rules on them. A card was given to the patient directly after admission and verbal instructions concerning the exit rules were also given at this moment. Furthermore, a sign was attached to the ward door. This sign explained the purpose of the locked door and described exit rules.

4. Providing information about the dates and hours of staff meetings. In a previous study (Nijman et al., 1997a), it was found that aggression occurred relatively often just before and during certain staff meetings. Apparently, for patients with a low frustration tolerance, the absence of staff members on the ward and a lack of understanding about the reasons for their absence may cause problems. Therefore, a sign was attached to the door of the nurses' office, every time a meeting was held with the hours and the name of the meeting printed on it. The entire weekly schedule of meetings was explained on another sign on the ward. Staff members were instructed to avoid allowing meetings to last beyond their scheduled time.

5. Improving and clarifying the procedure of making appointments with the (assistant) psychiatrist. A schedule of the office hours of the (assistant) psychiatrist was posted in the staff office. When a patient wished to make an appointment with the (assistant) psychiatrist, this was written down on the schedule in the presence of the patient.

It was examined to what extent these 5 interventions lead to a reduction of aggressive incidents in the experimental ward compared to the control wards. In addition, it was investigated whether control and experimental wards differed with regard to the average severity of the aggressive incidents. Finally, it was evaluated whether differences between the wards in number and severity of aggressive incidents could be related to the number and length of admissions on the wards during the pre-and the post-intervention 
measurements. This was done in order to rule out alternative interpretations of reductions in aggressive behavior.

\section{RESULTS}

\section{FREQUENCY OF AGGRESSIVE INCIDENTS}

Figure 1 depicts the frequencies of aggressive incidents during the pre- and post-intervention periods. The overall reduction in aggressive incidents across all three wards from pre-to post-intervention was $52 \% . \mathrm{A} \mathrm{X}^{2}$ test indicated that this was a significant reduction: $X^{2}(1)=28.4, p<.01$. For the experimental ward, the total number of aggressive incidents was reduced from 67 (pre-intervention) to 25 (post-intervention), a reduction of $63 \%$. For the two control wards, an average reduction of $44 \%$ was found. The difference in aggression reduction between the experimental and control wards did not attain significance: $X^{2}(1)=1.95, p=.16$.

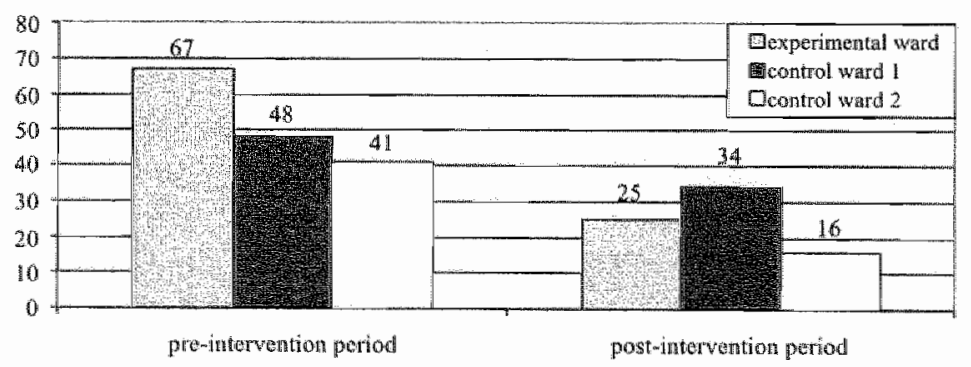

Figure 1. Frequencies of aggressive incidents in experimental and control wards during pre-andpost-intervention periods.

Figure 2 shows the frequencies of physical aggressive incidents (i.e., verbal aggression excluded) for the three wards. Again, for the wards combined, the total number of physical aggressive incidents showed a significant reduction from pre-to post-interwention period: $X^{2}(1)=5.83, p<.05$. For the experimental ward, a reduction from 30 to 14 physical aggressive incidents $(53 \%)$ 
was found. For the two control wards combined, the number of physical incidents declined from 41 to 31 incidents $(24 \%)$. The reduction found for the experimental ward did not significantly differ from that of the two control wards: $X^{2}(1)=1.45, p=0.23$.

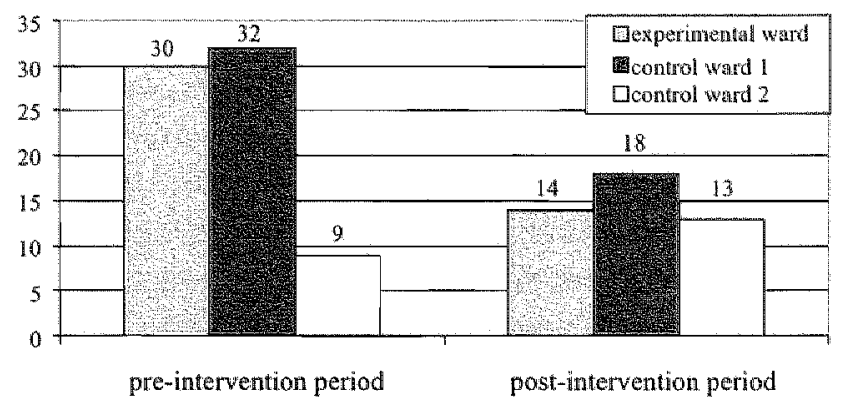

Figure2. Freguencies of physical aggressive incidents in experintental and control wards during pre and post intervarion periods.

\section{SEVERITY OF THE AGGRESSIVE INCIDENTS}

The mean severity score of the incidents was calculated with the scoring system proposed by Palmstierna and Wistedt (1987). Since auto-aggressive incidents are not included in the original version of the SOAS, they were not taken into account here. Accordingly, 30 of 231 incidents (13\%) were excluded from the analysis. For the experimental ward, the mean severity score decreased from 4.51 to 4.05 , while the mean severity score for the control wards increased from 4.20 to 4.55 . This difference was found to be marginally significant: $F(1,194)=3.83, p=0.052$.

\section{OCCUPANCY RATES}

The overall reduction of the number of aggressive incidents in the three wards occurred despite an increase in the occupancy rates. The number of admission days (number of admissions $X$ length of the admissions) in the three wards increased from 5281 in the pre-intervention measurement to 5671 in the post-intervention measurement: $X^{2}(1)=13.89, p<0.01$. No 
difference in admission days between experimental ward and control wards during pre- and post-intervention periods was found: $X^{2}(1)=0.90, p=$ 0.34 .

\section{DISCUSSION}

The main results of the present study can be summarized as follows. Firstly, the overall frequency of aggressive incidents in the three wards decreased during the post-intervention measurement. In line with the findings of Nilsson et al. (1988), it appeared that systematic monitoring of aggression with the SOAS contributed to a reduction in aggressive incidents. Nilsson et al. $(1988$, p. 174) speculated that "this reduction phenomenon is caused by a learning process from the ordinary nursing staff, who during a study of this kind are forced to systematize their observation of their patients". Possibly, then, the SOAS makes staff members more sensitive to risk factors that elicit aggressive behavior. If true, monitoring of violence with an instrument such as the SOAS can be considered as an aggression-reducing intervention. Note that changes in occupancy rates of the wards offered no explanation for the overall reduction in aggression. Still, in this type of quasi-experimental study, factors other than SOAS measurements may have contributed to the reduction of incidents. For example, staff members were aware of the fact that their wards were the object of research. Consequently, expectancy-effects might have played a role in the reduction of aggressive incidents. Particularly with more subjective outcome measures, as is the case with verbal aggression, expectancy-phenomena may affect the results. However, the overall reduction was also found if only physical aggressive incidents were included in the analysis. Still, a tendency of the staff to report fewer incidents during the study might have changed the criteria for completing the SOAS. This may have resulted in fewer reports rather than an actual decrease of violence.

Secondly, compared to the control wards, the experimental ward did not exhibit a significant reduction of incidents as a result of the intervention measures. In terms of percentages, the experimental ward showed the largest reduction of both verbal and physical incidents. Given the serious threat 
aggression poses to the safety of both patients and staff members, one could argue that any reduction of the number of violent incidents may be regarded as clinically relevant. Our failure to obtain a significant effect of the interventions on the number of incidents could be related to the overall reduction in incidents. This reduction may have "masked" an experimental effect. Furthermore, the interventions and the changes in attitude and behavior they require from staff members may have needed more time to become effective.

Thirdly, a marginally significant reduction $(p=0.052)$ occurred in the average severity of the aggressive incidents on the experimental ward. It is plausible that this reduction was obtained by staying alert on early signs of violent escalations and using more timely verbal interventions as described in the therapeutic management protocol of Kalogiera et al. (1989). Although in some instances the verbal steps were difficult to use because direct (physical) action was required to avoid dangerous situations, the protocol did seem to make the staff members more alert on early signs. Apart from this, the evaluative part of the protocol was judged as valuable and useful by the ward team. Because most patients on the experimental ward were aware of what had happened before and during the aggressive incidents, the nurses were able to find out more about the patients' reasons for becoming aggressive and to talk with them about behavioral alternatives. Discussing the anxieties, delusions, and distorted perceptions underlying the disruptive behavior with the patient may be helpful in reducing negative countertransference reactions.

In sum, although the interventions did not result in a significant reduction of the number of aggressive episodes, the results of the present study do show that staying alert on what happens before and during aggressive incidents is the first, and perhaps the most important, step in reducing violent behavior. Therefore standardized reporting of aggression on closed psychiatric wards seems useful and may result in a robust reduction of incidents. 

CHAPTER 4

Crowding and aggression ${ }^{1}$

1 This chapter is based on Nijman, H. \& Rector, G. (1999) Crowding and aggression on impatient psychiatric wards. Psyiatric Senvices, 50,830-831. 


\section{SUMMARY}

In the current study, the connection between crowding and ward space, on the one hand, and aggressive behavior, on the other hand, was investigated. On two closed psychiatric wards, all aggressive behavior that occurred in the period from February 1,1996 untill December 15,1996 was recorded. A modest correlation between the number of patients on the ward and the number of incidents per patient was found. Enlargement of the ward surface, by the addition of a courtyand to one of the wards, did not lead to a significant decline in aggressive incidents. These findings suggest that a lack of psychological space on the ward (e.g., having no privacy or not being able to get rest) may be more important in triggering aggression than a lack of physical space as measured in square meters.

\section{INTRODUCTION}

Aggression of psychiatric patients represents a serious threat to the safety of both patients and staff members (e.g., Nijman et al., 1997a; Nijman, Metckelbach, Allertz, \& à Campo, 1997; Hunter \& Carmel, 1992). Apart from the physical and psychological consequences, patient violence has considerable financial implications (Hunter \& Carmel. 1992).

Research concerned with aggression in psychiatric hospitals has focused mainly on patient variables to account for inpatient violence. Less emphasis. has been placed on the contribution of staff or ward variables to the occur rence of aggression (e.g., Krawkowski \& Czobor, 1997; Friis \& Halldin, 1994). For example, Krakowski and Czobor (1997) argue that although the characteristics of violent patients have been studied intensively, no consideration has been given to "the situational factors promoting violence" (p.230). As for the situational determinants, surprisingly little empirical research has addressed the issue of ward space and architecture in relation to inpatient violence. One exception is a Swedish study by Palmstiena et al. (1991) who investigated the effects of ward crowding on the frequency of aggression. They found that schizophrenic patients were more likely to become aggressive when the ward was packed. Remarkably, however, the same research 
group failed to find a decline in individual aggression frequency on a psychiatric ward after the number of beds had been reduced by $50 \%$ (Palmstierna $\&$ Wistedt, 1995).

In spite of these conflicting findings, the association between ward variables and violent behavior is worth studying because it may lead to concrete and lasting (architectural) interventions. In the present study, the relationship between ward space and aggression in a Belgian psychiatric hospital was studied.

\section{METHODS}

In the period from February 1, 1996 untill December 15, 1996, all verbal. and physical aggressive acts of patients admitted to two closed observation wards of the psychiatric hospital Broeders Alexianen were recorded. The aggressive behavior was scored with a revised version of the Staff Observation Aggression Scale (SOAS-R; Nijman et al., 1999). The SOAS consists of five columns in which the provocation of the aggression, the means used during the aggressive incident, the target of the aggression, the consequences of the aggression, and the measures taken to stop aggression are described.

The main task of the wards that were studied is crisis intervention and diagnostic evaluation. The mean lengths of stay in 1996 on the two wards was 33 days (median $=13$ days) and 17 days (median $=9$ days). Due to the short admission duration, and the resultant high turnover, there is relatively much variation in the occupation rates of these wards. This makes them suitable for studying the effects of crowding on inpatient aggression. Furthermore, at the start of the study, one of the observation wards was scheduled to be rebuilt. In the middle of the study (on July 9,1996 ), a courtyard was opened for the patients of observation ward 1 . The inner-court was connected with two entrances to the ward, which increased the opportunity to walk around freely. The aggression frequencies for the rebuilt observation ward 1 were compared to those for observation ward 2 , before and after the spatial enlargement of observation ward 1 .

The purpose of this study was to examine: 
1. Whether ward crowding is associated with aggressive incidents per patient.

2. Whether enlargement of the ward surface results in a decline in aggressive incidents.

\section{RESULTS}

\section{ADMISSIONS}

During the study period, 212 male and 142 female patients were admitted to the wards. The average age was 41 years (range 15 to 55 years). The most common diagnoses were drug related problems (38\%), mood disorders (20\%), psychotic disorders (18\%), and personality disorders (18\%).

\section{AGGRESSIVE INCIDENTS}

In total, 226 aggressive incidents were recorded. The weekly number of aggressive episodes varied from 0 to 15 , the average being 4.9 incidents per week. About half of the incidents $(115 ; 51 \%)$ concerned physical aggression. Eighteen of the 226 aggressive episodes ( $8 \%$ ) led to harm or injury of victims.

\section{RESEARCH QUESTION 1: CROWDING AND AGGRESSION} A Pearson product-moment correlation was calculated between the weekly occupancy rates of the wards and the individual aggression frequency. The weekly occupancy rates were calculated by multiplying the number of occupied beds by the number of days each bed was occupied. After controlling for ward, a modest, but significant correlation was found between the weekly occupation rates and the number of incidents per patient $(r=0.21, p$ $<0.05$, one-tailed). The correlation between the weekly occupation rates and incidents of physical aggression was about the same $(r=0.19, p<0.05$, one-tailed).

RESEARCH QUESTION 2: WARD SPACE AND AGGRESSION Table 1 presents the aggression frequencies of the rebuilt and the 'control' ward. Compared to the frequencies for the control ward, the number of aggressive incidents on the reconstructed ward was not found to have 
Table

Aggression frequencies om the two locked observation wards, before and after the spatial enlargement of observation ward $r$.

$\begin{array}{llll} & \begin{array}{l}\text { Before spatial } \\ \text { enlargement }\end{array} & \text { after spatial enlargement } & \text { total } \\ \text { locked observation ward } & 104 \text { incidents of which } & 67 \text { incidents of which } & 171 \text { incidents of which } \\ \text { 1(trebuilf ward) } & 45(43 \%) \text { concerned } & 41(61 \%) \text { concerned } & 86(50 \%) \text { concermed } \\ & \text { physical aggression } & \text { physical aggression } & \text { physical aggression } \\ \text { locked observation ward } & 41 \text { incidents of which } & 14 \text { incidents of which } & 55 \text { incidents of which } \\ 2 \text { control ward) } & 21(5 \% \%) \text { concerned } & 8(57 \%) \text { concerned } & 29(53 \%) \text { concerned } \\ & \text { physical aggression } & \text { physical aggression } & \text { physical aggression } \\ \text { total } & 145 \text { incidents of which } & 81 \text { incidents of which } & 226 \text { incidents of which } \\ & 66(46 \%) \text { concerned } & 49(60 \%) \text { concerned } & 115(5 . \%) \text { concerned } \\ & \text { physical aggression } & \text { physical aggression } & \text { physical aggression }\end{array}$

declined after the opening of the courtyard. As a matter of fact, a borderline significant trend contrary to the expectation was found $\left[X^{2}(1)=3.4, p=\right.$ $0.07]$. When only physical aggressive incidents were taken into account, a highly similar result emerged: $X^{2}(1)=3.6, p=0.06$.

Note that the aggression frequencies were found to decline on both wards during the second part of the study: $X^{2}(1)=18.1, p<0.01$. However, when only physical aggressive incidents where taken into account, the decline in the second part of the study did not reach significance: $X^{2}(1)=2.0, p=0.16$

\section{DISCUSSION}

In the present study, ward crowding was found to be modestly correlated with the number of aggressive incidents per patient. Although the effect-sizes were small and the causality of the association remains unclear, this funding corresponds with the clinical impression that high ward turmoil may play a rolle in overstimulating and frustrating patients.

Contrary to the expectation, extension of ward space of one of the two wards did not result in a significant reduction in aggressive incidents. Perhaps, then, it is not the physical space in terms of square meters but rather the psychological or social space that matters (see Drinkwater \& Gudjonsson, 1989). On a crowded ward, more patient-patient interactions will take place 
and it will be harder for patients to find rest or privacy. The average noise-level on a packed ward will also be higher. Future research should investigate whether an increase in (undesired) patient-patient contacts is, indeed, associated with aggressive behavior. Also, a lack of opportunity for patients to retreat and be alone if they desire may be a predictor of aggression. A related point is that the staff-patient ratio will be lower on a crowded ward. The resulting relative inaccessibility of the nursing staff on a crowded ward may frustrate and anger patients (Nijman et al., 1997a). One way or the other, preventing crowding is likely to enhance the ward atmosphere and may improve safety.

In line with earlier SOAS-studies (van Rixtel, et al., 1997; Nilsson et al,, 1988; Nijman et al., 1997b), a significant reduction of overall aggression frequency was observed regardless of the precise intervention. One could argue that the SOAS, with its focus on the antecedents of aggression, makes staff members more sensitive to early signs of escalation. This increased awareness may improve the predictability of incidents, thereby stretching the time to intervene. If true, standardised monitoring of violence with an instrument such as the SOAS may be considered an aggression-reducing intervention in itself. Alternatively, the criteria for completing SOAS may have changed during the research time frame. Possibly, staff members were inclined to only report the more serious incidents in the second part of the study. The decline in incidents did not reach significance when only physical aggression was taken into account. A potential tendency to report fewer incidents as time passes clearly stresses the need to include control conditions in evaluating aggression preventing measures. 
CHAPTER 5

\section{The Staff Observation Aggression Scale - Revised (SOAS-R) ${ }^{1}$}

1 This chapter appeared as Nijman, H.L.I, Muris, P., Merckelbach, H.L.G.j., Paimstiema, "T., Wisted, B., Vos, A.M., van Rixtel, A. \& Allertz, W.W.F. \{1999\}. The Staff Observation Aggression Scale- Revised (SOAS-R). Aggressive behavion, 25, 197.209. 


\section{SUMMARY}

Proper assessment of aggressive behavior is essential for understanding its causes. In 1987, Palmstierna and Wistedt introduced the Staff Observation Aggression Scale (SOAS), an instrument for monitoring the frequency, nature, and severity of aggressive incidents. In the present study, the validity of the SOAS severity scoring system was examined and the severity scores were refined. The SOAS was used to record aggression on 6 closed wards of 3 psychiatric hospitals. The SOAS severity scores of 556 aggressive incidents were compared to severity estimates given on Visual Analogue Scales (VAS) by staff members. The original SOAS scores were found to be moderately correlated with the estimates of severity given by staff on the VAS. The SOAS severity scoring system was refined on the basis of the staff severity estimates. The revised scoring method and other refinements in the contents of the instrument led to the construction of the SOAS-R. The SOAS-R appears to be a promising tool for monitoring a wide range of (self-)destructive acts on psychiatric wards.

\section{INTRODUCTION}

Inpatient aggression is a prevalent phenomenon on psychiatric wards. For example, a study on a closed psychiatric admissions ward with 20 beds reported almost one aggressive incident per day (Nijman et al., 1997a). Eleven percent of these incidents had physical consequences for victims (i.e. patients, staff members). These results demonstrate that aggression poses a serious threat to the safety and well-being of psychiatric patients and their caregivers. In particular, psychiatric nurses are at risk of being confronted with aggression (Shah et al, 1991; Tamm et al., 1996; Nijman et al., 1997a). Not only does patient violence have physical and psychological consequences, it also has considerable financial implications (Hunter \& Carmel, 1992; Hyde \& Harrower-Wilson, 1995). For these reasons, the measurement and prevention of aggression should have a high priority in psychiatric hospitals. The Staff Observation Aggression Scale (SOAS) is an instrument for monitoring aggressive incidents in psychiatric wards. It was first presented by 
Palmstierna and Wistedt (1987). The inter-observer reliability of the scale was found to be satisfactory (Palmstierna \& Wistedt, 1987). In a later study (Nijman et al., 1997a), staff members were asked to record aggression on the SOAS independently. The correlation of the SOAS total severity scores between observers was 0.87 and the kappa was 0.61 , indicating fair-to-good agreement (Lambert \& Hill, 1994). Furthermore, the scale is quick to complete and there is no need for staff to be trained to use it. In their review on violence among psychiatric patients, Shah et al. (1991) describe the SOAS as an instrument, "of particular interest (..) with evidence of good reliability and validity" (p. 307).

Since its introduction, the SOAS has been used as a measurement tool in a number of descriptive studies (Nilsson et al., 1988; Palmstierna et al., 1989; Palmstierna \& Wistedt, 1989; Palmstiema et al., 1991, Chueng et a].., 1996; Nijman et al., 1997a) and in studies on the effects of preventive strategies on psychiatric wards (Palmstierna \& Wistedt, 1995; Omérov, Wistedt \& Elgen, 1995; Nijman et al., 1997b).

The SOAS can be used to rate both the nature and the severity of aggressive incidents. However, no research on the validity of the severity scoring system of the SOAS has been carried out. The clinical significance of a good severity index of aggression seems evident. Although several studies have collected information about the prevalence of aggressive behavior among psychiatric inpatients (e.g., Tamm et al., 1996), few attempts have been made to evaluate these prevalence rates in terms of severity. A severe aggressive incident resulting in injury to staff members is likely to have a greater impact than an incident in which only verbal threats are used or material is damaged. Therefore, a valid severity scoring system for incidents is needed to assess the level of aggressiveness on psychiatric wards. Furthermore, such a severity scoring system may be helpful in evaluating interventions. The effects of certain interventions may be expressed not only in a decrease in the aggression frequency, but also in a decline in the average severity of the incidents.

In the present study, two questions were addressed. Firstly, are the SOAS severity scores that Palmstierna and Wistedt proposed in 1987 valid? And secondly, can the SOAS severity-scoring system be improved? 


\section{METHODS}

\section{DESCRIPTION OF SAMPLE}

The study was conducted on 6 wards of 3 psychiatric hospitals. The patients admitred to these wards were adults with severe psychiatric disorders (e.g., schizophrenia or severe mood disorders). The wards that participated were locked in order to protect the patients from harming themselves or their environment. Four of the wards were admissions wards, in which crisis intervention took place and a clinical diagnosis was reached. The other two wards were wards to which patients were referred who needed additional treatment. Table 1 lists the observation periods and the number of beds in the 6 wards that participated in the present study.

THE ORIGINAL SOAS

The SOAS was completed each time a staff member witnessed aggressive behavior of a patient. The SOAS consists of 5 columns. In column 1, the provocation which led to the aggressive incident, is recorded. For example, if aggression occurred after a patient's request had been turned down, the provocation 'patient being denied something' is marked in column 1. In column 2, the means used by the patient during the incident are scored. These means can vary from verbal aggression to dangerous objects such as knives. In column 3, the target of the aggression is scored. Aggression can be targeted at "nothing or nobody", 'objects", "patients', "staff members', or 'other persons'. In column 4, the consequences for victims are tecorded, ranging from no consequences to physical consequences that need treatment by a physician. In column 5 , the measures taken to stop or control aggressive behavior are described. Examples of these measures are talking to the patient or holding the patient with force.

Palmstierna and Wistedt (1987) developed a scoring system for rating the overall severity of an aggressive incident. Severity points ranging from ' 0 ' (= no aggression) to '4' (= extremely severe aggression) are given by the researcher to the columns, 'means used by the patient' (column 2), 'target of aggression' (column 3) and "consequence(s) for victim(s)" (column 4). The overall severity of aggressive incidents is obtained by summing the scores 
across the columns. Consequentely, the maximum severity score of the original SOAS is 12 .

\section{ADIUSTMENTS TO THE SOAS}

On the basis of previous work with the Dutch version of the SOAS (Nijman et al., 1997a; Nijman et al., 1997b; Rixtel et al., 1997), a number of adjustments were made to the format of the SOAS. The most important change was the addition of an option to record auto-aggressive behavior. The SOAS is an easy-to-use instrument that monitors a wide range of dangerous behaviors of patients. Auto-aggressive acts such as self-mutilation and suicide attempts are certainly relevant in that context. In the original version of the SOAS, this type of aggressive behavior was not considered since it might have complicated the initial psychometric testing of the instrument (Palmstierna, 1992). In the presently used version of the SOAS, auto-aggression was introduced in the SOAS by discriminating in column 3 between 'patient self and 'other patients' (see appendix 1) as possible targets of the aggression. In this way, auto-aggression was defined as all aggressive acts aimed at the patient himself / herself.

Apart from adding an auto-aggression category, a definition of aggression was provided in the instruction printed on each SOAS form (see appendix 1). The definition used was taken from Morrison (1990) who describes aggression as, "any verbal, non-verbal or physical behavior that was threatening (to self, others, or property), or physical behavior that actually did harm (to self, others, or property)" (p.67). Note that this definition is in accordance with the original purpose of the SOAS, but that it also inclucles auto-aggressive behavior. Finally, 'seclusion' and 'restraints' were added to column 5 as possible measures for stopping aggression.

\section{PROCEDURE}

After each aggressive incident, a staff member witnessing the aggression completed the SOAS. Following this, the severity of the incident was also judged on a $100 \mathrm{~mm}$ Visual Analogue Scale (VAS). On this VAS, the staff member marked the severity of the aggression on a continuous $100 \mathrm{~mm}$ scale ranging from 'not severe at all' (at the 0-end of the VAS) to 'extremely 
severe" (at the 100 mend of the VAS). The VAS is particularly suitable for the assesment of subjective phenomena (Gift, 1989).

As the staff members were unaware of how the (originaly SOAS severity scores were calculated (the investigators derived the score), no carry-over effects from SOAS severity to VAS severity were expected. Staff members only assessed the severity of aggression on the VAS. Sex and experience (i.e., number of years working in mental health services) of staff observers were included as covariates. This was done because it seems plausible that men or highly experienced staff members might have a different perception of aggression severity than women or less experienced staff members.

\section{STATISTICAL ANALYSES}

To examine whether the scoring system of the original SOAS was valid, a Pearson product-moment correlation was calculated between the original SOAS severity scores and the VAS severity ratings. Auto-aggressive incidents were omitted from the analysis, as they were not recorded in the original SOAS.

In order to investigate whether the severity scoring system could be improved, the connection between the VAS severity ratings and all 5 SOAS column scores was studied. In other words, it was investigated which answer options were associated with higher VAS severity scores. Those SOAS severity options that were linked to higher VAS scores were given additional severity points, starting from zero in ach of the 5 columns. Following this procedure, the 5 newly obtained SOAS column scores were entered in a multiple regression analysis (after controlling for the observer's sex and years of working experience) in order to determine how well the VAS severity scores could be predicted with the new SOAS column scores. In this regression analysis, VAS severity score was the dependent variable and the 5 new SOAS columan scores were entered together as predictor variables. The relative impact that each of the 5 SOAS columns scores had in predicting VAS severity was derived from the (partial) correlations between the 5 SOAS columns scores and the VAS severity scores. 
\begin{tabular}{r|r} 
CHAPTER 5 & The Staff Observation Aggression Scale - Revised (SOAS-R) \\
69 &
\end{tabular}

Table 1. Institution, observation period, and number of incidents (per bed per year) on the wavds participating in the study.

\begin{tabular}{|c|c|c|c|c|c|}
\hline Psychiatric hospital & ward & period & $\begin{array}{l}\text { number of } \\
\text { beds }\end{array}$ & $n$ (incidents) & $\begin{array}{l}\text { incidents per } \\
\text { bed per year }\end{array}$ \\
\hline \multirow[t]{2}{*}{$\begin{array}{l}\text { Psychiatric Hospital } \\
\text { Welterhof, Heerlen. } \\
\text { The Netherlands }\end{array}$} & $\begin{array}{l}\text { closed acute } \\
\text { admissions } \\
\text { ward }\end{array}$ & $\begin{array}{l}3 \text { months } \\
1-7-96 / \\
1-10-96\end{array}$ & 20 beds & 112 & 22.4 \\
\hline & $\begin{array}{l}\text { closed ward } \\
\text { for further } \\
\text { treatment }\end{array}$ & $\begin{array}{l}12 \text { months } \\
1-1-96 / \\
1-1-97\end{array}$ & 20 beds & 135 & 6.8 \\
\hline \multirow[t]{2}{*}{$\begin{array}{l}\text { Psychiatric Hospital Valerius, } \\
\text { Amsterdam, The Netherlands }\end{array}$} & $\begin{array}{l}\text { closed acute } \\
\text { admissions } \\
\text { ward }\end{array}$ & $\begin{array}{l}24 \text { weeks } \\
8-7-96 / \\
23-12-96\end{array}$ & 15 beds & 138 & 19.9 \\
\hline & $\begin{array}{l}\text { (semil closed } \\
\text { ward for } \\
\text { further } \\
\text { treatment }\end{array}$ & $\begin{array}{l}24 \text { weeks } \\
8-7-96 \\
23-12 \cdot 96\end{array}$ & 22 beds & 66 & 6.5 \\
\hline \multirow[t]{3}{*}{$\begin{array}{l}\text { Psychiatric Hospital Broeders } \\
\text { Alexianen, Tienen, Belgium }\end{array}$} & $\begin{array}{l}\text { closed } \\
\text { observation } \\
\text { admissions } \\
\text { ward }\end{array}$ & $\begin{array}{l}10,5 \text { months } \\
1-2-96 / \\
16-12-96\end{array}$ & 14 beds & 171 & 13.9 \\
\hline & $\begin{array}{l}\text { closed } \\
\text { observation } \\
\text { admissions } \\
\text { ward }\end{array}$ & $\begin{array}{l}10,5 \text { months } \\
1-2{ }^{n} 96 / \\
16-12-96\end{array}$ & 13 beds & 55 & 4.8 \\
\hline & (total numbe & incidents) & $N$ & 677 & \\
\hline
\end{tabular}

\section{RESULTS}

\section{INCIDENCE OF AGGRESSIVE EPISODES}

Table 1 lists the observation periods, number of beds, and aggressionfrequencies for the six wards. In total, 677 SOAS-foms were completed. Note that the reported frequencies for the wards were quite similar. On the two closed admissions wards, 22.4 and 19.9 incidents per bed per year were recorded. (for Heerlen and Amsterdam, respectively). On the two closed wards for further treatment, 6.8 and 6.5 incidents per bed per year were found. For the two closed observation admissions wards in Belgium, the numbers were 13.9 and 4.8 incidents per bed per year. The difference 
between these two observation wards has to do with differences in local admission criteria; patients with a history of aggression are preferably admitted to the ward with the higher aggression frequency.

\section{VALIDITY OF THE ORIGINAL SOAS SEVERITY SCORES}

SOAS or VAS severity scores were missing for 30 incidents. These incidents were excluded from the statistical anallysis. Ninety-one of the remaining 647 incidents (14\%) involved auto-aggressive acts. The 556 outwardly directed aggressive incidents had a mean SOAS severity score of $4.5(s . d .=1.3)$ and a mean VAS severity score of $40.2(s . d=27.0)$. About two thirds $(65 \%)$ of the forms were completed by male and one third $(35 \%)$ by female staff members. No difference was found between the VAS severity estimates given by male staff members and female staff members $[t(627)<1.0]$. On average, staff members had 11.1 years of working experience $(s . d .=9.0)$. The number of years working in the field of mental health was found to be negatively correlated to the VAS severity scores $(r=-.20, p<0.05)$. In other words, the more experienced a staff member was, the less severe (or threatening) a violent incident was perceived by him or her.

The Pearson product-moment correlation (while controlling for sex and years of working experience) between the original SOAS severity scores and the VAS severity scores was $0.38(p<0.01)$. Inspection of the scatterplot indicated that the relationship between SOAS and VAS severity scores was linear.

NEW SEWERITY SCORING SYSTEM

in constructing a revised SOAS scoring system, all 5 SOAS columns were taken into account. Below, the proposed changes in severity ratings are described for each of the SOAS columns. For each column, the corresponding mean VAS severity scores (controlled for sex and experience of the rater) and newly assigned SOAS severity scores are summarised in table 2.

Colmmn 1 Provocation of the aggressive incident

In column 1 of the SOAS, the circumstances that provoked aggressive behavior are recorded. As can be seen in table 2, the VAS severity scores were relatively high in those cases where the provocation of the incident was 
CHAPTER 5 The Stafi Obsenvation Aggression SCale-Revised (SOAS-R.

71

Table 2

Mean VAs scones and standard devations fafter controling for the obserurers sex and years of wothing experience, and $50 A 5$ severify points assigned.

SOAS Column

1. Provocation

2. Means used by pâtient

\footnotetext{
3.Target of aggression nothing/ nobody

objects

other patient(s)

staff member(s)

patient self

other persons (people from outsiide the ward)

4. Consequence(s) for no victim(s)

objects damaged

felt threatened

physical consequences (pain:

injury, need for treatment) 5. Measurels to stop
aggression

none/talk with patient/ calmly 27 brought away

peroral or parenteral medication/ other measures

held with force / seclusion/ 223 physical restraints
}

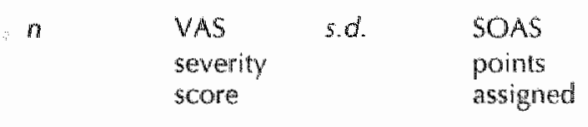

$\begin{array}{llll}361 & 37.0 & 25.8 & 0\end{array}$

$\begin{array}{llll}166 & 44.7 & 28.4 & 1\end{array}$

$\begin{array}{llll}29 & 53.5 & 27.5 & 2\end{array}$

$\begin{array}{llll}197 & 33.3 & 26.3 & 0\end{array}$

$\begin{array}{llll}76 & 35.0 & 23.5 & 1\end{array}$

$\begin{array}{llll}264 & 45.6 & 26.4 & 2\end{array}$

$\begin{array}{llll}19 & 56.4 & 33.7 & 3\end{array}$

$\begin{array}{llll}18 & 19.2 & 16.2 & 0\end{array}$

$\begin{array}{llll}106 & 34.3 & 24.1 & 1\end{array}$

$\begin{array}{llll}90 & 35.5 & 25.6 & 2\end{array}$

$\begin{array}{llll}325 & 43.8 & 27.6 & 3\end{array}$

$\begin{array}{llll}91 & 45.5 & 24.3 & 3\end{array}$

$\begin{array}{llll}17 & 54.2 & 27.9 & 4\end{array}$

\section{1}

41

$\begin{array}{llll}186 & 49.6 & 25.2 & 2\end{array}$

$\begin{array}{llll}8.8 & 65.0 & 24.6 & 3\end{array}$

279

5.4

51.0

26.6

$26.6 \quad 2$


unclear or not understood by the staff and even higher in cases where the aggression had been triggered by staff requiring the patient to take medication. Following the VAS severity scores, an additional severity point was assigned to 'No understandable provocation' and two severity points to 'Staff requiring patient to take medication'. No severity points were given to other provocations recorded in column 1.

Colum 2 Means used by the patient in the aggressive inadent

The means used to act out the aggressive behavior are evaluated in column 2 of the SOAS. The VAS data showed that verbal aggression was rated as the least severe form of aggression and thus no severity points were assigned. The mean VAS severity score of incidents in which (ordinary) objects were used to act out the aggression was found only slightly raised compared to the verbal aggressive acts. Aggressive incidents in which ordinary objects were thrown or smashed were judged to be significantly less severe than incidents in which parts of the body were used in the assault (e.g., feet to kick, hands to punch, or teeth to bite). VAS severity scores were found to be especially high in cases where patients used weapons (e.g., knives), or other dangerous objects, or made attempts to strangle someone. Column 2 was scored as follows: aggression in which ordinary objects were used were given one point, incidents in which parts of the body were used were rated with two severity points, and incidents in which weapons were used or strangulation attempts were made were given 3 points in the SOAS-R (see table 2).

\section{Colwow 3 Target of the ageression}

In column 3, the target of the aggression is scored. In accordance with the original scoring system, no points were given when the aggression was not targeted at anything or anybody. In cases where the aggression was aimed at objects, the mean VAS severity score was higher than the score for aggression aimed at nothing or nobody. Accordingly, aggression aimed at objects was assigned one additional severity point. Aggression directed at fellow patients was given slightly higher VAS severity scores than aggression directed at objects. In cases where staff members were the objects of aggression, the VAS severity scores were elevated even more than when the aggression was aimed at fellow patients. Aggression aimed at people other 
than staff members and fellow patients (i.e., people from outside the ward) was judged as the most severe form of aggression (see table 2). SOAS severity points were assigned as follows; aggression aimed at fellow patients was rated with two, aggression against staff with 3 , and aggression aimed at people from outside the ward with four severity points.

Colmm 4 Consequences of the aggression

In column 4 , the effects of the aggressive behavior on the environment are recorded. Incidents that had neither physical nor psychological consequences were given no severity points. In cases where objects were damaged, one severity point was given. Incidents that had psychological consequences, evaluated with the category 'felt threatened' in the fourth column, were assigned two severity points. 3 severity points were given to all incidents that had physical consequences for the victim.

Columu 5 Measure(s) to stop aggression

In column 5, measures taken to prevent further escalation of aggression are registered. As can be seen in table 2, the lowest severity scores (rated with no points) were given when the aggression could be controlled without taking any special measure or simply by talking to the patient (non-restrictive measures). The administration of psychotropics (e.g., neuroleptics and benzodiazepines; see Tardiff, 1997) was related to higher VAS scores, and was assigned an additional severity point. In cases where the patient had to be restrained or had to be secluded in order to protect the patients and staff, VAS severity was raised even more; two severity points were assigned to the use of these restrictive measures.

\section{AUTO-AGGRESSIVE INCIDENTS}

The mean VAS severity score for the 91 auto-aggressive incidents was found to be similar to that for the incidents directed at staff (see table 2). Therefore, 3 severity points were given to column 3 in cases of auto-aggression. Although the limited sample size did not allow for the construction of a separate scoring system for auto-aggressive acts, the inclusion of this type of behavior in the SOAS-R did shed light on the circumstances surrounding such acts. For instance, as compared with the aggression directed outwardly, 
the auto-aggressive incidents were more likely to occur when ward activity was low. Mote than half of the auto-aggressive incidents (58\%) occurred in the evening from 6 p.m. to 12 p.m. In contrast, only $27 \%$ of the other incidents occurred in this time frame $\left[X^{2}(3)=33.4, p<0.05\right]$. Although not significant, there was a trend for auto-aggression to occur more frequently during the weekend $\left[X^{2}(1)=3.6, p=0.06\right.$; percentages being $32 \%$ versus $23 \%$, respectively]. The antecedents of auto-aggressive incidents remained relatively often unclear. This was the case in $56 \%$ of the auto-aggressive incidents versus $30 \%$ of the other types of aggressive incidents $\left[X^{2}(1)=24.1, p<\right.$ 0.05 ]. Furthermore, the use of dangerous methods was more common for auto-aggression than for other types of incidents $\left[X^{2}(1)=155.1, p<0.05\right.$; $44 \%$ versus $3 \%$ respectively]. In line with this, the consequences of auto-aggression were severe. In $59 \%$ of the cases, the consequences of auto-aggressive incidents were physical in nature and a physician was needed to treat the patient in almost a quarter of the incidents (23\%). For outwardly directed aggression, the percentages were $16 \%\left[X^{2}(1)=86.4, p<0.05\right]$ and $1 \%\left[X^{2}(1)=111.2, p<0.05\right]$, respectively.

\section{RESULTS OF THE NEW SCORING SYSTEM}

After the assignment of new severity scores to each of the 5 SOAS columns, the column severity scores were entered in a multiple regression analysis to predict VAS severity scores (after controlling for the observer's sex and years of working experience). The partial correlations resulting from this analysis reflect the relative weights that the 5 column scores should have in the calculation of the overall SOAS severity. Table 3 shows the partial correlations and significances for the 5 SOAS columns.

As can be seen in Table 3, column 4 ['consequence(s) for victim(s)'], and column 5 ["measure(s) taken to stop aggression"] were strongly connected to the VAS severity scores, their partial correlations being 0.47 and 0.24 , respectively. To reflect their relatively greater contribution, it was decided to multiply the scores of these two columns by a factor 3 and 2, respectively. The revised SOAS and the resulting new severity scores appear in Appendix 1. The total severity score of the revised SOAS (SOAS-R) was calculated by summing the severity scores of the 5 SOAS columns. The total severity score 


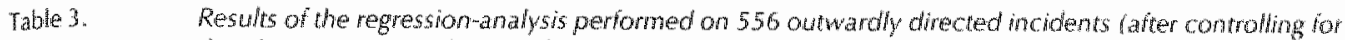
the obierver"s sex and years of working experience).

$\begin{array}{llll}\text { SOAS Column } & \text { partiall } r & \text { partial r changs } & \text { significance } \\ \text { column 4: The consequences for victims } & 0.47 & 0.221 & p<0.05 \\ \text { column 5: Measure to stop aggression } & 0.24 & 0.058 & p<0.05 \\ \text { column 3: Target of aggression } & 0.15 & 0.023 & p<0.05 \\ \text { column 1: Provocation } & 0.13 & 0.017 & p<0.05 \\ \text { column 2. Means used by the patient } & 0.08 & 0.006 & p=0.07\end{array}$

of the SOAS-R can vary from 0 (least severe form of aggression) to 22 points (most severe form of aggression). In the present study, the mean revised severity score for the 556 outwardly directed aggressive incidents was 9.4 $(s . d=5.1)$. The correlation between the revised SOAS severity scores and the severity estimates of the staff given on the VAS was 0.60 . Residual analysis revealed two outliers with a standardized residual greater than 3. After removal of these two cases, the correlation between new SOAS severity scores and the VAS severity scores increased to 0.62 .

\section{DISCUSSION}

A correlation of 0.38 between the severity ratings of the staff and the original SOAS total scores was found. This suggests that there is a modest relationship between judgements made by the staff members about the severity of aggression and original SOAS total scores proposed by Palmstierna and Wistedt (1987). One could argue that the significant correlation between SOAS severity and VAS severity is a spurious by-product of the fact that the same observers completed both scalles. Although such a carry-over effect cannot entirely be ruled out, this interpretation seems unlikely because the SOAS draws on factual information about aggressive incidents (e.g., means used in the aggression, target of the aggression) and does not require the observer to assess the severity of the incident. As a matter of fact, we derived the severity post hoc from the factual SOAS categories. 
The severity scoring system of the instrument was refined by comparing the VAS severity estimates with the SOAS scores. These refined severity scores, combined with the changes made in the contents of the SOAS (e.g., inclusion of auto-aggression), led to the proposal of a Revised Version of the SOAS. In this Revised Version, called the SOAS-R, severity scores are assigned to all 5 columns. The total severity score of the revised SOAS ranges from 0 to 22 points. A correlation of 0.60 for outwardly directed aggression was found between the VAS and the SOAS-R severity scores. After the exclusion of two outliers, this correlation was 0.62 .

When evaluating the strength of the association between the SOAS-R and the VAS severity scores, one should keep in mind that the SOASs and the VASs were completed by a considerable number of staff members from 6 closed wards in 3 different psychiatric hospitals. Since aggression severity is a subjective measure, inter-observer variation will have played a role. However, as there is no objective index of aggression severity, the judgement of professionals who work with aggressive patients on a daily basis was used as a starting point for validating and refining the severity scoring system of the SOAS. To our knowledge, no cross-validation of severity ratings of the available descriptive aggression scales (e.g., the Overt Aggression Scale; the OAS of Yudofsky et al., 1986; the modified version of this instrument; the MOAS of Kay et al., 1988; the Violence Scale of Morrison, 1993; or the SOAS) with the clinical judgment of aggression severity of psychiatric professionals has been reported.

Clearly, the validity of the proposed revised severity scoring system should be examined further in an independerit sample. In order to further improve the validity of the SOAS severity scores, future studies should investigate the nature of verbal. violence in more detail. A threat to stab someone would probably be perceived as more severe than a threat to push or kick someone. As is the case with physical aggression, the (announced) means used in the verbal aggression may play a role in severity. Other instruments used for measuring aggression, such as the OAS (Yudofsky et al., 1986) and the Violence scale (Morrison, 1993), divide verbal aggression into various severity categories. The perceived likelihood that the patient will carry out a threat will also modulate these severity ratings. For example, the Violence Scale discriminates between threats for which the patient has a plan of action 
and threats for which no plan of action exists. The validity of this sort of differentiation in terms of the severity of aggression perceived by the staff warrants further research.

Due to the low sample size, no separate scoring system for auto-aggressive incidents was developed. The new SOAS method for calculating severity should therefore be preferably applied to aggression that is directed outwardly. However, considering the severe physical consequences of auto-aggressive incidents, we do hope that the inclusion of auto-aggression in the SOAS-R will facilitate research on the origins of the different types of aggression. In this context, Hillbrand (1995) points out that " $($.$) the rela-$ tionship between self-destructiveness and interpersonal violence has received little scientific scrutiny (..), there has been limited interest in elucidating whether aggression against self and aggression against others overlap in prevalence, etiology, or both" (p. 668). The fact that the provocation of auto-aggression was often not understood by the staff further illustrates the need for research on the etiology of self-destructive behavior. The lack of clarity about the antecedents of auto-aggression makes it hard to predict and thus to prevent these incidents. The present study did reveal, however, that auto-aggressive incidents frequently took place when ward activity was low (i.e. in the evening and weekends), a situation which possibly gave anxiety and tension more opportunity to build up. Apparantly, with a larger sample size, a specific scoring system for self-destructive acts can be developed.

In conclusion, the SOAS-R provides researchers with a instrument that not only reliably assesses the nature of aggressive incidents (Palmstierna \& Wistedt, 1987; Nijman et al,, 1997a), but can also be used to give a vallid approximation of their severity. Further development of the severity scoring system would allow for more detailed epidemiological information to be obtained about the severity of incidents on psychiatric wards. The importance of this endeavour lies in the fact that various preventive strategies in psychiatric wards can be initiated only when aggressive escalations are already taking place (see Nijman et al., 1997b). Such interventions may reduce the average severity of aggressive incidents rather than their frequency. Obviously, examining this important issue requires a sensitive instrument and the SOAS-R is a promising candidate in this respect. 

CHAPTER 6 Self-mutilating behavior of psychiatric inpatients ${ }^{1}$

1 This chapter appeared as Nijman, H.L.I., Dauzzenberg, M., Merckelbach, H.L.G.I., Jung, P., Wessel, I. \& à Campo, J.M.L.G. (1999) Self-mutilating behavior of psychiatric inpaticnts. Etropean Psychiatry, $14,4-10$. 


\section{SUMMARY}

In the present study, two broad hypotheses about the origins of self-mutilation in psychiatric patients were evaluated. The first hypothesis states that self-mutilation originates from child abuse and experiences of neglect and is connected to dissociation in later life. The second hypothesis views self-mutilation as the consequence of impulse control problems. To test these two hypotheses, data about traumatic childhood experiences and dissociative symptoms (hypothesis 1), as well as data about aggressiveness, obsessive-compulsiveness and sensation seeking (hypothesis 2) were collected in a sample of 54 psychiatric inpatients. Twenty-four out of 54 patients (44\%) reported having engaged in self-mutilation. Mean age of onset of this behavior was 23 years. Self-report measures of self-mutilators were more in line with the first than with the second hypothesis. That is, patients who engaged in self-murilation reported more traumatic childhood experiences and dissociative symptoms than did control patients. The two groups did not differ in terms of aggressiveness, obsessive-compulsiveness, and sensation seeking. In line with earlier studies, the current results indicate that self-mutilating behavior is linked to a history of abuse and neglect. The discussion critically evaluates this link.

\section{INTRODUCTION}

Self-mutilation is defined as direct and deliberate harm to one's body without conscious intent to die (Winchel \& Stanley, 1991; Simeon et al., 1992). Its reported prevalence in psychiatric inpatients varies considerably (i.e., from 5.8\% to 77\%; Langbehn \& Pfohl, 1993; Zlotnick et al., 1996), but it is clear that this behavior poses a severe threat to the safety and well-being of psychiatric patients (Favazza, 1989). In the general population, the life-time prevalence of self-injury is estimated to be $0.75 \%$ (Favazza \& Conterio, 1988).

In particular, patients with borderline personality disorders run a high risk of injuring themselves (Shearer, 1994; Soloff, Lis, Kelly, Cornelius et al., 1994; Brodsky, 1995; Suemoto, 1998). Other diagnoses have also been found to be 
linked to self-mutilation. For example, Favaro and Santonastaso (1998) demonstrated high rates of self-injurious behavior among women with bulimia nervosa. These authors argue that self-injury may be part of a general impulsiveness that characterises a range of diagnostic categories.

Many theories have been invoked to account for self-mutilating behavior. For example, self-mutilation has been portrayed as a strategy to reduce tension or distress (Simeon et al., 1992; Favazza, 1989; Shearer, 1994; Darche, 1990; Favazza \& Rosenthal, 1993; Barstow, 1995), as an expression of anxiety, anger, shame, guilt (Simeon et al., 1992; Barstow, 1995), a form of self-punishment (Shearer, 1994; Favazza \& Rosenthal, 1993; Barstow, 1995), or manipulative behavior (Favazza, 1989; Favazza \& Rosenthal, 1993; Hillbrand, 1995). Alternatively, some authors have linked self-mutilation to difficulties in impulse-control (Simeon et al., 1992; Favazza, 1989). Self-mutilation is also viewed as a way to control past tranmatic experiences (Favazza, 1989; Favazza \& Rosenthal, 1993; Barstow, 1995) or as an attempt to stop feelings of dissociation or depersonalization (Zlotnick et al., 1996; Favazza, 1989; Brodsky, Cloitre \& Dulit, 1995; Favazza \& Rosenthal, 1993; Barstow, 1995) or alexithymia (Zlotnick et al., 1996). This lack of agreement about the etiology of self-mutilation is emphasised by Shearer (1994) who concluded, after studying 62 cases of female borderline patients, that "there was considerable diversity in the practice of self-injury on dimensions such as impulsivity versus premeditation, privacy versus exhibitionism, and experience of pain and relief' (p. 524). However, the self-mutilating patients in that study more often reported an abusive history and displayed more dissociative symptoms than patients who did not engage in self-injury. Note that an association between self-reported traumatic youth experiences and self-injury has been reported in a number of other studies (e.g. Darche, 1990; Lester, 1991; Langbehn \& Pfohl, 1993; Zlotnick et al., 1995), although Brodsky et al. (1995) found that self-mutilation in female borderline patients was connected to dissociation rather than to sexual and/or physical abuse. However, a limitation of all these studies is that information about abuse experiences was collected in rather crude way (e.g., as a dichotomous absence-presence variable). Consequently, the reliability and validity of the critical measures used in these studies are unknown. To further investigate the relationship between self-mutilation and traumatic 
youth experiences, the present study relied on the Childhood Trauma Questionnaire (CTQ) developed by Bernstein and associates (Bernstein, 1995; Bernstein, Fink, Handelsman, Foote et al., 1994; Bemstein, Ahluvalia, Pogge, Handelsman et al., 1997). The CTQ is a validated instrument that records information about aversive childhood experiences in five separate domains: emotional abuse, physical abuse, sexual abuse, emotional neglect, and physical neglect (Bernstein et al., 1997).

The current study sought to evaluate two broad hypotheses about the origins of self-mutilating behavior: 1) self-mutilation is linked to traumatic childhood experiences and dissociative symptoms; and 2) self-mutilation should be understood as a part of a more general impulse control disorder. If true, these problems should also be reflected in high levels of hostility, sensation seeking, and obsessive compulsiveness. Both hypotheses are, of course, not mutually exclusive. That is to say, it is conceivable that, for example, traumatic experiences can lead to both impulse control problems and self-mutilation.

\section{METHODS}

\section{PATIENTS}

Patients were recruited from inpatient facilities at Psychiatric Hospital Welterhof, Heerlen, the Netherlands. More specifically, they were recruited from 5 short-term treatment wards, 3 of which were closed wards. Patients who were admitted for a period longer than 4 weeks and whose main therapist did not object to participation were invited to participate in the study. Patients who were admitted for less than four weeks were not included for both therapeutic and psychometric reasons. That is to say, it was anticipated that psychiatric patients would find it difficult to talk about self-mutilating behavior and childhood trauma in the acute phase of their illness. Apart from that, the reliability of self-reports of acutely disturbed psychiatric inpatients is questionable (see chapter 1). In total, 55 patients gave written informed consent. One interview had to be interrupted due to the patient's lack of concentration. The data of this patient were excluded from the analyses, leaving 54 patients in the final sample. 


\section{MATERIALS AND METHODS}

Patients were asked whether they had ever engaged in self-mutilation. Self-mutilation was explained to them as dangerous behavior leading to direct and deliberate harm of the body without the intent to die. Cutting of the skin and banging with the head were given as examples of self-mutilating. behavior.

Patients who reported self-mutilating behavior, were asked to provide details about the type of self-injury, the frequency, and the age of onset of this behavior. Severity of self-mutilation was assessed using $100 \mathrm{~mm}$ Visual Analogue Scales (VASs) that ranged from $0=$ not severe at all to $100=$ extremely severe. More specifically, patients were invited to describe their most serious self-mutilating incident. The patient as well as two researchers (H.N. and M.D.) rated the severity of this most serious incident on the VAS measure. Mean scores of the 3 VASs were regarded as an estimate of the severity of the self-mutilating behavior of the patient.

Following the interview, patients completed the CTQ (Bernstein et al., 1994; Bernstein, 1995; Bernstein et al., 1997), the Dissociative Experiences Scale (DES; Bernstein \& Putnam, 1996), the Buss-Durkee Hostility Inventory-Dutch (BDHI-D; Lange, Pahlich, Sacucco, Smits et al., 1995), the Maudsley Obsessional-Compulsive Inventory (MOCI; Rachman \& Hodgson, 1980), and the Dutch Sensation Seeking Scale (SSS; Feij \& van Zuilen, 1984). If necessary, the questions were read out to the patient.

The CTQ was originally designed as a 70-item self-report inventory that asks about traumatic experiences that took place before the age of 18. A sample item would be "When I was growing up someone in my family hit me or beat me". The answers are recorded on 5-point Likert scales ranging from never true to very offen true. A revised 53-item version with five subscales measuring emotional abuse, physical abuse, sexual abuse, emotional neglect, and physical neglect was developed (Bernstein, 1995; Bernstein et al., 1997). In the current study, CTQ-scores were calculated according to this 53-item version.

The DES (Bernstein \& Putnam, 1996) is a widely used self-report instrutment for measuring dissociative symptoms. It consists of 28 items describing dissociative experiences such as feelings of depersonalization and 
derealization, and disturbances in identity, memory, awareness, and cognition. Respondents can indicate on $100 \mathrm{~mm}$ VASs the degree to which the experiences described in the items apply to them.

The Dutch adaptation of the BDHI (Lange et al., 1995) consists of 40 items measuring aggressive behavior to which the respondent has to answer either twe or untrue. The BDHII-D has two major subscales: Overt aggression, which refers to the tendency to express verbal and physical aggression; and Covert aggression, measuring hostility, irritability, suspicions and anger (Lange et al., 1995). Examples of BDHI-D-items are: "If somebody hits me, I let him have it" (Overt aggression) and "I am irritated a great deal more than people are aware of" (Covert aggression).

The MOCI (Rachman and Hodgson, 1980) is a well-established 30-item true-false questionnaire to measure obsessive-compulsive symptoms. It comprises four subscales, namely checking, cleaning, slowness, and doubting-conscientiousness.

Finally, a Dutch version of the Sensation Seeking Scale (SSS) was completed. This scale was developed by Feij and van Zuilen (1984) on the basis of the SSS introduced by Zuckerman (1.979). It is designed to measure an individual's need for stimulation and it contains four subscales: thrill and adventure seeking, experience seeking, boredom susceptibility, and disinhibition.

\section{ANALYSES}

Differences in CTQ, DES, BDHI-D, MOCI, and SSS scores between patients with and without a history of self-injurious behavior were evaluated with $t$-tests.

A separate analysis was carried out for item 19 of the DES. This item evaluates an individual's ability to ignore pain at certain times and may be relevant for understanding why patients are capable of harming themselves in the systematic fashion that is sometimes observed on psychiatric wards. Further, two specific items of the SSS were analysed in more detail. Namely, the daily number of cigarettes smoked and the hours of sleep needed. In addition, Pearson product-moment correlations between VAS severity and the five questionnaire measures were computed. For all analyses, alpha was set at .01 ; $p$-values between .01 and .05 were regarded as marginally significant. 


\section{RESULTS}

\section{PATIENT CHARACTERISTICS}

Of the 54 interviewed patients, 28 were men $(52 \%)$ and 26 women $(48 \%)$. The mean age was 37.5 years $(s . d .=12.4)$. The most common diagnoses were:

- psychotic disorders (22 patients, 41\%; of whom 14 were diagnosed as schizophrenic);

- personality disorders (16 patients, 30\%; of whom 13 patients had a borderline personality disorder);

- affective disorders (14 patients, $26 \%$; of whom 8 were suffering from depression and 6 were diagnosed as manic or bipolair).

Of the 54 patients, 24 (i.e., $44 \%$ ) reported a history of self-mutiation. Neither $\operatorname{sex}\left[X^{2}(1)<1,0\right]$, nor age were found to be related to self-mutilation $[t(52)=1.66, p=0.10$, two-tailed $]$. As expected, the self-mutilating patients were more often diagnosed as having borderine personality disorders $\left[X^{2}(1)=7.3, p<0.01\right]$

\section{SELF-MUTILATING BEHAVIOR}

For the 24 self-mutilating patients, the reported lifetime frequency of self-mutilating incidents varied from as low as 1 episode to as high as 1000 episodes. The median number of self-mutilating acts was 8 . The mean age of onset of this behavior was 23 years $(s . d .=10.7)$.

The most commonly reported type of self-mutilation was cutting or scratching of the skin. Nineten of the 24 self-mutilators (79\%) referred to this particular method. Seven patients reported having burnt their skin at one or more points in time and 5 reported having banged their head against a wall.

Fourteen of the 24 self-mutilators $(58 \%)$ indicated that they had received medical treatment for the consequences of their self-injurious behavior. The mean severity of the self-mutilative behavior in terms of averaged VAS scores was $47.7(s . d .=24.6)$. It is noteworthy that a strong and highly significant correlation was found between the VAS severity ratings of the two researchers $(r=.87 ; p<.01)$. The associations between patients' VAS 
Tabie 1. Mean scores of selfomutilators $(n=24)$ and control patients $(n=30)$ an the Child hood Trauma Question naire (CTOT and the Dissociation Experiences 5 cate (DES).

Psychomatric variable

weighted CTQ total score

[chillhood tratma]

mean item scone $\mathrm{DES}^{2}$

(dissociation) self-mutilators

mean $(s . d)$ mean (s.d)

13.87

(4.63)

3.22

(1.60)

(0.96)

$(17.5)$

(34.5) control patients

$10.01 \quad(3.96)^{* * *}$

$2.23(0.97)^{* *}$

$1.96(1.01)^{* *}$

$1.41 \quad(0.89)^{*}$

$2.77 \quad(0.94)^{*}$

$1.65 \quad(0.75)^{*}$

$20.8 \quad(15.6)^{*}$

$37.3 \quad(34.3)^{*}$

Notes; $* 0<.01$, one-tailed; ${ }^{*} .01<p<.05$, one-taited; ${ }^{1} 4$ missing observations in the self-mutilating sample and 3 in the control sample; ${ }^{2} 2$ missing observations in the self-mutilating sample and 4 in the control sample

severity scores and those of the two researchers were moderate, but still marginally significant $(r=.46, p<.05$ and $r=.45, p<.05$, respectively).

\section{CORRELATES OF SELF-INIURY}

Table 1 shows trauma-related information, i.e., CTQ and DES scores of self-mutilators and control patients. Table 2 shows the results of the self-report scales measuring impulse control aspects (i.e. hostility, obsessive-compulsiveness, and sensation seeking). Due to their psychopathology, some pationts were unable to complete all questionnaires. Consequently. test comparisons have varying degrees of freedom.

The main findings can be sumarised as follows. Firstly, self-mutilating patients reported more tramatic childhood experiences than patients who did not engage in self-mutilation. This significant effect was carried mainly by the CTQ subscales emotional abuse and physical abuse, which were reliably higher for self-mutilating patients. Trends in the same direction were found for the other CTQ subscales (i.e., sexual abuse, emotional neglect, and physical neglect). 
Table 2. Mean scores of self muatlators ( $n=24)$ and control patients ( $=30$ ) on the Buss -Durkee Hosthty hwentory-Dutch (BDHI-D), the Maudsley Obsessionat-Compulsive inventory (MOCh, and the Dutch Sersit. tron Seeking Scale (SSS).

Psychometric variable

mean item score $\mathrm{BDH}-\mathrm{D}^{1}$

(aggressiveness)

mean itern score $\mathrm{MOCl}^{2}$

lobsessive-

compulsiveness)

weighted SSS total score

isensation seeking. self-mutilators

mean $(s, d)$

0.53

(0.17)

$(0.24)$

$(0.21)$

(0.19)

(0.26)

$(0.19)$

(0.21)

$(0.31)$

0.48

doubting

conscientiousmess
10.84

2.60

(2.47)

(1.10)

2.62

$(0.79)$

$(0.70)$

2.86

2.77

disinhibition

cigarettes per day ${ }^{4}$

hours of sleep needed ${ }^{5}$
24.05

7.82
(0.88)

(2.07) control patients

mean (s.d.)

$0.46 \quad(0.18)$

0.38

0.53

0.21

0.52

10.69

2.34

2.64

3.01

2.70

14.96

7.68

Notes; ${ }^{*} .01<\rho<.05$, one-tailed; " 1 missing observation in the sample of selfumutilators: 22 missing observations in both the self-mutilating sample and the control sample: 3 missing observations in the self-mutilating sample and 2 in the control sample; ${ }^{4} 3$ missing observations in both the selfmutillating sample and the control sample; 3 missing observations in the selt-mutilating sample and 4 in the control sample

Secondly, compared to the control patients, self-mutilators exhibited higher dissociation scores. Furthermore, analysis of item 19 of the DES revealed a marginally significant trend that self-mutilators were better at ignoring pain than the non-nutilators.

Thirdly, contrary to expectation, neither the total scores, nor the subscale scores of the BDHI-D, the MOCI, or the SSS were higher in self-mutilating patients than in control patients. As for the SSS smoking item, self-mutilators reported smoking a mean of 24 cigarettes per day, whereas the mean for the 


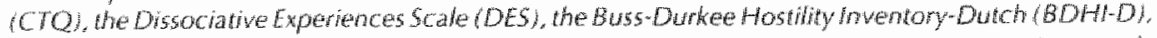

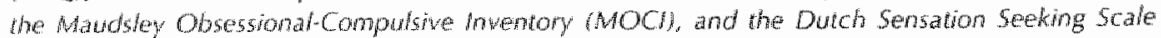
1955 .

\begin{tabular}{|c|c|c|c|c|}
\hline Questionnaire & $\begin{array}{l}\text { DES } \\
\text { (dissociation) }\end{array}$ & $\begin{array}{l}\text { BDHI-D } \\
\text { (aggressiveness) }\end{array}$ & $\begin{array}{l}\mathrm{MOCl} \\
\text { (obsessive- } \\
\text { compulsiveness) }\end{array}$ & $\begin{array}{l}\text { SSS } \\
\text { (sensation } \\
\text { seeking) }\end{array}$ \\
\hline $\begin{array}{l}\text { CTQ score } \\
\text { (childhood trauma? }\end{array}$ & $0.72^{\text {** }}$ & $0.33^{*}$ & 0.21 & 0.16 \\
\hline $\begin{array}{l}\text { DES } \\
\text { (dissociation) }\end{array}$ & - & $0.33^{*}$ & 0.18 & 0.14 \\
\hline $\begin{array}{l}\text { BDHIILD } \\
\text { (Aggressiveness) }\end{array}$ & - & - & $0.30^{*}$ & 0.23 \\
\hline $\begin{array}{l}\mathrm{MOCl} \\
\text { (obsessive-compulsiveness) }\end{array}$ & - & - & - & -0.21 \\
\hline
\end{tabular}

Notes; $p<.01$ (two-talledj; $* 01<p<.05$ (two-tailed)

control group was 15 cigarettes, a difference that approached significance $(p$ $=.014)$.

Fourthly, only the CTQ total score was found to be marginally correlated with the severity of self-mutilation $(r=.38, p<.05)$ as derived from the VAS scores given by the patient and two researchers. No fiurther significant correlations between the severity and the other scale scores were found.

Finally, table 3 shows the correlations between total CTQ, DES, BDHI-D, MOCL, and SSS scores. Interestingly, CTQ and DES scores were strongly correlated $(r=.72, p<.01)$. The inter-relationships between traumatic experiences, dissociation and selfmutilation were further explored using a forward stepwise logistic regression analysis. In this analysis, the CTQ and DES scores served as independent variables and self-mutilation as the dependent variable. It was found that after entry of CTQ scores on the first step, the DES scores did not make a significant contribucion to the prediccion of self-mutilating behavior. Solely on the basis of the CTQ scores, $73 \%$ of the patients could be conrectly classified as being either self-mutilators or non-mutilators. The sensitivity of the equation was low (55\%) as compared to its specificity $(88 \%)$. The opposite analysis, that is to say, an analysis in which the DES scores were entered in the first step, yielded similar results. 
After entry of the DES scores, the CTQ could not significantly improve the prediction of self-mutilation. The overall percentage of patients correctly classified on the basis of their DES scores was $66 \%$.

\section{DISCUSSION}

Of the 54 psychiatric inpatients interviewed, $24(44 \%)$ reported selfmutilation. Due to the obvious limitations of the present study, this prevalence rate for self-mutilating behavior should be interpreted with caution. The collection of data relied on self-reports and the reported incidents were not checked against patient files. Further, patients who were admitted for less than four weeks were not included in the current study for therapeutic reasons. It was anticipated that these patients would find it difficult to talk about self-mutilating behavior and childhood trauma in the acute phase of their illness. Because the duration of hospitalisation was used as an inclusion criterion, the prevalence rate found in the present study may represent an overestimation. That is, self-mutilating patients may sometimes require longer hospitalisation than non-mutilating patients (see Dullit et al., 1994), In addition, the small sample size of the present study $(n=54)$ does not permit accurate estimates of the prevalence of self-mutilation.

The main purpose of the current study was to examine two broad hypotheses about the origins of self-mutilation. According to the first hypothesis, self-mutilation originates from an abusive and neglectful childhood and is connected to dissociative tendencies (e.g., Zlotnick et al., 1996). The second hypothesis links self-mutilation to problems in impulse control (e.g., Simeon et $\left.a l_{.}, 1992\right)$. The present findings support the first rather than the second hypothesis. That is, self-mutilators differed with regard to traumatic experiences and dissociative symptoms, but not with regard to indices of impulse control. In literature, dissociation is often portrayed as a psychological link bewween trauma and self-mutilation. By this view, dissociation is thought to be a mechanism for handling extreme traumatic experiences (Chu \& Dill, 1990). Self-mutilation, in turn, is regarded as a reaction to severe dissociative states (see Zlotnick et al., 1996; Favazza, 1989; Brodsky et al., 1995). In the present study, self-mutilating patients did, indeed, report (marginally) more 
dissociative complaints and the severity of traumatic experiences in childhood was correlated with dissociative tendencies (Pearson's $r=0.72$ ). Alternatively, it should be noted, that dissociation is also linked to fantasy proneness which could lead to either a tendency to confuse real autobiographical memories with those that derive from fantasies or to the adoption of liberal criteria for reporting past events (Merckelbach \& Muris, 1999). For these reasons, Merckelbach and Muris argue that: "one distinct possibility that should be considered is that high DES individuals display a positive response bias on retrospective self-report indices of trauma" (Merckelbach \& Muris, 1999 . p. 6). Note also that an interpretation of self-mutilation in terms of childhood trauma and dissociation fails to explain why self-mutilation begins at a relatively late age.

Further, the present findings could be explained by arguing that dissociation is the result rather than the antecedent of self-mutilation (e.g., Zlotnick etal., 1996). The release of beta-endorphin after self-injury might underlie the connection between dissociation and self-mutilation (Winchel \& Stanley, 1991; Konicki \& Schulz, 1989). Beta-endorphin is known to decrease awareness and pain (Konicki \& Schulz, 1989). In line with this, the current study found that self-mutilators tend to report a higher threshold for pain at certain moments than control patients. This may explain why some patients are able to injure themselves in such an extreme manner as is sometimes observed. Perhaps, then, in these cases, self-mutilating behavior is reinforced by the positive (anaesthetic) effects of endogenous opiates and self-mutilators may be more susceptible to these effects (Winchel \& Stanley, 1991).

There is increasing evidence to support the hypothesis that lowered serotonergic activity is involved in suicidality and self-mutilation Winchel and Stanley, 1991; Linnoila \& Virkunnen, 1992; Verkes, Kerkhof, Beld, Hengeveld et all, 1996). Interestingly, Southwick, Krystal, Bremner, et al. (1997) recently demonstrated chronic alterations in the serotonergic system in a subgroup of traumatised combat soldiers. Clearly, research concerned with the association between childhood trauma and adult self-mutilation should examine this issue in more detail.

To summarise, one could argue that, although the reliability of retrospective self-reports of traumatic events has not been clearly established (see 
Merckelbach \& Muris, 1999), the findings of the present study do suggest that self-mutilation in psychiatric patients is linked to aversive childhood experiences. Therefore, primary prevention of this harmful and dangerous behavior should start with intervention in abusive families. If self-mutilation in psychiatric hospitals is to be prevented, it is crucial that the psychological and biological mechanisms underlying the (delayed) association between childhood trauma and self-mutilation in later life are better understood. Jones and Daniels (1996) presented a model in which physical, psychological, and social isolation in early developmental phases are important antecedents of self-mutilation in adult animals and humans. Confinement and isolation in later life can serve as triggers for self-destructive acts, especially in individuals with a history of deprivation (Winchel \& Stanley, 1991; Jones \& Daniels, 1996). On the basis of the literature, Suyemoto (1998) concludes that: "isolation from others almost always precedes the actual act of self-mutilation" (p.534). Paradoxically, in psychiatric hospitals, seclusion and restraint are often used as measures to control severe self-mutilation. These methods may give temporary symptomatic relief, but do not appear to result in lasting behavioral changes. Clearly, there is an urgent need for studies exploring how patients can be taught to cope with (perceived) negative childhood experiences without engaging in self-destructive behavior. 
CHAPTER 7

An explanatory model of aggression in psychiatric hospitals ${ }^{1}$

1 This chapter is based on Nijman, H.L.I, a Campo, J M.L.G., Ravelli, D.P. \& Merckelbach, H.L.G.J. (1999). A tentative model of aggression on mpatient psychiatric wards. Psydhiarric Sentices, 50, 832-834. 


\section{SUMMARY}

Violence in psychiatric hospitals threatens the safety and well-being of patients and staff members. Yet, the determinants and correlates of inpatient aggression are not well understood. In the present paper, an effort is made to integrate patient, staff, and ward variables into an explanatory model of aggressive behavior. In this model, psychopathology and distorted cognitions of the patient are combined with the environmental and communicationall stressors that are specific for psychiatric wards. The model also elucidates how repeated inpatient aggression may be the result of a vicious circle, i.e., inpatient violence is often followed by an increase in environmental and/or communication stress on the patient, thereby heigthening the risk of a repeated outburst of violence. Although the proposed model is tentative, it may shed light on the mechanisms that lead to (repeated) violence, thereby creating a basis for more systematic prevention of aggressive behavior in psychiatric institutions.

\section{INTRODUCTION}

Inpatient aggression is a prevalent phenomenon on psychiatric wards. For example, in one of our studies involving a closed psychiatric admissions ward with 20 beds, almost one aggressive incident per day was reported (Nijman et al., 1997a). Eleven percent of these incidents had physical consequences for victims (i.e., patients, staff members). These results indicate that aggression poses a serious threat to the safety and well-being of psychiatric patients and professionals. Especially, psychiatric nurses run the risk of being confronted with severe aggression (Nijman et al., 1997a; Tam et al., 1996; Shah et al., 1991). Apart from its physical and psychological consequences, patient violence has considerable financial implications (Hyde \& Harrower-Wilson, 1995; Hunter \& Carmel, 1992). For these reasons, prevention of aggression. should have a high priority in psychiatric hospitals.

Whittingthon and Wykes (1996) found that the vast majority (i.e., 86\%) of aggressive episodes on psychiatric wards are preceded by some form of (aversive) stimulation of the patient by the staff. This finding suggests that in 
addition to psychopathological and biological factors, environmental and interpersonal variables contribute to aggression. Accordingly, Whittingthon and Wykes conclude that "... any complete model of violence by mentally disordered people must include both aversive environmental stimulation and cognitive interpretations of these events with recognition that such interpretations may be distorted as a result of psychopathology" (p. 17). Likewise, Harris and Rice (1997) argue that attempts to reduce aggression "must be guided by what we know about the empirical relationships between situational variables and personal variables on the one hand and violence and antisocial behavior on the other" (p. 1172). Germane to this issue is also the observation of Krawkowski and Czobor (1997) that in contrast to the systematic study of violent patients' characteristics, "no consideration of the situational factors promoting violence" (p. 230) has been given (see also Morrison, 1994; Friis \& Helldin, 1994).

The present paper describes an explanatory model that attempts to account for inpatient aggression in psychiatric hospitals in terms of psychopathology, distorted cognitions as well as situational variables that are specific for psychiatric wards. Concerning these situational variables, the model differentiates between environmental variables (e.g., ward crowding) and communication variables (staff-patient interaction).

Figure 1 depicts the proposed model. The left part specifies three categories or levels of aggression-eliciting factors, namely patient, ward, and staff variables.

\section{PATIENT VARIABLES: PSYCHOPATHOLOGY}

With regard to the patient variables, serious psychopathology is thought to be one of the major sources of inpatient aggression. Psychotic disorders, mania personality disorders, substance abuse, and organic brain disease have all been found to be associated with aggressive behavior (Tardiff, 1992). However, as discussed in chapter 1 of the current dissertation, the connection between diagnostic categories and aggression is not a straightforward one. For example, a number of studies did find schizophrenia to be linked to aggression (see Davis, 1991; Tam et al., 1996), while others did not confirm this association (e.g., Nijman et al., 1997a; Cooper \& Mendonca, 1991; 


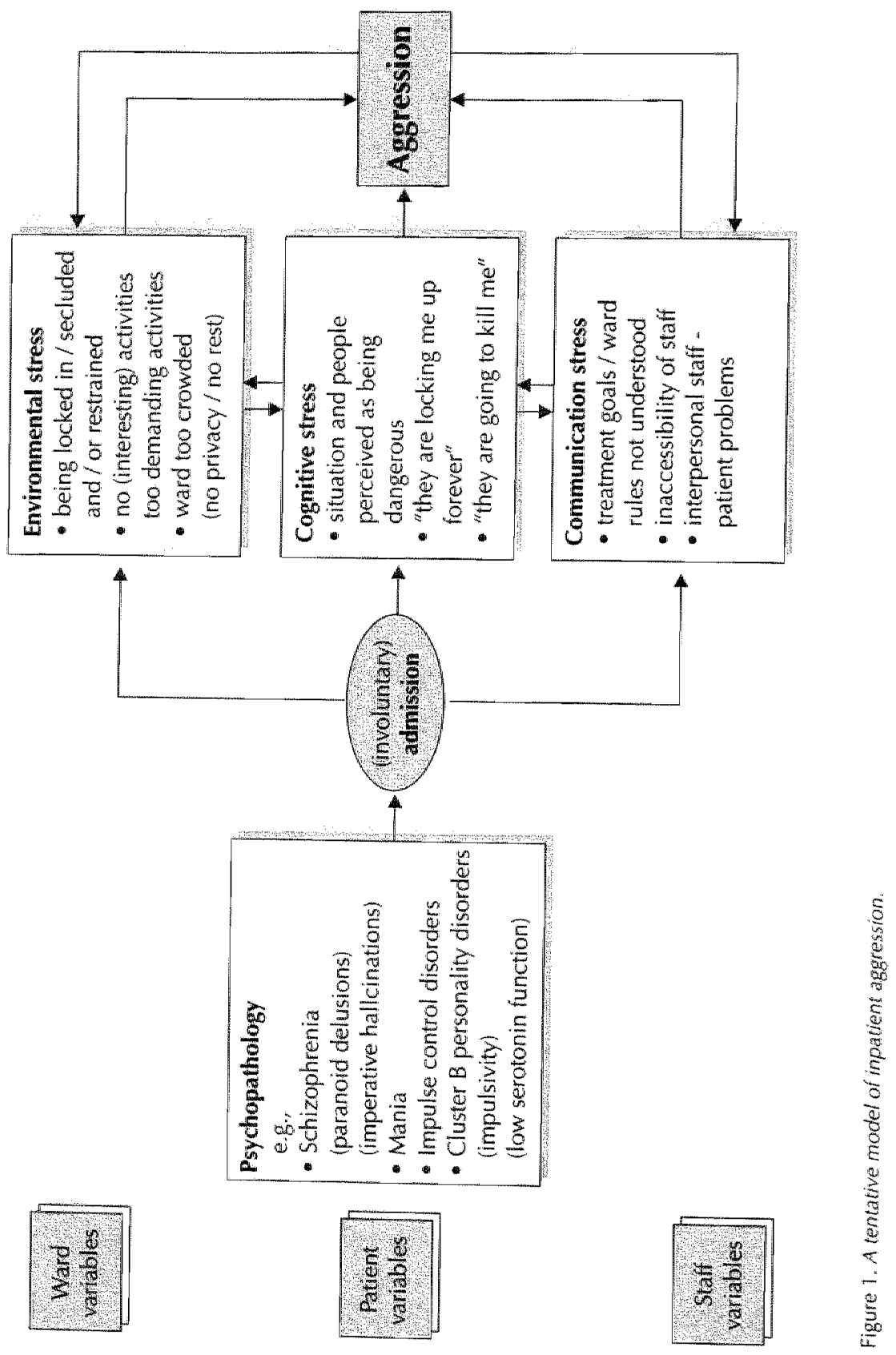


Palmstiema et al., 1989). As argued in chapter 2 , more fine-grained analyses of the connection between the schizophrenia subtypes and aggression may resolve this controversy. For example, Grossman et al.(1995) found paranoid schizophrenia in particular to be linked to violence. Even more sophisticated analyses, at the active symptom level, may further elucidate the nature of the association between psychosis and aggression (see Junginger, 1990; 1995; 1996). Apart from that, the role of certain psychopathological dimensions (e.g., impulsivity) and their biological correlates, in triggering violence needs to be studied throughout the barriers of the nosologic diagnostic categories (see Brown, Botsis \& van Praag, 1994).

Unfortunately, psychopathological problems (and their biological determinants) are sometimes chronic. For example, 5 to $25 \%$ of the schizophrenic patients do not benefit from anti-psychotic agents (Brenner, Dencker, Goldstein et al., 1990). Consequently, psychopathology as a source of aggression is not always easy to influence through intervention techniques. Psychopathology of the patient leads to the (involuntary) admission of the patient to a psychiatric hospital, but this admission inevitably introduces a number of new stressors.

\section{WARD VARIABLES: ENVIRONMENTAL STRESS}

With admission to a psychiatric ward, several environmental stressors come into play. For example, the patient may have to be locked up for safety reasons and he or she will generally have little privacy. On a crowded psychiatric ward, the patient may be exposed to overstimulation due to ward turnoil (Krakowski \& Czobor, 1997). Indeed, crowding may be a risk factor for aggression, especially for psychotic patients (see Palmstiema et al., 1991). Note, however, that it is not so much a lack of square meters, but rather a lack of psychological space that may carry the relationship between crowding and aggression (see Drinkwater \& Gudjonsson, 1989; Nijman \& Rector, 1999). Furthermore, patients may be exposed to (too) demanding therapies, resulting in frustration, anger or violence. This connection was documented for mentally disabled children (e.g., Carr \& Newsom, 1985). Understimulation, due to a lack of (interesting) activities, is also found to promote distuptive behavior (e.g., Sigafoos \& Kerr, 1994). 


\section{STAFF VARIABLES: COMMUNICATION STRESS}

Possibly, problematic communication between staff and patient contributes to aggression (Whittington \& Wykes, 1996; Nijman \& Merckelbach, 1997). To prevent this, treatment goals and ward rules need to be explained carefully and repeatedly to psychiatric inpatients (see Nijman et al., 1997b). Unfortunately, because the ward staff usually has a high workload, this vital information is not always presented clearly. Inaccessibility of the staff and the impossibility for patients to obtain information about their treatment may elicit aggression (see Nijman et al., 1997a). Inconsistency in limit setting may also act as an incentive for aggression (see Blair, 1991).

\section{PATIENT VARIABLES: COGNITIVE DISTORTIONS}

In the centre of the model, at the patient variable level, the perception of the situation plays a key role in whether a patient will become aggressive. Under the influence of psychopathology, environmental and communication stressors may fuel distorted cognitive interpretations of ward activities. Examples of incorrect interpretations are: "they"re going to lock me up for ever", "they"re slowly poisoning me with pills", or "they're going to kill me". As a result, environmental and communication stressors will be appraised as extremely threatening. Thus, tension and anxiety will build up and, evencually, panic or aggressive behavior may occur.

\section{VICIOUS CIRCLE}

After the first outburst of aggression, a vicious circle may develop: as a reaction to violent behavior of the patient, environmental stressors may be increased in order to guard the safety of all parties involved. For this reason, the patient may have to be secluded or will no longer be allowed to leave the ward. These measures will generally affirm the distorted beliefs of the patient about being endangered and may make him or her more afraid of the ward team (see Corrigan, Yudofsky \& Silver, 1993). Clearly, such an intensification of distorted cognitions will have a negative influence on the therapeutic alliance. Further, the aggressive behavior may elicit negative countertransference reactions in the staff, thereby creating additional problems in communication. That is to say, due to violence, staff members may become annoyed, angered or simply too anxious to talk to the patient. 
As a result of these additional environmental and communication stressors, a repetitive pattern of violent behavior followed by the use of more restricting measures may emerge, eventually leading to the total disruption of the therapeutic atmosphere on the ward. In the case of schizophrenic patients, physical aggression during hospitalisation was, indeed, found to be positively correlated with the length of stay (Greenfeld, McNiel \& Binder, 1989). Yet, preadmission violence was not related to subsequent length of stay. These findings leave room for speculations about the precise role that interpersonal staff-patient variables play in eliciting aggression.

\section{INTERVENTIONS}

On the basis of the model presented here, interventions to reduce aggression can be planned and evaluated. In violent psychotic patients, the administrat tion of neuroleptics is an effective and commonly used intervention (see Tardiff, 1996). For the vast majority of psychotic patients, neuroleptic agents will reduce hallucinations and delusional thoughts. By diminishing the negative cognitive schemes depicted in the centre of the model, hostility and aggression are downplayed. Normalisation of the cognitions of the schizophrenic patient will facilitate communication with the staff and will reduce the need for restrictive measures. Besides anti-psychotic agents, lithium, sedatives, anxiolytics, anticonvulsants, and beta blockers have been succesfully described in the treatment of aggression secondary to psychopathology (Corrigan et al., 1993).

However, in therapy-resistant schizophrenia, cluster B personality disorders, or impulse control disorders, no unequivocal pharmacological strategy exists. With sedative medication, the behavioral problems may become more manageable, but this approach does not lead to a lasting amelioration of psychiatric conditions. Therefore, to prevent aggression in the psychiatric hospital, interventions at the ward level and staff variable level should be carefully considered. The aim of such interventions should be to keep the environmental and communication stress as low as can be justified from a therapeutic point of view. 
Environmental stress may be reduced by providing each patient with his or her own room, by preventing overcrowding on psychiatric wards (see Palmstierna et al., 1991; but see also Palmstiema \& Wistedt, 1995), and by making sure that ward activities and therapies fit the needs and capacities of patients.

Communication stress may be diminished by providing better information about treatment goals and investing more time in explaining why certain restrictions are necessary in the treatment (Kalogiera et al., 1989; but see also Nijman et al, 1997b). Training staff how to act in threatening situations has also been found to be an effective strategy for regulating violence (Infantino \& Musingo, 1985; Carmel \& Hunter, 1990; Grainger \& Whiteford, 1993; Phillips \& Rudestam, 1995; but see also van Rixtel et al., 1997). By increasing the number of (skilled) staff members, questions or demands of patients can be better met. This will also give the ward team more opportunities to react adequately to threatening situations. Work of Rice et al. (25) illustrated that in most cases there is time to initiate interventions before aggression escalates and becomes uncontrollable. These authors conclude that "(.) violence rarely erupts without warning, (.) patients usually first go from a calm state, through an anxious state, to a hostile state." (25, p. 95). For effective prevention, it is important that clinicians are able to accurately predict aggression. Whether clinical or actuarial judgement is superior in this prediction is a much debated issue. In clinical judgment, information about probability and risk of violence is processed inside the head of the dectsion-maker (Dawes et al., 1989), whereas in the actuarial (or statistical) method conclusions are drawn on the basis of established empirical knowledge.

McNiel and Binder $(1991 ; 1995)$ found that the reliability and validity of clinical predictions of violence in the first week of admission were good. However, in a review about risk appraisal of violent behavior, Harris and Rice (1997) conclude that "actuarial methods are more accurate in predicting risk than unaided clinical judgement" (p. 1168; see also Dawes et al. 1989). The present model may provide clinicians and researchers with more clues as to which situational variables play a role in eliciting aggression. More specifically, the model encourages decision-makers to take not only the psychiatric condition of individual patients into account, but also the 
context in which a patient resides. In this way, the model may help to reconcile clinical and actuarial prediction methods of violence.

\section{DISCUSSION}

The mode] described here encompasses psychopathological, cognitive, environmental, and communication variables in order to explain mpaticnt aggression. It is clear, however, that these variables have different weights in various groups of patients. For example, Krawkowski and Czobor (1997) demonstrated that envirommental stress (i.e., ward agitation) had a greater impact on transiently violent patients than on persistently violent patients. Persistent violence was found to be linked to poor frontal functioning. Yet, even in cases where psychopathology appears to be the primary antecedent of violent behavior, the contribution of environmental and communication stressors to aggression should not be ruled out.

The environmental and communicational interventions suggested by the presented model are, of course, hindered by their financial implications. However, in view of the potential consequences of aggressive incidents in psychatric facilities, one could argue that large-scale attempts to prevent such incidents will reduce the costs of treatment in the long run. That is to say, aggression prevention programs may lead to a decline in sick leave by staff members (Hunter $\&$ Carmel, 1992), enhancement of job satisfaction (Dougherty, Bolger, Preston, Jones et al., 1992), and to a shorter length of stay in hospital "particularly for schizophrenic patients (see Greenfeld et al., 1989). We do hope that the model described in this paper will facilitate the implementation and evaluation of such preventive measures. 
$\alpha$ 
CHAPTER 8

General Discussion 
In this chapter the limitations and implications of the presented studies are discussed in detail. Following this, avenues for future research are addressed.

\section{LIMITATIONS OF STAFF OBSERVATIONS}

One obvious limitation of the studies presented in the previous chapters is that they largely relied on staff observations of aggressive behavior. Staff observations were used to collect data about aggressive incidents, except for the study on the determinants of self-mutilating behavior (chapter 6 ). The question arises to what extent staff members witnessing aggression are able to provide an accurate account of it. Staff reports were chosen above other data collection methods (e.g., self-reports or non-participating observations) for a number of psychometric and pragmatic reasons. To begin with, psychiatric nurses monitor patients' behavior 24 hours per day, for 7 days per week. Therefore, they are able to provide a complete picture of aggression. Secondly, self-reports of aggression of acutely disturbed patients are likely to be less reliable than staff observations (see Yudofsky et al., 1986; Bjørkly, 1995; Bech, 1994). Thirdly, at this point in time, staff observations are, and likely will continue to be, the main information source for research on inpatient aggression. One could argue, though, that camera registrations of ward activity would have yielded more reliable and detaled information. However, this procedure clearly has ethical disadvantages (e.g., it violates privacy of pa(ients, it elicits suspicion in psychotic patients).

The evaluation and further development of the SOAS was an important issue in the present dissertation. More specifically, the reliability (chapter 2) and validity (chapter 5) of the severity scoring system of the scale were examined. A revised version of the SOAS, with validated severity scores, was proposed. It is hoped that the SOAS-R will allow researchers to evaluate interventions in a more standardised and valid way and will enhance the comparability of results.

However, in validating the SOAS severity scores, the judgements of staff members concerning aggression severity were, again, used as the starting point. Therefore, in evaluating the findings of the current dissertation, the limitations of staff observations should be taken into consideration. Below, 
an attempt is made to critically review the findings of the present dissertation. More specifically, prevalence rates obtained in our research are discussed and the factors found to be associated with inpatient aggression are reviewed. The results concerning the correlates of auto-aggressive acts will be described separately.

\section{PREVALENCE OF AGGRESSION}

The studies described in chapters 2 and 5 found that on 6 locked wards, the reported frequencies of (verbal and physical) aggressive incidents varied from 4.8 to 22.4 per bed per year. For the acute admissions ward of psychiatric hospital Welterhof, frequencies of 17.8 and 22.4 incidents per bed per year were found. On a similar ward in Amsterdam, staff members observed 19.9 incidents per bed per year. On the wards for further treatment in Heerlen and Amsterdam, prevalence rates were 6.8. and 6.5 incidents, respectively. In spite of the differences in the way aggression was recorded, these results are in the same range as those reported by the Dutch researchers Broers and de Lange (1996). In using an adapted version of the MOAS, they found (derved) yearly numbers of incidents per bed between 7.8 and 33.2 . In line with the present findings, the aggression frequencies were highest on the admissions wards, with an average of 22.8 incidents per bed per year. Interestingly, the Dutch prevalence rates are considerably higher than those found in Sweden by Palmstierna and associates. On Swedish acute admissions wards, aggression frequencies ranged from 5.7 incidents 0013.0 incidents per bed per year (Palmstiena \& Wistedt, 1989; Palmstiema et al. 1989; 1991). In these studies, auto-aggressive incidents were not included. Of special relevance is that the number of staff members per patient was about twice as high in the Swedish studies as compared to that in the Dutch studies (Palmstiema, personal communication). Thus, one could speculate that due to this higher staff-patient ratio and the resulting higher avalability of staff, a number of aggressive episodes were prevented.

The staff reports described in the current dissertation pertained to both verbal and physical as well as inwardly and outwardly directed aggression. The percentage of (outwardly directed) incidents involving physical force 
was about $65 \%$ (see chapter 5 ). In line with earlier studies, the vast majority of aggressive incidents did not result in injury of victims. Of the reported incidents, between $8 \%$ and $16 \%$ (see chapter 2,4 , and 5) had physical consequences for victims.

Between $2 \%$ and $14 \%$ (chapters 2, 3, and 5) of the incidents concerned auto-aggression. In general, the consequences of this type of aggression were severe. About 6 out of every 10 auto-aggressive episodes (chapter 5) resulted in harm or injury of the patient. The self-reported life-time prevalence of self-mutilating behavior was found to be $44 \%$ in a sample of 54 psychiatric inpatients (see chapter 6). In line with staff observations, the self-reported consequences of self-mutilating behavior were severe. About $60 \%$ of the self-rnutilating patients (i.e., 14 out of 24 ) had received somatic treatment for their injuries on one or more occasions (chapter 6). However, as these data were obtained through retrospective self-reports and were not checked against any form of written documentation, these frequencies need to be regarded with caution. The current statistics do suggest, however, that among psychiatric inpatients, auto-aggressive behavior is a prevalent phenomenon with generally severe consequences.

\section{DETERMINANTS OF AGGRESSION}

The present dissertation made an attempt to gain more insight into the factors that contribute to inpatient aggression. In chapter 2 , the determinants of aggressive behavior on an acute psychiatric admissions ward were studied. Aggressive patients were found to be younger, more often involuntarily admitted, and to have a higher re-admission rate. Aggressive incidents frequently took place in the afternoon (just before and during afternoon staff meetings) and clustered in certain places (i.e., the day-rooms, near the staff office, and in front of the locked door). No association between diagnosis and violence was found. It should be noted, though, that the analysis was performed on rather crude diagnostic categories. It may well be the case that a more fine-grained analysis of diagnostic subtypes and active symptoms would have provided more clues about the precise role that psychopathology plays in eliciting aggression. 
Even so, the fact that aggressive patients were not characterised by certain psychopathological profiles, while time and place were found to be associated with inpatient violence gives room to speculation about the influence of situational factors. The finding that about 1 out of every 3 incidents was preceded by rejection of a patient request further illustrates that environmental stressors, such as ward policies and regulations, may contribute to inpatient aggression. In line with this idea, an attempt was made to prevent aggressive incidents by changing the way the staff communicated ward rules and treatment policies to the patient. This intervention, however, did not lead to a straightforward decline in incidents (see chapter 3 ).

With regard to ward variables, the impact of ward crowding and lack of space on the aggression frequency were studied (chapter 4). In accordance with common sense, a correlation between ward crowding and the number of incidents per patient was found. However, the magnitude of this correlation was modest and the causality underlying this association remained unclear with the correlational approach used in that study. One of the main problems of this type of research is that it has to depend on 'natural' fluctuations in patient numbers, since an experimental approach in a ward crowding study would be unethical. In clinical practice, variations in patient numbers are usually kept small. That is to say, all beds are almost always occupied. For this reason, it is hard to get a clear picture of the strength of the association between ward crowding and aggression. On the basis of the association between crowding and aggression, it seems plausible to argue that the therpeutic atmosphere will benefit from keeping patient groups small and providing each patient with sufficient private space (e.g., their own bedrooms). Since the extension of physical space on the ward clid not result in a decline in incidents one could argue that the 'psychological' or 'social space' is more important in predicting aggression than the ward surface, as measured in square metres. This assumption warrants further study.

On the basis of the empirical evidence reported in chapter 5 , one could argue that auto-aggression appears to be less affected by situational and interactional variables than aggression directed at others. That is to say, the auto-aggressive incidents took place more often when ward activity was low and were less often triggered by interactional cues (see chapter 5). Corresponding with this, a previous study demonstrated that patients are more 
likely to retreat to their room before engaging in self-mutilating behavior (Regterschot, Nijman, de Schinkel, Allertz et al., 1996; see also Suyemoto, 1998). Combining these results with those of chapter 6 , namely that self-mutilating patients reported more negative childhood experiences and dissociative complaints, one could speculate that auto-aggression is driven more by intra-psychic cues than by external ones. However, the data about abusive and neglectful experiences were obtained by retrospective self-reports and were not checked against patient files. Therefore, the question arises to what extent self-mutilating patients are more inclined - and possibly more encouraged by their therapists - to seek explanations for their self-destructive behavior in terms of childhood trauma. Also, the role of certain interactional variables in initiating and maintaining self-mutilating behavior have not been investigated in the current dissertation. One should keep in mind the possibility that "self-mutilation creates environmental responses that are reinforcing to the individual" (Suyemoto, 1998, p. 537).

\section{PREVENTION OF AGGRESSION}

Two intervention studies were conducted in the current dissertation (see chapters 3 and 4). The interventions of chapter 3 consisted of a protocol for talking to patients who exhibited aggressive behavior, discussing treatment goals with patients shortly after admission, explaining why the ward's door was locked and the exit rules, providing a schedule of staff meetings to explain the absence of staff members from the ward, and clanifying the procedure for making an appointment with the psychiatrist. These interventions did not produce a robust decline in the aggression frequency. A marginally significant difference in severity of aggressive incidents - as measured with the original severity scoring system of Palmstierna and Wistedt (1987) - was found between experimental and control wards after the introduction of the preventive measures. In chapter 4, the effects of spatial enlargement of a locked ward was tested. Again, this intervention did not result in a reduction of aggressive incidents.

Interestingly, regardless of the precise interventions, an overall reduction of aggressive incidents was observed in both intervention studies. Such a 
"reduction phenomenon" (Nilsson et al., 1988) has been reported in other studies that relied on the SOAS as well (e.g., van Rixtel et al., 1997; Nilsson et al., 1988). Possibly, the SOAS, which focuses on what precedes the aggressive incident, makes staff members more sensitive to risk factors of violence. This increased awareness may improve the predictability of incidents, thereby stretching the time to intervene. If true, monitoring of violence with an instrument such as the SOAS may be considered as an aggression-reducing intervention in itself. Altematively, a tendency of staff members to report fewer incidents during the research time frame can not be ruled out. Note that, in chapter 4 , the reduction did not reach significance when only physical aggressive incidents were taken into account.

The possible explanations of the "reduction phenomenon" mentioned above, underline the importance of using control wards in the evaluation of interventions. Unfortunately, many studies on the effects of (non-pharmacological) interventions failed to include control conditions (see table 1). Therefore, the possibility remains that the reported reductions were not brought about by the interventions per se, but were the result of other, time-related factors.

To summarise, then, the findings of the current dissertation do suggest that situational factors play a role in eliciting inpatient aggression. Yet, these factors are not easily influenced by preventive measures. Indeed, a closer look at table 1 leads to three straightforward conclusions. To begin with, the number of studies that made an attempt to reduce aggressive behavior by intervening at the ward or stafflevel is relatively small. Second, some of these studies reported positive effects (e.g., substantial reductions in the use of seclusion and restraint; Kalogjera et al., 1989), but at the same time suffered from methodological shortcomings. Third, some of the better-controlled studies in this domain yielded negative results (e.g., van Rixtel et al., 1997). Below, a number of promising research lines for future studies are discussed. The way intervention studies should preferably be designed is also addressed. 


\section{DIRECTIONS FOR FUTURE RESEARCH}

A tentative model of the origins of inpatient aggression was described in chapter 7. The model was developed on the basis of evidence from the literature. In order to explain inpatient aggression, patient, staff, and ward vartables were integrated in the model. Yet, the impact of a number of the mediating variables that are listed in the model need further testing.

\section{ENVIRONMENTAL STIMULI}

For instance, the role of staff variables, other than the ones examined in the current dissertation, needs to be clarified further. The influence of staff-patient ratios and the impact of psychological characteristics of staff on the aggression frequency remains unclear. Also, the quality of the therapeutic alliance between the therapist and the patient may be a predictor of violence; the poorer the working alliance the more likely patients are to become aggressive (Beauford, McNiel \& Binder, 1997). Clearly, the influence of specific interactional staff patient variables on the aggression frequency deserves further study.

Also, a general lack of (interesting) activities in psychiatric hospitals was portrayed in the model as a potential aggression eliciting variable. A nice illustration of this is provided by the finding that the number of seclusions of male patients in psychiatric hospital Welterhof was found to be lower during the 1990 world soccer championship (Nijman et al., 1992). Note also, that auto-aggression in particular occurs relatively often when ward activity is low (chapter 5). Possibly, then, self-injurious behavior of psychiatric inpatients can be reduced by providing more (meaningful) activities during evenings and weekends. So far, the connection between the ward program and aggression has not aroused much scientific attention.

\section{EXPERIENCE SAMPLING}

New sophisticated data collection techniques may prove to be useful in gaining more insight into environmental stressors that are involved in triggering aggression within psychiatric facilities. The technique termed experience sampling is a case in point. For example, Waite (1994) suggests that "current thinking has moved towards person-situation interactional 
models" and that "experience sampling is a methodology that is a good fit with such models" (p. 191). In experience sampling, participants wear beepers emitting signals whenever a questionnaire has to be completed. As these signals are randomly distributed over time, this method may yield very representative data. Thus, events and symptoms are reported at the very moment they occur and so, the information is less likely to be distorted by recall bias (see Waite, 1994). However, as mentioned earlier, reliability of self-reported aggressive behavior provided by acutely disturbed patients is problematic. Therefore, an approach in which the subjective experiences of staff and patients are sampled simultaneously may provide more insight in the situational antecedents of aggression.

\section{DISTORTED COGNITIONS AND PSYCHOLOGICAL TRAITS}

In the centre of the model, distorted cognitions and irrational beliefs of the patient about ward activities play a key role in eliciting aggressive reactions. However, the number of studies addressing this issue is limited. An exception is the work of Junginger $(1990 ; 1995 ; 1996)$, who investigated the role of command hallucinations in dangerous behavior. About $40 \%$ of psychiatric inpatients suffering from command hallucinations, comply to the hallucinated orders (Junginger, 1990; 1995). The compliance rates were especially high in cases where the hallucinated voice was known to the patient (e.g., the voice of a family member) and in cases where the commands were embedded in delusional thinking (Junginger, 1990). The more dangerous the hallucinated orders were, the less likely they were to be obeyed by the patient. Nevertheless, on the basis of the empirical evidence, Junginger (1990; 1995) concludes that command hallucinations involving dangerous behavior increase the risk of actually engaging in such behavior.

As for delusions, persecutory ideation has been found to be a predictor of violence of schizophrenic patients (e.g., Kalisky \& Zabow, 1995). However, not all studies confirm that icleas of persecution are linked to aggressive behavior (e.g., Palmstierna \& Wistedt, 1989). Perhaps, experience sampling can contribute to a better understanding of which irrational beliefs act as antecedents of violence. Systematic attempts to evaluate aggressive occurrences with the patient after he or she has calmed down - as was done in the 
intervention study described in chapter 3 - may also provide new clues as to which distorted beliefs play a role in eliciting violence.

Further, as studies on diagnostic characteristics of aggressive psychiatric patients have yielded little consensus, it appears to be more promising to focus on fundamental psychological traits that run through a number of nosologic DSM-IV categories (see van Praag, Kahn, Asnis, Wetzler et al., 1987; van Praag, 1991). Several studies have addressed the role of distinct (neuro)psychological traits (e.g., impulsivity) in triggering or mediating violence (see Brown et al., 1994; Grosz, Lipschitz, Eldar, Finkelstein et al., 1994), Grosz et al. (1994), for example, found empirical support for the notion that "impulsivity is an important mediator of violent behavior" ( $p$. 298). Relying on a sample of 76 adolescent psychiatric inpatients, Grosz and co-workers showed that impulsivity differentiates between patients with a history of violence and those without such history. Violence was determined retrospectively by self-reports of patient and family members and by reviewing patients' files. Impulsivity was assessed with the Impulsivity Scale (IS) of Plutchick and van Praag (1989). Precisely because this scale is easy to complete and assesses impulsivity independent of actual violence, it may turn out to be a promising tool for the prediction of aggression. In line with the findings of Grosz et al. (1994), Cherek, Moeller, Dougherty, and Roades (1997) found in their laboratory study that violent parolees make more impulsive choices than non-violent controls. That is to say, parolees who had a history of violent crimes preferred immediate, but small monetary rewards, over delayed, larger payments. However, the number of subjects in that study was limited (i.e., 9 violent and 21 non-violent parolees) and subjects with major psychiatric disorders were excluded. Therefore, it can be questioned whether these findings can be generalised to psychiatric inpatients. Apart from that, it should be noted that some studies conducted with psychiatric samples failed to find a robust connection between impulsivity and aggression. For example, in studying forensically admitted schizophrenic patients, Kalisky and Zabow (1995) found no association between impulsivity and sensation seeking, on the one hand, and violence, on the other hand. In that study, impulsivity was measured with Barratt's Impulsivity Scalle (BIS; Barratt, 1965). Similarly, the self-mutilation study described in chapter 6 of the current dissertation did not find support for the 
notion that impulsivity and dyscontrol were important determinants of self-mutilation. Unfortunately, that study employed rather indirect measures of impulsivity (i.e., hostility and irritability, sensation seeking, and obssessive compulsiveness). Also, in accordance with the wide variety of motives that patients provide for engaging in self-mutilation, it may well be the case that self-mutilators are a heterogeneous group. Indeed, there is growing empirical support for the idea that some patients exhibit more impulsive patterns of self-mutilation, while others seem to engage in a more premeditated form of self-destructiveness (Herpetz, Steimmeyer, Marx, Oidtmann, et al., 1995). Due to the limited number of self-mutilating patients investigated in chapter 6 , this important differentiation could not be made.

\section{BIOLOGICAL VARUABLES}

In the current dissertation, the biological determinants of aggression have not been studied. It is clear, though, that biological factors are implicated in triggering and mediating violence. Biological determinants of aggression represent a broad spectrum, ranging from genetic variables to brain infections, endocrinological diseases, and neurotransmitter dysfunctions (Johnson, 1996). As discussed in chapter 7, numerous psychotropic agents have been successfully prescribed in the treatment of aggression that is secondary to psychiatric disorder. In psychosis, for example, the most effective aggression reducing pharmacological strategy is the administration of neuroleptic drugs (Tardiff, 1996). However, for the development of effective treatment programs for persistent violence of psychiatric patients, more knowledge about specific neurotransmitter systems involved in eliciting aggression is needed. Brown et al. (1994) summarise the existing studies on this topic as follows: "the major foci of research (..) have been on acetylcholine, the cathecholamines (i.e., dopamine, or DA, and norepinephrine, or NE) and indoleamine serotonin, or 5-hydroxytryptamine (5-HT)" (p. 27). On the basis of their thorough review, these researchers conclude that "decreased serotonin function has consistently been shown to be highly correlated with impulsive aggression (..)" (p. 27). On a related note, Johnson (1996) points out that "the most significant relationship between violent behavior and specific transmitters occurs with the neurotransmitter sero- 
tonin" (p. 8). The connection between lowered serotonin function and aggression has particularly been well-documented for self-murilating and suicidal behavior (e.g., Winchel \& Stanley, 1991; Linnoila \& Virkunnen, 1992; Brown et al, 1994; Verkes et al., 1996). However, as discussed in chapter 1 of the current dissertation, inwardly and outwardly directed aggression are strongly associated (see Brown et al, 1994). In line with this, Hillbrand (1995) found that psychiatric patients who engaged in self-mutilating and suicidal behavior also had significantly raised OAS scores conceming outwardly directed aggression. Possibly, then, decreased serotonin activity is implicated both in inwardly and outwardly directed aggression. Brown et al. (1994) found low 5-HIAA (the major metabolite of 5-HT) as measured in the cerebrospinal fluid " (...) to be related to both forms of aggression, and is found in individuals with histories of suicide attempts and violent acts" (p. 30). Interestingly, this association has been found across a variety of psychiatric diagnoses (Brown et al., 1994). It is curious, therefore, that well-controlled studies on the effects of serotonin re-uptake inhibitors (which are known to enhance the serotonin function in the brain) on the aggressive behavior of psychiatric inpatients are scarce (see Coccaro \& Kavoussi, 1997). In a non-blind study, Markowitz, Calbrese, Schultz, and Meltzer (1991) administered fluoxetine, a widely used serotonin re-uptake inhibitor, to 22 patients with borderline or schizotypal personality disorder. Apart from an improvement in the general psychiatric condition of the patients, a decline in self-injurious behavior was observed. Accordingly, these investigators conclude that: "controlled trials of fluoxetine and investigations of the serotonergic system in these disorders would be useful" (p. 1064). Recently, one well-controlled study has been conducted in a sample of 40 non-depressed personality disordered patients (Coccaro \& Kavoussi, 1997). Compared to pllacebo, fluoxetine treament did produce a sustained reduction of aggression and irritability.

Apart from serotonin re-uptake inhibitors, the recent development of new atypical antipsychotic agents holds great promise for the treatment of psychotic patients with tecurrent violence. The atypical antipsychotics combine serotonergic and dopaminergic effects and may "be preferably to traditional antipsychotics with their primary dopaminergic action in schizophrenic patients who have a history of violence" (Hughes, 1998, p. 369). 
Clearly, well-controlled research is urgently needed to evaluate the efficacy of these atypical antipsychotics in controlling aggression.

\section{ABUSE AND NEGLECT IN CHILDHOOD}

Apart from the biological mechanisms underlying (self-)destructive behavior, the nature of the association between childhood tratuma and self-mutilation needs to be clarified. The current results and those of other researchers (e.g., Darche, 1990; Lester, 1991; Langbehn \& Pfohl, 1993; Shearer, 1994; Zlotnick et al., 1995) converge on the notion that auto-aggressive patients report more abusive and neglectful experiences. Whether this relationship is a causal one has not been established yet. Since most research relied on self-reports, the possibility remains that self-mutilating individuals are characterised by a tendency to exaggerate negative experiences rather than that they actually have been abused more often in childhood. Apart from a raised prevalence of childhood trauma, self-mutilating patients consistently have been found to have high DES-scores (Brodsky et al., 1995; Shearer, 1995; Zlotnick et al., 1995; Nijman, Dautzenberg, Merckelbach, Jung et al,, 1999). Although this connection has been portrayed as support for the notion that self-mutilation stems from childhood abuse (e.g., Suyemoto, 1998), dissociation may also be strongly related to fantasy proneness (Merckelbach, Muris \& Rassin, 1999; Merckelbach \& Muris, 1999). Based on a series of experiments, Merckelbach and Muris summarise the interrelationships between DES scores, fantasy proneness, and positive response biases on self-report questionnaires as follows: "all in all, these findings suggest that individuals who score high on the DES exhibit a positive response bias that is strongly linked to their heightened levels of fantasy proneness" (Merckelbach \& Muris, 1999). Thus, it appears that more research is needed which includes fantasy-proneness and positive response biases as potential covariates. In this way, it can be established whether there is, indeed, a causal link between childhood trauma and self-mutilation. Another strategy to evaluate whether childhood trauma is an etiological factor for the development of self-mutilation is to find practical and ethical ways to check self-reported traumatic experiences against independent sources. Police records and family doctor medical notes (obtained in childhood) may be valuable sources 
for verification. Finally, positive response biases may also contribute to exaggerated reports of self-mutilating behavior. Therefore, in future research, independent verification of self-reported auto-aggressive behavior seems to be warranted. The revised SOAS, in which auto-aggression is recorded along with the other forms of aggression, may be a promising tool for this type of research.

\section{HOW PREVENTION STUDIES SHOULD BE DESIGNED}

Most studies that evaluated non-pharmacological interventions (e.g., aggression management trainings for staff) reported a reduction of aggression, following the implementation of preventive measures (see table 1). However, as discussed earlier, several of these studies failed to include control conditions. The vast majority of studies on the effects of staff training compared assault rates of trained staff members to those of untrained ones. However, no prior randomisation took place (e.g., van Rixtel et al., 1997; Camel \& Hunter, 1990). In clinical practice, random allocation of staff members to an aggression management course may be problematic. It is likely, however, that characteristics of staff members who choose to attend such courses differ from those who do not attend such courses. As a result, self-selection effects, operating already during base-line, can not be ruled out. Therefore, baseline measurements of aggression frequencies, prior to training, appear to be indispensable in testing the effects of aggression management courses. Considering the severe consequences of inpatient aggression, one could argue that randomising studies on the effects of staff trainings is legitimate. Further, research that contrasts the effects of aggression management trainings to those of pharmacological. interventions is needed. Curiously enough, no studies comparing the effects of these different strategies can be found in literature.

It should be noted that, due to ethical and practical concerns, measures intervening at the overall ward level (e.g., doubling the number of staff members, changing the way the ward team works) may be difficult to test in an experimental fashion. Random assignment of potentially dangerous patients to an experimental or a control ward is hard to achieve. With interventions like these, a quasi-experimental design, with a long pre and post intervention measurement period, may be a sound alternative. Including measurements 
of aggression on control wards provides, at least, more insight in the effects of registration per se. Note, that in the current dissertation, a failure to obtain control data, would have led to the misleading conclusion that the tested interventions were highly effective in reducing the frequency of aggression. One of the main problems of comparing the aggression data from different wards is that staff members from an 'experimental' ward will be aware of the fact that their ward is the object of research. Due to this, the influence of expectancy-effects on the reported aggression frequencies can not be ruled out. The registration of more subjective outcome measures (e.g., verbal aggression) is likely to be particularly vulnerable to expectancy-phenomena. For this reason, separate analyses of physical aggressive incidents were conducted in the current dissertation. Possibly, the validated severity scoring system of the SOAS will prove to be useful in evaluating the effects of preventive measures. By using a high cutoff point of aggression severity including only the more serious aggressive incidents - the reliability of the analyses may be further increased. Clearly, a strategy like this will require longer observation periods or a higher number of participating wards. In sum, to be informative to the field, prevention studies should preferably be designed along the following lines:

1. inclusion of long, pre-intervention baseline measurements of aggression

2. inclusion of control conditions

3. comparisons between interventions that target at different levels of the model described in chapter 7

4. reliance on well-validated measures of aggression, focusing on more severe manifestations of aggression.

\section{PREDICTION OF AGGRESSION}

In order to prevent inpatient aggression, validated prediction methods of aggression may be indispensable. Accurate prediction of dangerous behavior will increase the time the ward team has to intervene effectively. However, there is a paucity of studies concerning the validity of the clinical assessment of the risk of violence, particularly on locked psychiatric wards. In psychiatric hospital Welterhof, one such study (Nijman, Evers, Leunnissen, Allertz et al., 1999) recently has been completed. In line with earlier findings of McNiel and Binder (1991;1995), the results indicate that directly at the 
beginning of an admission, staff members of an acute admissions wards are able to give an accurate estimate of the aggression risk.

The development of better prediction methods, however, will also increase the responsibility and the liability of psychiatric care-givers. A striking example of the increasing tendency to hold psychiatrists accountable for the behavior of their patients is the case of $\mathrm{Mr}$. Williamson, a young paranoid schizophrenic patient (Ewing, 1999). After termination of his treatment, Williamson shot and killed several people. His psychiatrist was found guilty of negligence. A jury rulled that Mr. Williamson' violence had been foreseeable by the psychiatrist.

\section{FINAL REMARKS}

Obviously, there is a lack of well-controlled research on the effects of aggression reducing (non-pharmacological) interventions. Only large-scale (quasi-)experimental studies, in which the hospital environment is drastically manipulated, can provide clarity about which ward environment is best stuited to prevent aggression. Most of the situational interventions discussed in this chapter, are likely to improve the living conditions of patients and possibly prevent violence. Testing and implementing these measures seems to be hindered by financial implications. However, even from an economic point of view, investments in aggression prevention research may be worthwhile, since inpatient aggression is connected to higher costs of treatment. That is to say, inpatient violence may be linked to a longer length of stay in the hospital and an increase in staff sick leaves (see chapter 7). Violence, and the resulting need to impose restrictions on the patient, clearly harm the therapeutic alliance. Seclusion and restraint sometimes are perceived as extremely humiliating and traumatising by patients, and therefore may add to a further decrease of the psychiatric well-being of the patient. For all of these reasons, researchers should be provided with the resources to increase their efforts to investigate what measures reduce violence, seclusion, and restraint. 

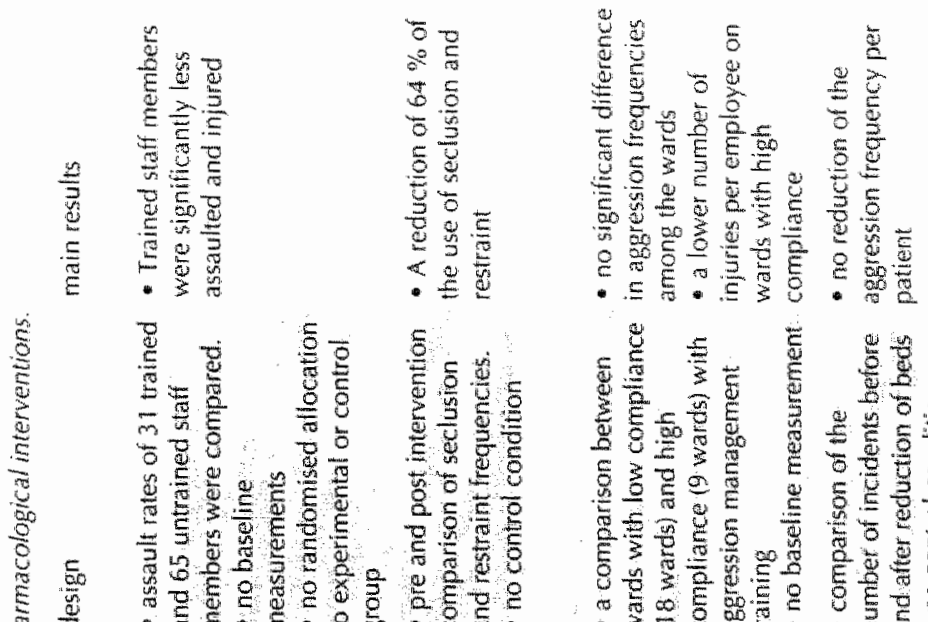

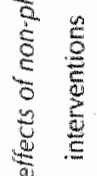

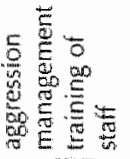

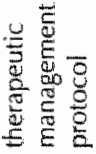

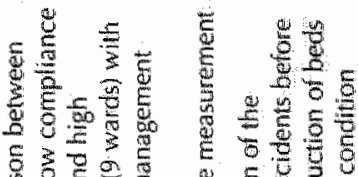

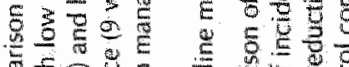

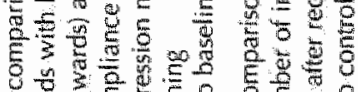

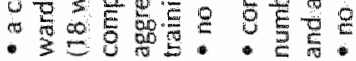

른

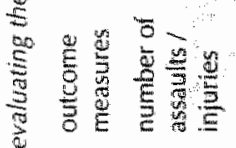

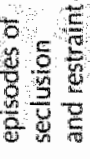

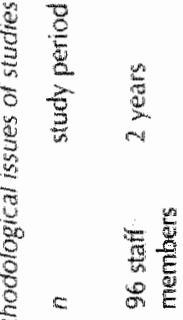

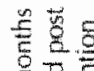

E

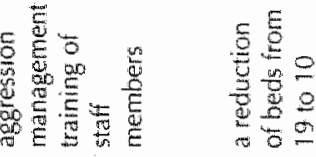

क $\frac{2}{5}$

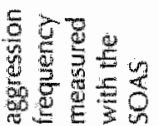

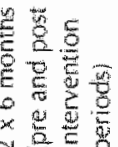

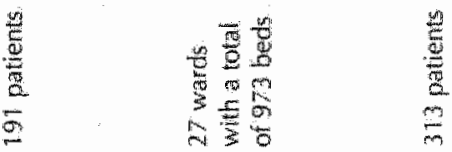

है

蔍员

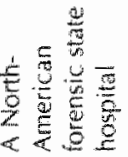

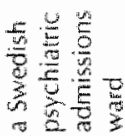

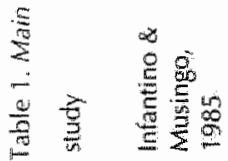

类

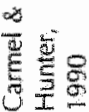

恶总 


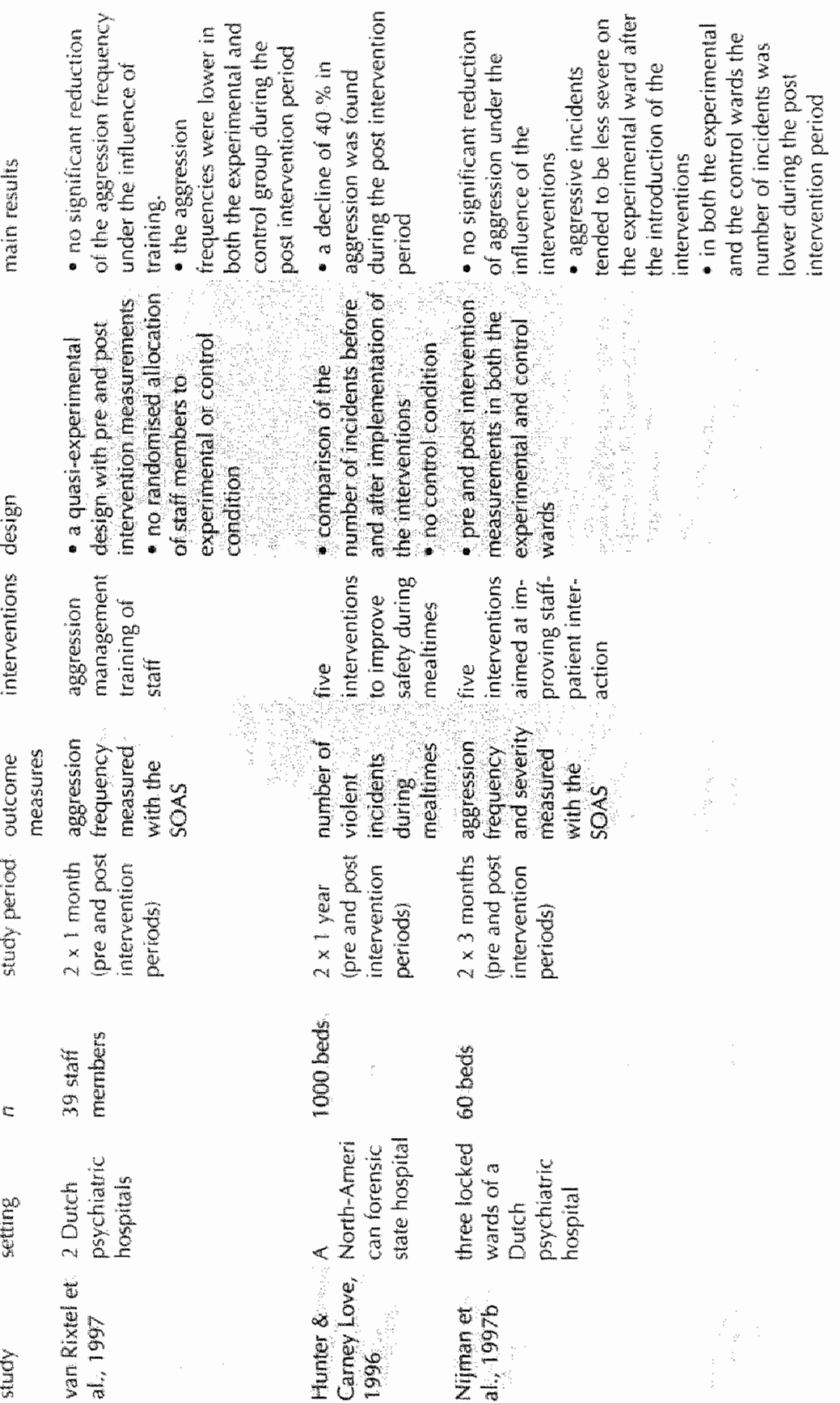


\begin{tabular}{r|r|} 
CHAPTER & General Discussion \\
121 &
\end{tabular}
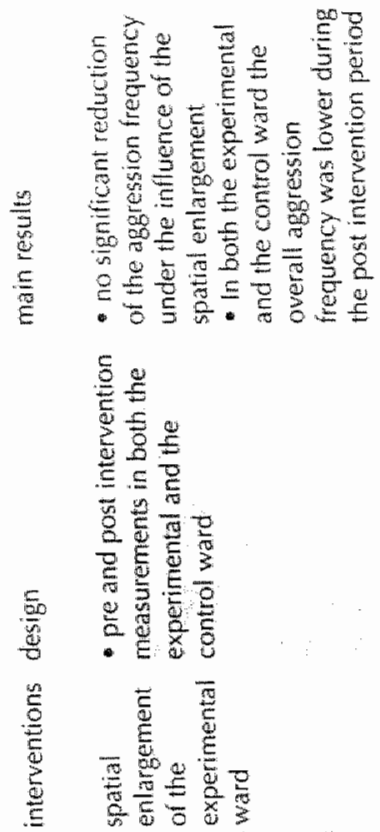

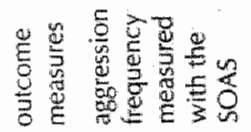

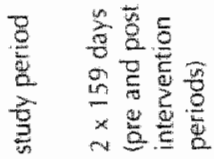

$=\frac{\frac{n}{6}}{8}$

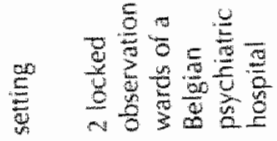

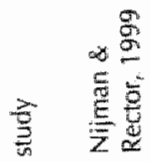





\section{SAMENVATTING}

Dit proefschrift handelt over de prevalentie, meting en preventie van agressieve incidenten op gesloten afdelingen van psychiatrische ziekenhuizen. Onder agressief gedrag wordt hier zowel agressie tegen objecten of tegen personen verstaan als agressie die de patiënt tegen zichzelf richt. De aandacht gaat niet alleen uit naar de karakteristieken van agressieve patiënten (bv. diagnose, leeftijd, sekse en juridische status) maar ook naar de rol die de afdelingsomgeving speelt bij het ontstaan van agressieve incidenten.

De belangrijkste resultaten kunnen als volgt worden samengevat. In een descriptieve studie werd gevonden dat ongeveer één agressief incident per dag optrad op een gesloten opnameafdeling met 20 bedden. Van de in totaal 164 geregistreerde incidenten die in een periode van 24 weken plaatsvonden had $11 \%$ fysieke gevolgen voor slachtoffers. Daarbij ging het meestal om kortstondige pijn, schaafwonden of blauwe plekken waarvoor geen behandeling noodzakelijk was. Bijna de helft van de 164 incidenten (49\%) werd gevolgd door separatie van de patiënt. Deze cijfers illustreren hoe de veiligheid en het welzijn van zowel medepatiënten, stafleden als die van de betrokken patiënt in het geding zijn bij agressief gedrag.

De aanleiding voor het agressieve gedrag van de patiënt was voor de behandelteamleden relatief valk onduidelijk. In 71 van de 164 geregistreerde incidenten (43\%) zeiden de hulpverleners de directe oorzaak wan de agressie miet te kennen. Verder trad agressie vaak op (33\%) nadat een verzoek van de patiënt niet gehonoreerd werd door de stafleden. In $13 \%$ van de incidenten werden de agressieve handelingen geclassificeerd als een reactie op het gedrag van medepatiënten. Deze cijfers suggeren dat de afdelingsomgeving waarin de patiënt (vaak tegen zijn of haar wil) verblijft een grote kan rol spelen bij het ontstaan van agressie.

Voorts werd gevonden dat agressie vaak in de woonkamers van de afdeling ontstond (21\%). Hierbij ging het meestal om agressie tussen patiënten onderling. In of vlak voor het verpleegkundig kantoor trad $20 \%$ van de incidenten op. In die gevallen richtte de agressie zich valk tegen de behandelteamleden. Voor de gesloten deur van de afdeling trad $15 \%$ van de 
incidenten op warbij de agressie zich meestal tegen de afdelingsdeur zelf richtte.

Op basis van dit eerste exploratieve onderzoek werd een interventie-studie met een quasi-experimenteel design opgezet. Het doel van deze studie was om agressieve incidenten zowel in aantal als in errnst te laten afnemen met behulp van een vijftal geprotocolleerde interventies. Zo werd een agressie-protocol ingevoerd waarin nauwgezet werd omschreven hoe de teamleden (dreigend) agressief gedrag tegemoet moesten treden. Het protocol, dat gebaseerd was op een studie van Kalogjera et al. (1989), omschreef een aantal verbale interventies die bij dreigende situaties stap voor stap uitgevoerd dienden te worden (zie hoofdstuk 3). Wanneer de agressie, ondanks deze verbale interventies, niet gecontroleerd kon worden door de patiënt, en separatie of fixatie onvermijdelijk bleek, dan diende het voorval later, wanneer de patiënt gekalmeerd was, te worden nabesproken. Deze nabespreking geschiedde aan de hand van een gestandaardiseerd agressie-evaluatie-formulier en had tot doel patiënt én staf bewust te maken van de oorzaken van het agressieve gedrag. In deze nabespreking werd de patiënt nogmaals uitgelegd waarom de staf zich genoodzaakt had gezien beperkende maatregelen te nemen tijdens de agressieve escalatie. Aan het einde van de evaluatie werden door patiënt en hulpverlener de mogelijkheden onder de loep genomen om toekomstige agressieve incidenten te voorkómen. Eventuele afspraken hieromtrent werden op het agressie-evaluatie-formulier vastgelegd.

Naast het agressie-protocol werden nog vier andere maatregelen, die alle tot doel hadden de informatievoorziening en communicatie tussen staff en patiënt te verbeteren, ingevoerd (zie hoofdstuk 3). Na invoering van de interventies nam het aantal agressieve incidenten op de experimentele afdeling met $63 \%$ af. Ten opzichte van de twee controle-afdelingen was deze daling echter niet significant $(p=0.16)$. Op de controle-afdelingen werd een daling waargenomen van agressieve voorvallen met 44\%. De gemiddelde ernst van de agressieve incidenten nam op de experimentele afdeling, in vergelijking met de controle-afdelingen, marginaal significant af $(p=0.052)$.

In een derde studie (hoofdstuk 4) werd het vizier gericht op de rol die afdelingsruimte en -drukte spelen bij het optreden van agressieve incidenten. Vergroting van de afdelingsruimte, door toevoeging van een binnenplaats, leidde niet tot een vermindering van het aantal agressieve incidenten. Wel 
werd een bescheiden doch significante correlatie gevonden tussen afdelingsdrukte en het aantal incidenten per patiënt $(r=0.21, p<0.05)$. Deze bevinding lijkt erop te wijzen dat afdelingsdrukte, en het daaruit voortvloeiende gebrek aan rust en privacy, de veiligheid op psychiatrische afdelingen negatief kunnen beinvloeden.

Voor het opzetten van prevalentie-en interventie-studies naar agressie is een betrouwbare en praktisch haalbare registratie van agressief gedrag van groot belang. De meeste metingen in onderhavige dissertatie werden uitgevoerd aan de hand van een herziene versie van de Staff Observation Aggression Scale (SOAS: Palmstierna \& Wistedt, 1987). Het vijfde hoofdstuk van dit proefschrift is gewijd aan de psychometrische kwaliteiten van dit instrument. Op grond van de bevindingen werd een herziene versie van de SOAS ontwikkeld. Met deze gereviseerd versie, die SOAS-R werd genoemd, kunnen naast agressie gericht tegen anderen of tegen objecten ook auto-agressieve handelingen (auto-mutilatie en suicidaal gedrag) op eenvoudige wijze worden geregistreerd. Het onderzoek naar de validiteit van de ernstscores van de SOAS was gebaseerd op gegevens omtrent 556 agressieve incidenten die op zes gesloten afdelingen van drie verschillende ziekenhuizen (in Heerlen, Tienen en Amsterdam) werden geregistreerd. Naast de 556 agressieve incidenten gericht tegen andere personen of objecten, werden ook 91 gevallen van auto-agressie (14\%) geregistreerd. De registraties wijzen erop dat bij auto-agressief gedrag andere determinanten een rol spelen dan bij de overige vormen van agressie. Zo trad auto-agressie vaker op wanneer er weinig afdelingsactiviteiten waren ("s avonds en in het weekend). De directe aanleiding tot zelfverwonding was, nog vaker dan bij de andere vormen van agressie, voor de stafleden nogal eens onbekend (namelijk in $56 \%$ van de gevallen). De fysieke gevolgen van auto-agressie waren in de regel ernstig. In bijna 6 op de 10 gevallen had het zelfdestructieve gedrag fysieke consequenties voor het slachtoffer en in 1 op de 4 gevallen was behandeling van ontstane letsels nodig.

Om meer zicht te krijgen op de beweegredenen van patiënten on zichzelf te verwonden werden 54 patiënten geïnterviewd. Van deze 54 at random geselecteerde proefpersonen gaven er 24 (44\%) aan zich eens of meerdere malen in hun leven intentioneel te hebben verwond. Het aantal zelfgerapporteerde episodes van zelfbeschadigend gedrag varieerde van 1 tot 1000, de mediaan 
$126 / 5$ Samenwating

was 8 . De gemiddelde leeftijd waarop het auto-mutilatieve gedrag startte was 23 jaar. De 24 auto-mutilerende patiënten rapporteerden meer negatieve en traumatiserende ervaringen in de jeugd te hebben meegemaakt dan de 30 niet auto-mutilerende controlepatiënten. Daarnaast rapporteerden de auto-mutilerende patiënten vaker dissociatieve klachten te hebben dan de controles. Tegen de verwachting in werden er geen verschillen gevonden tussen beide groepen voor wat betreft vijandigheid, obsessief-compulsiviteit en spanningsbehoefte.

Getracht werd de onderzoeksresultaten en literatuurbevindingen te integreren in een hypothetisch model over de determinanten van agressief gedrag zoals dat optreedt bij patiënten in psychiatrische ziekenhuizen. Dit model (hoofdstuk 7) omvat zowel relevante patiëntenkenmerken als situationele variabelen (staf-en afdelingsvariabelen) die een rol lijken te spelen bij het optreden (en in stand houden) van agressief gedrag in psychiatrische ziekenhuizen. Aan de hand van het model worden mogelijke interventietechnieken geïnventariseerd.

In het achtste hoofdstuk van onderhavig proefschrift wordt de blik vooral vooruit gericht. Nieuwe en veelbelovende ontwikkelingen voor verder onderzoek worden becommentarieerd. 


\section{SUMMARY}

Psychiatric patients have a raised risk of assaulting others or to engage in self-destructive behavior. Particularly on locked wards of psychiatric hospitals, aggressive behavior is a relatively prevalent phenomenon. In spite of the serious threat that inpatient violence poses for the safety and well-being of patients and their caregivers, the determinants of inpatient aggression are not well understood. In the current dissertation, an attempt is made to elucidate the factors that are involved in triggering inpatient aggression. The attention is not only focused on patient characteristics that are linked to wiolence, but also on the contribution of staff and ward variables to aggression.

The first chapter gives an outline of what is known about the prevalence, measurement, and determinants of aggressive incidents in psychiatric hospitals. From this background information, the main research questions of the current dissertation were derived.

In chapter 2, a study is presented on the prevalence of aggression on a locked 20 -bed psychiatric admissions ward. During a 24 week period, nearly one aggressive incident per day was reported by the staff. Eighteen out of $164 \mathrm{ag}-$ gressive incidents (11\%) resulted in injury or harm of victim(s). Nearly half of the incidents were followed by seclusion of the patient. These figures demonstrate that the safety and well-being of both patients and staff are threatened by inpatient aggression. The aggressive incidents were likely to occur in the afternoon (from $12 \mathrm{a} . \mathrm{m}$. to $3 \mathrm{p.m}$ ) and took place most frequently in the day rooms, near the staff office, and in front of the locked exit door of the ward. Patients involved in aggression were younger and more often hospitalized involuntarily than non-aggressive controls. Gender and diagnosis were not associated with aggression frequency. What triggered the aggressive behavior was relatively often unclear to the staff members. That is, in $43 \%$ of the cases, the reason for becoming aggressive was not understood. About 1 out of every 3 incidents was preceded by a denial of a patient' request. In $13 \%$ of the incidents, the aggression appeared to have been induced by fellow patients" behavior. These results indicate that the ward environment, with its specific rules, activities, and living conditions, may contribute to inpatient aggression. 
Chapter 3 describes an intervention study with a quasi-experimental design that aimed at reducing aggression by improving the way staff members explained ward rules and treatment policies to the patient. In this intervention study, the frequency and severity of aggressive incidents were measured on an 'experimental' and two control wards. Measurements were obtained for three-month periods before and after the implementation of 5 interventions. These interventions included a protocol for talking to patients who exhibited disruptive or aggressive behavior, discussing treatment goals with the patient shortly after admission, explaining why the ward's door was locked, providing a schedule of staff meetings to explain staff members' absence from the ward, and clarifying the procedure for making an appointment with the psychiatrist. A decline in aggression was found on all three wards, with no significant difference between the ward where interventions were implemented and the two control wards. A marginally significant difference in the severity of aggressive incidents was found between experimental and control wards after the introduction of the preventive measures; incidents on the experimental ward tended to be less severe $(p=0.052)$. In chapter 4 , the link between crowding and ward space, on the one hand, and aggressive behavior, on the other hand, was investigated. On two closed psychiatric wards, all aggressive behavior that occurred in the period from February 1, 1996 until. December 15, 1996 was recorded. A modest correlation between the number of patients on the ward and the number of incidents per patient was found. Enlargement of the ward surface, by the addition of a courtyard to one of the wards, did not lead to a significant decline in aggressive incidents. Possibly, a lack of psychological space on the ward (e.g., having no privacy or not being able to get rest) rather than a lack of physical space (square meters per patient) is involved in eliciting aggression.

In the empirical studies presented in chapters 2,3 , and 4 , aggression frequency and severity were recorded with the Staff Observation Aggression Scale (SOAS; Palmstiema and Wistedt, 1987). In chapter 5, the validity of the SOAS severity scoring system was examined in more detail. This was done by comparing the SOAS severity scores of 556 aggressive incidents to severity estimates given by witnessing staff members on Visual Analogue Scales (VAS). The original SOAS scores designed by Palmstierna and Wistedt in 1987 were found to be moderately but significantly correlated 
with the severity estimates given by staff on the VAS. On the basis of the staff severity estimates, the SOAS severity scoring system was refined. The revised scoring method and other refinements in the contents of the instrument led to the construction of a revised version of the SOAS, termed SOAS-R. The SOAS-R appears to be a promising tool for monitoring a wide range of (auto-) aggressive acts on psychiatric wards.

Chapter 6 addresses the origins of a specific type of aggressive behavior, namely self-mutilation. Two broad hypotheses about the origins of self-mutilation were tested. The first hypothesis states that self-mutilation originates from child abuse and experiences of neglect and is connected to dissociation in later life. The second hypothesis views self-mutilation as the consequence of impulse control problems. To test these two hypotheses, data about traumatic childhood experiences and dissociative symptoms (hypothesis 1), as well as data about aggressiveness, obsessive-compulsiveness and sensation seeking (hypothesis 2 ) were collected in a sample of 54 psychiatric inpatients. Twenty-four out of 54 patients (44\%) reported having engaged in self-mutilation. Patients who engaged in self-mutilation reported more traumatic childhood experiences and dissociative symptoms than did control patients. The two groups did not differ in terms of aggressiveness, obsessive-compulsiveness, and sensation seeking.

Chapter 7 made an attempt to integrate patient, staff, and ward variables into a model that explains inpatient aggression. In this model, psychopathological variables and distorted cognitions are combined with environmental and communication stressors that are specific for psychiatric wards. The model also elucidates how repeated inpatient aggression may be the result of a vicious circle, i.e., inpatient violence is often followed by an increase in environmental and/or communication stress on the patient, thereby heigthening the risk of a repeated outburst of violence. Although the proposed model is tentative, it may shed light on the mechanisms that lead to (repeated) violence, thereby creating a basis for more systematic prevention of aggressive behavior in psychiatric institutions.

Finally, in chapter 8 , the main findings of the dissertation are summarized and the evidence is critically reviewed. Promising research avenues for future studies are discussed. More systematic research on the role of certain situational (e.g., daily ward activities), biological (e.g., lowered serotonin func- 
$\left.130\right|^{\text {Surimary }}$

tion), and psychological variables (e.g., impulsivity) in triggering aggression needs to be conducted. In order to reduce violence in psychiatric hospitals, more well-controlled research on the effects of ward and staff interventions is needed. The optimal design for testing such (non-pharmacological) interventions is discussed in detail. 


\section{Appendix \\ 131}

Appendix: The Stafi Observation Aggression Scale - Revised

\begin{tabular}{|c|c|c|c|c|c|c|c|c|c|}
\hline \multicolumn{3}{|c|}{ Initials of the patient: } & \multicolumn{3}{|c|}{ Registration mo: } & \multicolumn{4}{|c|}{ Ward: } \\
\hline \multicolumn{2}{|l|}{ hoident no: } & \multicolumn{3}{|c|}{ Date: } & & \multicolumn{4}{|c|}{ Time (hotus and minutes) } \\
\hline \multicolumn{10}{|c|}{ 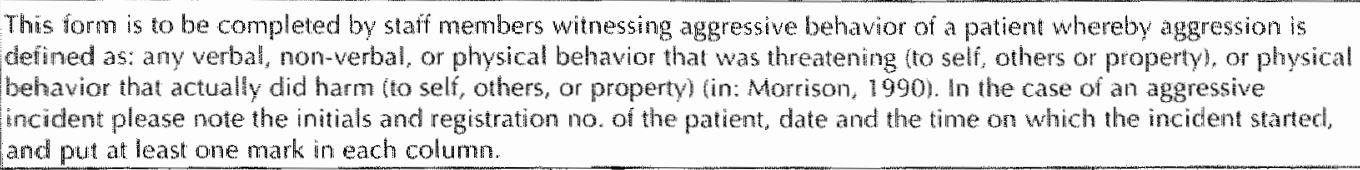 } \\
\hline \multicolumn{2}{|l|}{ 1. Prowocation } & \multicolumn{2}{|c|}{$\begin{array}{l}\text { 2. Means used by the } \\
\text { patient }\end{array}$} & \multicolumn{2}{|c|}{ 3. larger of aggression } & \multicolumn{2}{|c|}{$\begin{array}{l}\text { 4. Consequence(s) for } \\
\text { victimls) }\end{array}$} & \multicolumn{2}{|l|}{$\begin{array}{l}\text { 5. Measureis to stop } \\
\text { aggression }\end{array}$} \\
\hline $\begin{array}{l}\text { Mo honder- } \\
\text { standable } \\
\text { provocation }\end{array}$ & 1 & verbal ageression & 1 & nothing / nobody & n & no & 0 & none & 10 \\
\hline \multicolumn{2}{|l|}{ Prowolked by: } & \multicolumn{2}{|l|}{ Ordinary objects: } & objectss & 1 & \multicolumn{2}{|l|}{ Objects" } & talk to patient & 0 \\
\hline other patients) & 0 & chants & 1 & other pattents & 2 & $\begin{array}{l}\text { clamaged, not } \\
\text { replaced }\end{array}$ & s. & $\begin{array}{l}\text { Calmy brought } \\
\text { away }\end{array}$ & 10 \\
\hline help with ADL & 0 & glasslware) & 1 & patient selí & is & $\begin{array}{l}\text { damased. } \\
\text { replaced }\end{array}$ & 3 & $\begin{array}{l}\text { peroral } \\
\text { medication }\end{array}$ & 2 \\
\hline $\begin{array}{l}\text { Patient being } \\
\text { denied } \\
\text { somnething }\end{array}$ & 0 & other, namelly: & 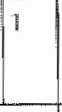 & staif member(s) & 3 & \multicolumn{2}{|l|}{ Persons: } & $\begin{array}{l}\text { parenteral } \\
\text { medicationt }\end{array}$ & 2 \\
\hline $\begin{array}{l}\text { staff reculiting } \\
\text { patient to take } \\
\text { mordication }\end{array}$ & 2 & \multicolumn{2}{|l|}{ Parts of the body: } & other person(s) & 4 & felt threatiened & 6 & held with force & 4 \\
\hline \multirow[t]{8}{*}{$\begin{array}{l}\text { Other } \\
\text { prowocations: }\end{array}$} & \multirow[t]{2}{*}{0} & $\begin{array}{l}\text { hand thitting, } \\
\text { purnching etch }\end{array}$ & 2 & & & pain < 10 min & b) & $\begin{array}{l}\text { sectusion/kola- } \\
\text { tion (locked doom }\end{array}$ & 4 \\
\hline & & fool (kicking) & 2 & & & parn > 10 min & 4 & restraints & 4 \\
\hline & & leetl (biting & 2 & & & visible injury & ) & other measentes: & 2 \\
\hline & & other "marnely: & 2 & & & $\begin{array}{l}\text { need for } \\
\text { treatment }\end{array}$ & ing & $\ldots$ & \\
\hline & & $\begin{array}{l}\text { Dangerous objects } \\
\text { methods: }\end{array}$ & sor & & & $\begin{array}{l}\text { need for } \\
\text { treamen by at } \\
\text { physician }\end{array}$ & $c_{\mathrm{B}}$ & & \\
\hline & & knife & 3 & & & & & & \\
\hline & & strangulation & 3 & & & & & & \\
\hline & & other, namely: & 3 & & & & & & \\
\hline
\end{tabular}





\section{REFERENCES}

Barratt, E. (1965) Factor analysis of some psychonetric measures of mpulsiveness and anxiery. Psychological Report, 16,547-554.

Barstow, D.G. (1995) Self-ingury and self-mutitation. Nursing approaches. foumal of Psychosial Nitusing, $33,19-22$.

Bech, P. (1994) Measurement by obserwations of aggressive behavior and activities in dinical situations. Criminal behwiout and Mental Health, $4290-302$.

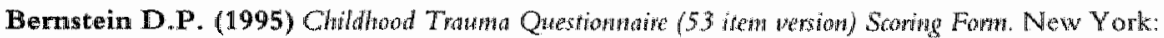
Mount Sinai School of Medicine.

Bermstein, D.P., Ahluvalia, T., Pogge, D. \& Handelsman, C. (1997) Validity of the childhood trauma questionnare in an adolescent psychiatric populatian. Jon wal of the Awhrow Acodeny of Adolescent Psydrutry, 36, 340-348.

Bernstein, D.P., Fink, L., Handelsman, L., Foote, J., Lovejoy, M., Wenzel., K., Sapareto, E. \& Ruggiero, J. (1994) Initial reliability and validity of a new retrospective measure of child abuse and neglect. Americun joumal of $P_{s y c h a t}, 151,1132-1136$.

Bernstein, E.M. Putram, F.W. (1996) Development, reliability, and validity of a dissoctation scalle. Jourtial of Nenous and Mental Disease, 174, 727-35.

Beauford, J.E., McNiel, D.E., Binder, R.L. (1997). Utility of the imitial therapentic alliance in evaluating psychiatric patients" nisk of violence. Anerican Joumal of Psychiany, 154, 1272-1276.

Bjarkly, S. (1995) Prediction of aggression in psychiatric patients. a review of prospective prediction studies. Clinical Psycholagy Rewiew, 15, 475-502.

Blair, T. (1991) Assaultwe behaviour; does provocation begin in the front office? Joh of of Pryoloorial Nursing, 29, 21-26.

Breuner, H.D., Dencker, S.J., Goldstein, M.J., Hubbard, J. W, Keegan, D.L., Kruger, C., Kulhanek, F., Liberman, R.P, Malm, U. \& Midha, K.K. (1990) Defining treament refractoriness in schizophrenia. Sitnzophewio Bulluti, 16,551-562.

Brizer, D.S., Convit, A., Krakowski, A. \& Volavka, J. (1987) A ming scale for reponting wolence on psychiatric wards. Hospital and Commonity Psychatry, $38,769-770$.

Brodsky, B.S., Cloitre, M. Bu Dulit, R.A. (1995) Relationship of dissociation to selfritutation

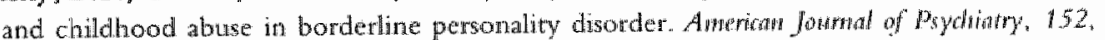
$1788-1792$.

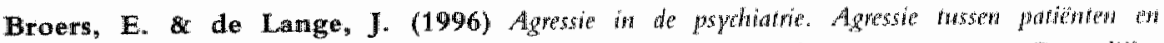

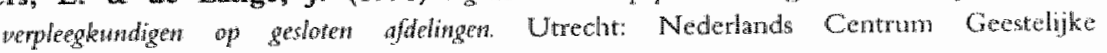
Volksgezondheid.

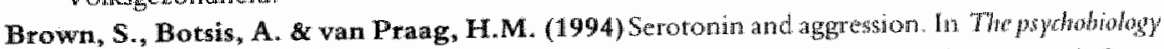
of Aggression (eds. M. Hillbrand d. Pallone), pp. 27-39. New York: Tho Haworth Press $\operatorname{lnc}$.

Bromenberg, W. 8 Bijl, R. (1998) Suicide en sucideprevente in het psychiatrisch ziekenhus. Matudblad Gestelife Volksgezondheid, $53,13-26$.

Buss, A.H. \& Durkee, A. (1957) An inventory for assessing different kinds of hostiling formal of Consulting Psychology, 21,343-349. 
Carmel, H. Hunter ${ }_{\mathrm{f}}$ M. (1989) Staff Injuries from inpatient violence. Hospital and Conmunty Pydiatry, $40,41-46$.

Carmel, H. Hunter, M. (1990) Compliance with training in managing assaultive behavior and injuries from inpatient violence. Hospital and Consmuntity Psychiary, 41,558-560.

Carr, E.G. \& Newsom, C.D. (1985) Demand related tantrums. Conceptualization and treatment. Behawong Modification, 9, 403m426.

Cherek, D.R., Moeller, G., Dougherty, D.M. Rhoades, H. (1997) Studies of wiolent and nonviolent parolecs II. Laboratory and psychometric measurements of impulsivity. Biologiant Pespliatry, 41, 523-529.

Chu, J.A. \& Dill, D.L. (1990) Dissociative symptoms in relation to childhood physical and sexual abuse. Antericars Joursal of Psychiatry, 147,887-892.

Chueng, P., Schweitzer, I., Tuckwell, V. \& Crowley, K.C. (1996) A prospective study of aggression among psychiatric patients in rehabilitation wards. Australian and New Zealand Joumal of Psychiatiry, 30, 257-262.

Coccaro, E.F. \& Kavoussii, R.J. (1997) Fluoxetine and impulsive aggressive behavior in personality-disondered subjects. Ardhives of Geneval Psychidtry, 54, 1081-1088,

Convit, A., Isah, D., Otis, D. \& Volavka, J. (1990) Characteristics of repeatedly assaultive psychiatric inpatients. Hospital and Contwanity Psychiany, 41, 1112-1115.

Cooper, A.J. \& Mendonca, J.D. (1991) A prospective study of patient assaults on nurses in a provincial psychiatric hospital in Canada. Acta Psychiavica Scandikatica, 84, 163-166.

Corrigan, P.W., Yudofsky, S.C. \& Silver, J.M. (1993) Pharmacological and behavional treatments for aggressive psychiatric inpatients. Hospital and Commonicy Psychintry, 44, 125-133.

Darche, M.A. (1990) Psychological factors differentiating self-mutilating and non-self-mutilating adolescent inpatient females. The Psychiaric Hospina, 21,31-35.

Davis, S. (1991) Violence by psychiatric inparients. A review. Hospital and Community Pychianry. $42,585-590$.

Dawes, R.M. Faust, D. \& Meehl, P.E. (1989) Clinical versus actuarial judgment. Sijence, 243. $1668-1673$.

Dekkar, G.V.C. (1997) Wer Bigzondere Opnenemingen in Psychantrische Ziekenhwizen. Lelystad: Koninklijk: Vemande $\mathrm{B} . \mathrm{y}$.

Dougherty, L.M., Bolger, J.P., Preston, D.G., Jones, S.S. \& Payne, H.C. (1992) Effects of cxposure to aggressive behavior on jols satisfaction of heath care statf. Joumal of Apptiod Gerrontology, 11.160-172.

Drinkwater, J. \& Gudjonsson, G.H. (1989) The rature of violence in Psychiatric Hospitals. In Camial appradhes to volent (eds. K. Howells \& C.R. Hollin, pp. 387-307. Johr Wiley and sons.

Dulit, R.A., Fyer, M.R., Leon, A.C., Brodsky, B.S. \& Frances, A.J. (1994) Clinical correlates of self-mutilation in borderline personality disorder. Americon Jourtual of Psychiary. 1.5. $1305-1311$.

Dutch Inspectorate for Mental Health (Geneeskundige Inspectie van de Geestelijke Volksgezondheid) (1992) Agressie in algemean pspothatrische ziekenhizen. Rijswijk. The Netherlands: GIGV.

Evenson, R.C., Sletten, I.W., Altman, H.A. \& Brown, M.L. (1974) Disturbing behavior. a study of incident reports. Psydwatri Qtanterly, 48, 266-275. 
Ewing, C.P. (1999) Liability for a patient's homocide. APA Monitor, 30 (Felmaty) 14.

Favaro, A. \& Santonastaso, P (1998) Impulsive and compulsive selfinjurious behavior in Bulimia Nerwosa: prevalence and psychological conelates. Jommal of Nenous and Montal Disease, $186,157-165$.

Favazza, A. Rosenthal, R.J. (1993) Diagnostic issues in self-mutilation. Hospital ante Commontisnity Psychiarry, 44, 134-140.

Favazza, A.R. (1989) Why patients mutilate themselves. Hogpinal asd Cotsmumity Psychatry. 40. $137-45$.

Favazza, A.R. \& Conterio, K. (1988) The plight of chronic self-mutilators. Conmunty Mewat Hewhith Jourwall, 24, 22-30.

Feij, J.A. \& Zuilen, R,W. van (1984) Handleding Spanningsbehoefte Ligs, SBL manual sensation seeking scalel. Lisse, The Netherlands: Swets \& Zeitlinger.

Fisher, W.A. (1994) Restraint and seclusion. A review of the literante. Anterican Jountal of Psycthiatry, 151,1584-1591.

Fottrell, E. (1980) A study of violent behavior among patients in psychiatric hospitals. British Journal of Pyychiatry, 136, 216-221.

Foucault, M. (1975) De geschiedenis wan de wantzim. Meppel: Uigeverij Boom.

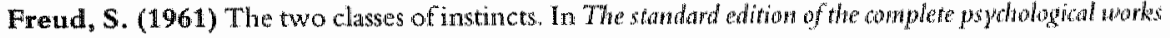
of Sigmund Freud volume XIX (eds. J. Strachet). pp. 40-47. London: the Hogarti Press.

Friis, S. \& Helldin, L. (1994) The contribution made by the clinical setting to violence among psychiatric patients. Criminal Behawior and Mental Healh, 4, 341-352.

Fuller Torrey, E. (1994) Violent behavior by individuals with serious mental illness. Hospitat and Conwanuity Psychiatry, 45, 653-662.

Gift, A.G. (1989) Visual Analogue Scales. Measurement of subjective phenomena. Nursing Research, 38, 286-288.

Grainger, C. Whiteford, H. (1993) Assault on staff in psychiatric hospitalls. A safety issue. Anstraliant and New Zealand Joumal of Psychiarry, 27, 324-328.

Greenfield, T.K., McNiel, D.E. Binder, R.L. (1989) Violent behavior and length of psychiatric hospitalization. Hospitei and Commatnity Psydiatry, 40,809-814.

Grossman, L.S., Haywood, T.W., Cavanaugh, J.L., Davis, J.M. Lewis, D.A. (1995) State psychiatric hospital patients with past arrests for violent crimes, Pyediatric Seryicts, 46, $790-800$.

Harris, G.T. \& Rice, M.E. (1997) Risk appraisal and naanagenent of violent behanvior. Pspidiatric Senvites, 48, 1168-1176.

Herpertz, S., Steinmeyer, M., Marx, D., Oidtmann, A. \& Saß (1995) The significance of

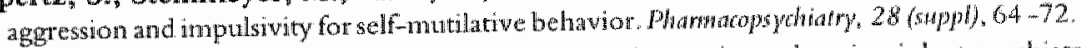

Hillbrand, M. (1995) Aggression against self and aggression against others in violent psychatric pacients. Jourmal of Consulfing and Clinical Psychology, 63, 668-67\%.

Hughes, D. H. (1998) Pharmacological managenent of the chronically aggressive patient. Psychiatric Arunals, $28,367-370$.

Hunter, M. \& Carmel, H. (1992) The cost of staff injuries from inpatient violence. Hospitat and Cannmunity Psydiatry, 43, 586-588.

Hunter, M.E. \& Carney Love, C. (1996) Total quality managenent and the reduction of inipatient wiolence and costs in a forensic psychiat ric hospital. Psychuderic Survices, 47, 751-754. 
Hyde, C.E. \& Harrower-Wilson, C. (1995) Resource consumption in psychiatric intensive care: the costs of aggression. Psychatric Bullen, 19,73-76.

Infantino, J.A. \& Musingo, \$. (1985) Assaut and injumes among staff with and without training in aggression control technques. Mospial and Cowwwtity Pydiatry. 36, 312-1314.

James, D.W.,Fineberg, N.A., Shah, A.K. Priest, R.G. (1990) An increase in wiolence on an acute psychiatric ward, a study of associated factors. Bribih fowmal of Psychatry, 156. $846-852$

Janssen, M. \& Steketee, $M_{*}$ (1996) Wordt de samenleving gekker en crimineler? Dioviant, 9 $12-16$.

Johnson, H.C. (1996) Violence and biology: a review of the literature. Families in Saciety, The Jonmul of compenponary homan services, 3-18.

Jones, I. H. \& Daniels, B.A. (1996) An ethological approach to self-injury. British Jownd of Psychiary, $169,263-267$.

Junginger, $\mathrm{J}$, (1990) Predicting compliance with command hallucinations. Ameticat Jourmal of Psydicitin, $147,245-247$.

Junginger, J. (1995) Command hallucinations and the prediction of dangerousness. Psychatric Sewples, 46, 911-914.

Junginger, J. (1996) Psychosis and violence: the case for a content analysis of psychotic experience. Schizophrenia Bulletin, 22,91-103.

Kalisky, S.Z. \& Zabow, T. (1995) Violence, sensation seeking, and impulsinity in schizophremics found unfit to stand trial. Bulletin of the Amerian Acaderny of Psychiany and Lau, 23: $147-155$.

Kalogjera, I.J, Bedi, A., Watson, W.N. a Meyer, A.D. (1989) Impact of themapeuric Management on use of seclusion and restraint with disruptive adolescent impatients. Hospial and Cammatity Pychiary, 40,280-285.

Kay, S.R., Wolkenfield., F. \& Murril, L. (1988) Profiles of aggression among psychatric patients I. nature and prevalence. Jownat of Nerous and Montal Disease, 176, 539-546.

Konicki, P.E. Schulz, S.C. (1989) Rationale for clinical twals of oplate antagonists in treating patents with personality disorders and seleinjurious behavior. Psyopharmacologica Bulleth, $25,556-563$.

Krakowski, M. C Czobor, P. (1997) Violence in prychiaric patients. The role of psychosis,

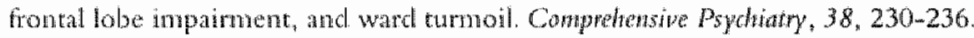

Lambert, M.J. \& Hill, C.E. (1994) Assessing psychotherapy outcomes and processes. In

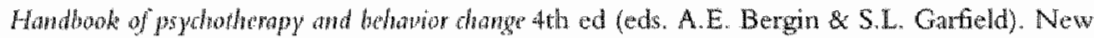
York: Wiley and Sons.

Lamgehn , D.R. \& Ptohl, B. (1993) Clinical corretates of self-rutilation among psychatric impatients. Antuts of Clinial Psyathaty, 5, 45-51.

Lange, A., Pahlich, A., Sarucco, M., Smits, G. Dehghani, B. H Hanewald, G. (1995) Psychometric characteristics and validity of the Dutch adaptation of the Buss-Durkec Hostinty lnventory (the BDHI-D). Behawiour Reseam and Theray , 33, 223-227.

Lee, FI.K., Villar, O., Juthani, N. \& Blwestone, H. (1989) Chatacteristics and behaviot of patients involved in psychatric ward incidents. Hosphal and Commanity Psychiaty, 40 , $1295-1297$.

Lester, D. (1991) Physical abuse and physical punishment as precursors of suicidal behavior. Stress Medicitur, $7,255-256$. 
Linnoila, V.M.I. Virkunnen, M, (1992) Aggression, smicidality, and serotonin. Joumal of Clinical Psydhatry. 53 (suppl), 46-51.

Markowitz, P. J. Calabrese J.R., Schultz, S.C. \& Meltzer, H. (1991) Fluwxetine in the treatment of borderline and schizotypal personality disorders. Amerian Jountal of Psychatry. $148,1064-1067$.

McNiel, D.E. \& Binder, R.L. (1989) relationship between preadnission threats and later violent behavior by acute psychiatrie patients. Hospital and Community Psyduatry, 40,605-608.

McNiel, D.E. \& Binder, R.L. (1991) Clinical assessment of the risk of violence among psychiatric inpatients. Aprerican Joufphal of Psydiatry, 148, 1317-1321.

McNiel, D.E. \& Binder, R.L. (1995) Correlates of accuracy in the assessment of psychiatric ingatients" risk of violence. American Joumal of Psychiatry, 152, 901-906.

Merckelbach, H. \& Muris, P. (1999) The causal link between selfi-reported tratuna and dissociation: A critical review. Behaviour Researd and Therapy, in press.

Merckelbach, H., Muris, P. \& Rassin, E. (1999) Fantasy proneness and cognitive failures as correlates of dissociative experiences. Personslity and Individual Differences, 26, $961-967$.

Monahan, J. \& Shah, S.A. (1989) Dangerousness and commitment of the mentally disordered in the United States. Schizophrenia Bulletin, 15, 541-.553.

Morrison, E.F. (1994) The evolution of a concept. Aggression and violence in prychiatric settings. Archives of Psychiarix Nuwsing, 8, 245-253.

Morrison, E.F. (1990) Viclent psychiatric inpatients in a public hospital. Scholarly Isquiry for Nursing Practice. An Imrenational Journal, 4, 65-82.

Morrison, E.F. (1993) The measurement of aggression and violence in hospitalized psychiatric patients. Intemational Journal of Nussing Studies, 30, 51-64.

Mulvey, E.P. (1994) Assessing the evidence of a link between mental illiness and violence. Hospital and Communvity Psydratry, 45, 663-668.

Nijman, H.L.I. (1992) Patronest in het gebraile wan separatie. Doctoradscriptic Gezondheidswetenschappen. Mastricht: Rijksuniversiteit Limburg.

Nijman, H.L.I., Allertz, W.W.F. \& à Campo, J.M.L.G. (1995) Agressie van patiènten. Een onderzoek naar agressiefgedrag van psychiatrische patiënten op en gesloten oponameaddelingy. Tildschift wor psychiatrie, 36, 329-342.

Nijman, H.L.I., Allertz, W.W.F., à Campo,J.M.L.G., Merckelbach, H.L.G.J. \& Ravelli, D.P. (1997a) Aggressive behavior on an acute prychiatric admissions ward. Europedn foumal of Psychiary, 11,106-114.

Nijman, H.L.I., à Campo, J.M.L.G. \& Ravelli, D.P. (1999) Stijging van het antal onwrijwillige opnammen. Tijdschnifi voor Psychiatric, 41,103-107.

Nijnan, H.L.I., à Campo, J.M.L.G., Ravelli, D.P. \& Merckelbach H.L.G.J. (1.999) A tentatuve model of aggression on inpatient psychiatric wards. Psychiatric services, 50, 832-834.

Nijman, H.L.I., Dautzenberg, M., Merckelbach H.L.G.J., Jung, P.. Wessel, 1. à Campo, J.M.L.C. (1999) Self-mutilating bethavior of psychiatric inpatients. Europsean Prychisiry, $14,4 \ldots 10$.

Nijman, H.L.I., Duangto, C., Ravelli, D.P., Merckelbach, H.L.G.J. \& Vorell, S.K. (1994) Personeelskenmerken in relatie tot separatie en afzondering. Tijdschrift poor Biphichrie, 37 , $130-139$. 
Nijman, H.L.I., Evers, C., Leumissen, A., Allertz, W.W.F., \& Campo, J. \& Fleuren, W. (1999) Predictie en preventic van agressieve incidenten. Voorjaurscongres van de Nederhandse Verengiging woor Psychiatrie (onderzoeksposter).

Nijman, H.L.I. \& Merckelbach, H.L.G.J. (1997) Preventing aggression. Psyduatic Senvices, 48 , 1467.

Nijman, H.L.I., Merckelbach, H.L.G.J., Allertz, W.W.F. \& à Campo, J.M.L.G. (1997b) Prevertion of aggressive incidents in a closed psychiatric ward. Psychtatric Services, 48,694-698.

Nijman, H.L.I., Muris, P., Merckelbach, H.L.G.J., Palmstierna, T., Wistedt, B., Vos, A.M., Rixtell, A. wan \& Allertz, W.W.F. (1999) The Staff Obserwation Aggression ScaleRevised (SOAS-1R). Aggressive Behturior, 25, 197-209.

Nijman, H.L.I., Ravelli, D.P. Merckelbach, H.L.G.J. (1992) Patronen in het gebruik van separatie. Matadblad Geestelijke Volksgezondheid. 47, 669-675.

Nijman, H.L.I. \& Rector G. (1999) Crowding and aggression on inpatient psychiatric wards. Psydhintric Services, 50,830-831.

Nilsson, K., Palmstierna, T. \& Wistedt, B. (1988) Aggressive behavior in hospitalized psychogeriatric patients. Acta Psychiatrica Sumpdinaniad, 78, 172-175.

Noble, P. \& Rogers, S. (1989) Violence by psychiatric inpatients. Britich Joumal of Psychiary, 155 , $384-390$.

Omértow, M., Wistedt, B. E Elgen, K. (1995) Treatment of acutely disturbed psychotic patients: assessment of a new treatment strategy. Nordic Joufnal of $p_{s y c h i a t}$, 35 (suppl), 63-76.

Palmstierna, T. (1992) Aggressive behavior from instiztionalized psychiatric parients. A methodological study uith dinical applicationts. (Dissertation). Karolinska Institute, Danderyd Hospital, Danderyd.

Palmstierna, T. \& Wistedt; B. (1987) Staff observation aggression scale. Presentation and evaluation. Acta Pspchiatrica Scandinavia, 76, 657-663.

Palmstierna, T. \& Wistedt, B. (1989) Risk factors for aggressive behawiour are of limited value in predicting the violent behaviour of acute involuntarily admitted patients. Acta Psyctsatrica Scandinaricicio, $81,152-155$.

Palnstierna, T. Wistedt, B. (1995) Changes in the pattern of aggressive behaviour anong inpatients with changed ward organization. Acha Psthiatrica Standatavica, 91, 32-35.

Palmstierna, T., Hwitfeldt, B. \& Wistedt, $\mathbb{B}$. (1991) The relationship of crowding and aggressive behavior on a psychiatric intensive care unit. Hospital and Community Psydhatry, 42 . $1237-1240$.

Palmstierna, T., Lassenius, R. \& Wistedt, B. (1989) Evaluation of the brief pspchopathological rating scale in relation to aggressive behavior by acure involuntarily admitted patients. Asta Psyduartia Sandintavica, 79, 313-316.

Phillips, D. \& Rudestam, E. (1995) Effect of nonwiolent selfedefense training on male psychatric staff members' aggression and fear. Psychiatric Senxices, 46, 164-168.

Poletiek, F.H. (1997) De wet BOPZ getoetst aan de ciffers. Maandbind Geestelife Volkspezondheid, $52,3.49-360$.

Praag, H.M., van (1991) Diagnostiek en beliandeling. De Psydoloog, 26, 515-519.

Praag, H.M., van, Plutchik, R. \& Conte, H. (1986). The serotonin hypothesis of (auto)aggression. Critical appraisal of the evidence. Ammis New York Acadeny of Sciences, 487 , $150-167$. 
Rachman, S. \& Hodgson, R.J. (1980) Obseswon awd wmpmlsons Englewood Chts, New Jersy: Prentiocum Hall the.

Ravelli, D.P., Vooght, L.A.E. de, Loo, R. Wan \& Nijman, H.L.I. (1996) Het

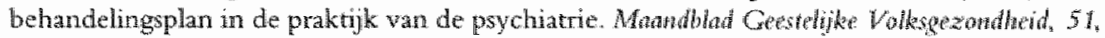
$4-45$.

Regterschot, A., Nijman, H.L.I., de Schinkel, C., Allertz, W. W.F., Deckers, E. \& Pletzers, N. (1996) Auto-agressie en allo-agressic van prychatrische patienten. In Whitwof Weicholuppedigk pp. 35, Heenter: PC Weltenot.

Rice, M.E, Harris, G.T., Varney, G.W. \& Quninsey, V.L. (1989) Vholence in intrifutions. Understawing, prevention, and control Toronto: Hogrefe \& Huber Publishers.

Rixtel, A.M.J. van, Nijman, H.L.I. Jansen, A. (1997) Agnessie on psychiatre. Heeft traning effect? Fupleegkinde, 12,111-119.

Shah, A.K., Fineberg, N.A. \& James, D.V. (1991) Violence anong psychatric inpatients, Ada P3ydratrica Sandiwawian. 84, 305-309.

Shearer, S.L. (1994) Phenomenology of self-injury among inpatione women with bonderline personality disorder. Jawm of Nerwows and Mental Discase, 182, 524-526.

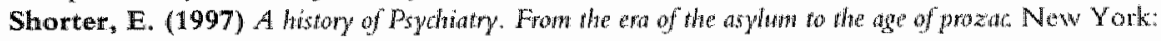
John Wiley and sons.

Sigafoos, J. \& Kerr, M. (1994) Provision of leisune activities for the reduction of challenging behaviot. Behaviowal lnenethions, $9,43-53$.

Simeon, D., Stanley, B., Frances, A., Mann, J.J., Wimchel, R. 8 Stanley, M. (1992) Self-mutilation in personality disorders psychological and biological correlates. American Joumal of Psychiary, 149,221-226.

Soloff, P.H., Lis, J.A., Kelly, T., Cornelius, J. \& Lllrich, R. (1994) Self-mutilation and sucidal behavion in borderline personality disorder. Joumal of Persondity Disanders, 8, 257-267.

Soutwick, S.M., Krystal, J.H., Breminer, J.D., Morgan III, C.A." Nicolaou, A.L., Nagy, L.M. Johnson, D.R., Heninger, G.R. \& Chamey, D.S. (1997) Nonadrenergic and

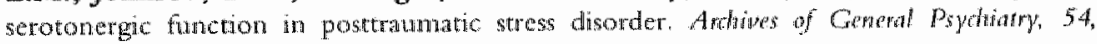
$749-758$.

Tamm, E., Engelsmann, F. \& Fugere, R. (1996) Paterns of violent incidents by parients on a general hospital psyctratric tacility. Psydiatic Sewice, $47,86-88$.

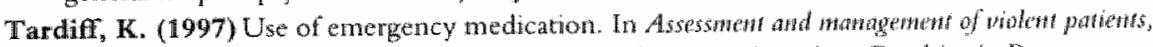
second edition (eds. K. Tardiff), pp. 53-60. Washington: Amedican Psychiatric Press.

Tardif, K. (1992) The current state of psychatry in the treatment of wolent patients. Archive of Gental Pschiatty. $49,493-498$

Tardif, K. \& Sweillam, A. (1980) Assalt, sucide, and mental ilness, Arbives of Gineral Psyditaty, 37, 164-169.

Taylor, P.J., Leese, M., Willanns, D., Burwell, M., Daly, R. \& Larkin, E. (1998) Mental

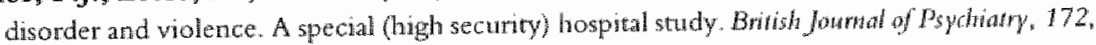
$218-226$

Verkes, R.J., Kerkhof, G.A., Beld, E., Hengeveld, M.W. wan Kempen, G.M.J. (1996) Suicidality, circardian accivity thythms and plateler serotonergic measures in pationts whth recurrent sucidal behavior Alda Psydhatrica Seavdinavica, 93, 27-34. 
Waite, B.M. (1994) Sampling the experience of chronically aggressive psychiatric inpatients. In The psycholvology of dgoression (eds. Hillbrand M. \& Pallone N.J.), pp. 187-201. New York: The Haworth Press linc.

Whittington, R. \& Wykes, T. (1996) Aversive stimulation by staff and wiolence by psychiatric patients. British Jow of al Clinical Psydodogy, 35, 11-20.

Winchel, R.M. Stanley, M. (1991) Self-injurious behavior. A review of the behavior and biology of self-mutilation. American Jowrnal of Psychiatry, 148, 306-315.

Wistedt, B., Rasmusser, A., Pedersen, L., Malm, U., Träskman-Bendz, L., Wakelin, J. \& Bech, P. (1990) The development of an observer-scale for measuring social dysfunction and aggression. Pharmacopsychintry, 23, 249-252.

Yudofsky, S.C., Silver, J.M., Jackson, W., Endicott, J. \& Williams, D. (1986) The overt aggression scale for the objective rating of verbal and physical aggression. Americon foumal of Pspchiatry, 143, 35-39.

Zlotnick, C.* Shea, M.T., Pearlstein, T., Simpson, E., Costello, E. \& Begin, A. (1996) The relationship between dissociative symptoms, alexithymia, impulsivity, sexual abuse, and self-mutilation. Comprehensive Psychiatry, 37, 12-16.

Zuckerman, M. (1979) Sersation seeking. beyond the optimal hevel of arousal. Hillsdale: Erlbaum. 


\section{LIST OF PUBLICATIONS}

Campo, J.M.L.G. à, Nijman, H.L.I. \& Merckelbach, H.L.G.J. (1997) Intermittent neuroleptic treatment of therapy-resistant schizophrenic psychoses. European foumal of Psyctiatry. 11, 69-71.

Campo, J.M.L.G. à, Frederikx, M., Nijman, H.L.I. \&erckelbach, H.L.G.J. (1998) Schizophrenia and changes in physical appearance. The Joumat of Clinical Psythitrit, 59, 4 (letter to the Editory.

Campo, J.M.L.G. à, Nijman, H.L.I. \& Merckelbach, H.L.G.J. (1998) Olanzapine as medication of first choice in therapy-resistant schizophrenia?. Ach Nevopsychiarica, 10, 97-81.

Jong, P.J. de, Merckelbach, H.L.G.J., Anntz, A. \& Nijman H.L.I. (1992) Covariation Bias in treated and untreated phobics. Journal of Abnomal Psydology, 101, 724-727.

Jong, P.J. de, Merckelbach. H.L.G.J. \& Nijman, H.L.I. (1995) Hemisplue preference, anxiety, and covariation bias. Personality and individual differentes, 18, 363-371

Merckelbach, H.LG.J., Muris, P, Nijman, H.L.I.\& de Jong, P.J. (1996) Selfreported cognitive failures and neurotic symptomatology. Joumal of Personality and Individual Differmes, $20,715-724$.

Merckelbach, H.L.G.J., Nijman, H.L.Y., Ravelli, D.P. \& Kenemans, R. (1995) Schizofrenie en Huidgeleiding: een literatuuroverzicht. Tijdidorifn woor Psydnarre, 37, 475-487.

Nijman, H.L.I. (1997) Preventie van agressieve incidenten (een antwoord op het postscriptum van Sival en Haffrnans). Tijdschrift voor Psychiatrie, 39, 264-266.

Nijman, H.L.I. (1997). Surcidegevaar. een familaire belasting? Nederlands Tidsdayf woor Genteskentide, 141, 1752 (referaat)

Nijman, H.X.I., Allertz, W.W.F. \& à Campo, J.M.L.G (1995) Agressie van Patiënten. Een onderzoek naar agressief gedrag van psychiatrische patienten op een gesloten opnameafdeling. Tids dhift woor prychinire, $36,329,342$.

Nijmatn, H.L.I., Allertz, W.W.F., van de Boogaard, M." Chatrou, E., Dassen, M., Flettren, W., Goertz, T. \& de Schinkel, C. (1996) Preventic van agressie. Tijded rift woor Psychiatrie, 38: 723-734.

Nijman, H.L.I., Allertz, W.W.F., Merckelbach, H.L.G.J., à Campo, J.M.L.G.\& Ravelli D.P. (1997) Aggressive behaviour on an acure psychiatric admissions ward. Entopean fournal of Psychintry 11. 106-114.

Nijman, H.L.I., wan den Boogerd, M.E.C.P., Gerrits, A. Meinster, J. (1998). Het voorspellen van valincidenten. Voppleegkunde, 13,25-30.

Nijman, H.L.I., a Campo, J.M.L.G, Ravelli, D.P. (1993) Inbewaningstellingen: Kort maar Krachtig? Tidschrift wor Psychiatrie, 25, $58-66$.

Nijman, H.L.I., a Canpo, J.M.L.G. \& Ravelli, D.P (1999) Stijging van het aantal onvrijwillige opnamen. Tijdschrfin woor Pyythistrie, 41, 103-107.

Nijman, H.L.I., à Campo, J.M.L.G. \& Ravelli, D.P (1999) Stijging van het aantal onvrijwillige opnamen (antwoord aan Bakker. Hanneman en Okker). Tidldshiff poor Pinthiatrie, 41, 247-248.

Nijman, H.L.I., à Campo, J.M.L.G., Ravelli, D.P. \& Merckelbach H.L.G.J. (1999) A tentative model of aggression on impatient psychiatric wards. Psychiaric servics, $50,832-834$ 
Nijman, H.L.I., Dautzenberg, M., Merckelbach H.L.G.J., Jung, P., Wessel, I. \& à Campo J.M.L.G. (1999) Self-mutilating behavior of psychiatric inpatients. European Psychiatry. 14, 4-10.

Nijman, H.L.I., Duangto, C., Ravvelli, D.P., Merckelbach, H.L.G.J. \& Vorel, S.K. (1994) Personeelskenmerken in relatie tot separatie en afzondering. Tijdschrift voor Psychiatrie, 37, $130-139$.

Nijman, H.L.I. \& Merckelbach, H.L.G.J. (1997) Preventing aggression. Psychiatri Sentices, 48, 1467 (Letter to the Editor).

Nijinan, H.L.I., Merckelbach, H.L.G.J. Allertz, W.F.F. \& Campo, J.M.L.G. (1997) Prevention of aggressive incidents in a closed psychiatric wart. Psychiafric Senvices, 48, 694-698.

Nijman, H.L.I., Merckelbach, H.L.G.J. \& Ravelli, D.P. (1994) De rejatie tussen roken en schizotrenie. Tijdschrift your Psychiatre, 36,243-253.

Nijman, H.L.I., Muris, P., Merckelbach, H.L.G.J., Palmstiena, T., Wistedt, B., Vos, A.M., van Rixtel, A. \& Allertz, W. (1999). The Staff Observation Aggression Scalem R. evised (SOAS-R). Aggressine Behavior, 25, 197-209.

Nijman, H.L.I., Ravelli, D.P. \& Merckelbach, H.L.G.J (1992) Patronen in het gebruik van separatic. Maadblad Geestelike Volksgezondheid, 47,669-675.

Nijman, H.L.I. \& Rector G. (1999) Crowding and aggression on inpatient psychiatric wards. Psychiatic Services, 50,830-831.

Nijman, H.L.I. \& Rector G. (1999) The crowded ward (reply). Psychatric Services, in press.

Nijman, H.L.I. Roodentijs, T.C. (1998) Het voorspellen van zelfdoding, dood door ongelukken en vroegtijdige dood. Nederlands Tijdschrift woor Geneskende, 142 (referaat).

Palmstierna, T., Nijman, H.L.I., Wistedt, B. \& Merckelbach, H.L.G.J. (1999) Revision of the Staff Observation Aggression Scale (SOAS): comment on Hallsteinsen er al.. Acta Psychiatrica Sandinavia, 100,80-81 (Letrer to the edicor).

Ravelli, D.P., de Vooght, L.A.E., van Loo, R. \& Nijman, H.L.I. (1996) Het behandelingsplan in de praktijk wan de psychiatrie. Maandblad voor Geestelijke Volksgezondheid, $51.41-44$.

Ravelli, D.P., de Vooght, L.A.E., Nijman, H.L.L. \& van Loo, R. (1996) Het behandelingsplan in de praktijk wan de psychatrie (een antwoond op de reactie van de Boer en Kuipers). Matridblad Geestelike Wolksgezondheid, 51,411-412.

Rixtel, A.M.J., van, Nijman, H.L.I. \& Jansen, A. (1997) Agressie an psychiatie. Heeft training effect? Yerpleskentde, 12,111-119.

Schultz, C. Nijman, H.L.I. (1996) Hoe betrouwbaar is de diagnose schizofrenue? Nedortands Tipdshiff wor Genesksunde, 140,2526 (referant).

Schuilta, C. \& Nijman, H.L.I. (1996) Het witerlijk van de psychiater. Nederlands Tujdsthriff woor Cencestunde, 142, 1395-1396 (referant).

Schuurmans, T., Nijman, H.L.I. \& Peters, P. (1997) Kenmerken van voltooiers en dropouts

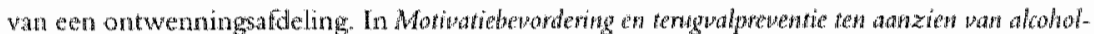

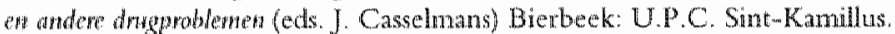

Schuurmans, T., Nijman, H.L.I. \& Peters, P. (1997) Characteristics of completers and dropouts of a detoxification unit. In Alcohol, Drags, and Tobaco Researd 1995-1996. (Eds. G.M. Schippers \& T.G. Broekman) Nijmegen: Bureau Bêtà.

Schuurmans, T., Nijman, H.L.I. \& Peters, P. (1999) Kemmerken van voltooiers van de ontwerningsbehandeling. Tijdshrift row Alrohol, Drags en atadere Psychotrope stofen, 24, 1-8. 


\section{DANKWOORD}

Mijn grote dank gaat uit naar Prof. Dr. Harald Merckelbach. Beste Harald, bedankt voor je geduld, toewijding en je uitzonderlijk gedetailleerde en altijd ijzersterke commentaar. Ook dank ik je voor de vele nieuwe inzichten die ik heb opgedaan door met jou te mogen werken en voor al het plezier dat ik aan het schrijven van deze dissertatie heb beleefd. Verder wil ik Joost à Campo, Dick Ravelli en Wiel Allertz van Psychiatrisch Centrum Welterhof speciaal bedanken. Zonder jullie deskundigheid op de meest uiteenlopende terreinen - waaronder psychopathologie, farmacologie, methodologie, ziekenhuismanagement en verpleegkundig handelen - had ik deze klus nooit kunnen klaren. Ook ben ik Frans Joosten van de medische administratieve dienst uitzonderlijk dankbaar. Frans, je hebt mij vanaf mijn eerste dag in Welterhof geholpen met het verzamelen van gegevens. Verder wil ik alle medewerkers van Psychiatrisch Centrum Welterhof bedanken voor hun bijdrage aan het onderzoek, met name de verpleegkundigen die hielpen met het registreren van agressie. In het bijzonder wil ik Wil Fleuren (rots in de registratie-branding), Piet-Hein Zwanikken en alle andere medewerkers van afdeling $\mathrm{BC}$ bedanken. Mijn collega's van de dienst bestuursondersteuning ben ik erkentelijk voor hun ondersteuning en goede adviezen. De Raad van Bestuur en het divisiemanagement van de Divisie Kortdurende Behandeling Volwassenen van Psychiatrisch Centrum Welterhof makten het mogelijk om de onderzoeken die in deze dissertatie beschreven zijn tiit te voeren. Erik Schouten van de Universiteit Maastricht dank ik voor zijn ormisbare hulp met de statistiek. Verder wil ik iedereen bedanken die inhoudelijk commentaar op een of meerdere hoofdstukken van dit proefschrift heeft gegeven: Tom Palmstiena, Börje Wistedt, Marcel van den Hout, Hans de Swart, Tine Vos, Ans van Rixtel, Paul Jung, Peter Muris, Ineke Wessel, Mariëlle Dautzenberg, Sylvia MacNab, Monique Frederikx, Chantana Duangto, Mariet vanderBroeck. Astrid Regterschot, Peter van Harten, Catharine Evers, Gust Rector, Chris de Schinkel, Emilie Chat-rou en Jane Alexander. De medewerkers van Janssen-Cilag b.v. dank ik voor hun interesse in het onderzoek van $\mathrm{PC}$ Welterhof en hun hulp bij de totstandkoming van dit proefschrift. Tot slot wil ik mijn ouders, schoonouders en naste familieleden bedanken voor hun steun en inspiratie. Door jullie geduld bleef het schrijven van dit proefschrift altijd een uitdaging en werd het nooit een beproeving. 


\section{CURRICULUM VITAE}

Henk Nijman werd op 18 juli 1967 geboren te Tilburg. In 1986 behaalde hij zijn atheneum diploma aan het St. Odulphus Lyceum in Tilburg. Daarna ging hij gezondheidswetenschappen studeren in Maastricht, met als afstudeerrichting Geestelijke Gezondheidkunde. Tijdens zijn studie was hij als student-assistent werkzaam voor Peter de Jong en Harald Merckelbach van de vakgroep Differentiële en Experimentele Psychologie. In 1992 studeerde hij af op een onderzoek naar de toepassing van separatie en fixatie in Psychiatrisch Centrum Welterhof te Heerlen. Sinds zijn afstuderen is Henk Nijman als wetenschappelijk onderzoeker werkzaam in Welterhof. Vanaf 1996 is hij als universitair docent verbonden aan de faculteit Psychologie van de Universiteit Maastricht. 